\title{
Numerical Investigation of Miter Gates
}

Guillermo A. Riveros, Jorge L. Ayala Burgos,

and Jaime Perez

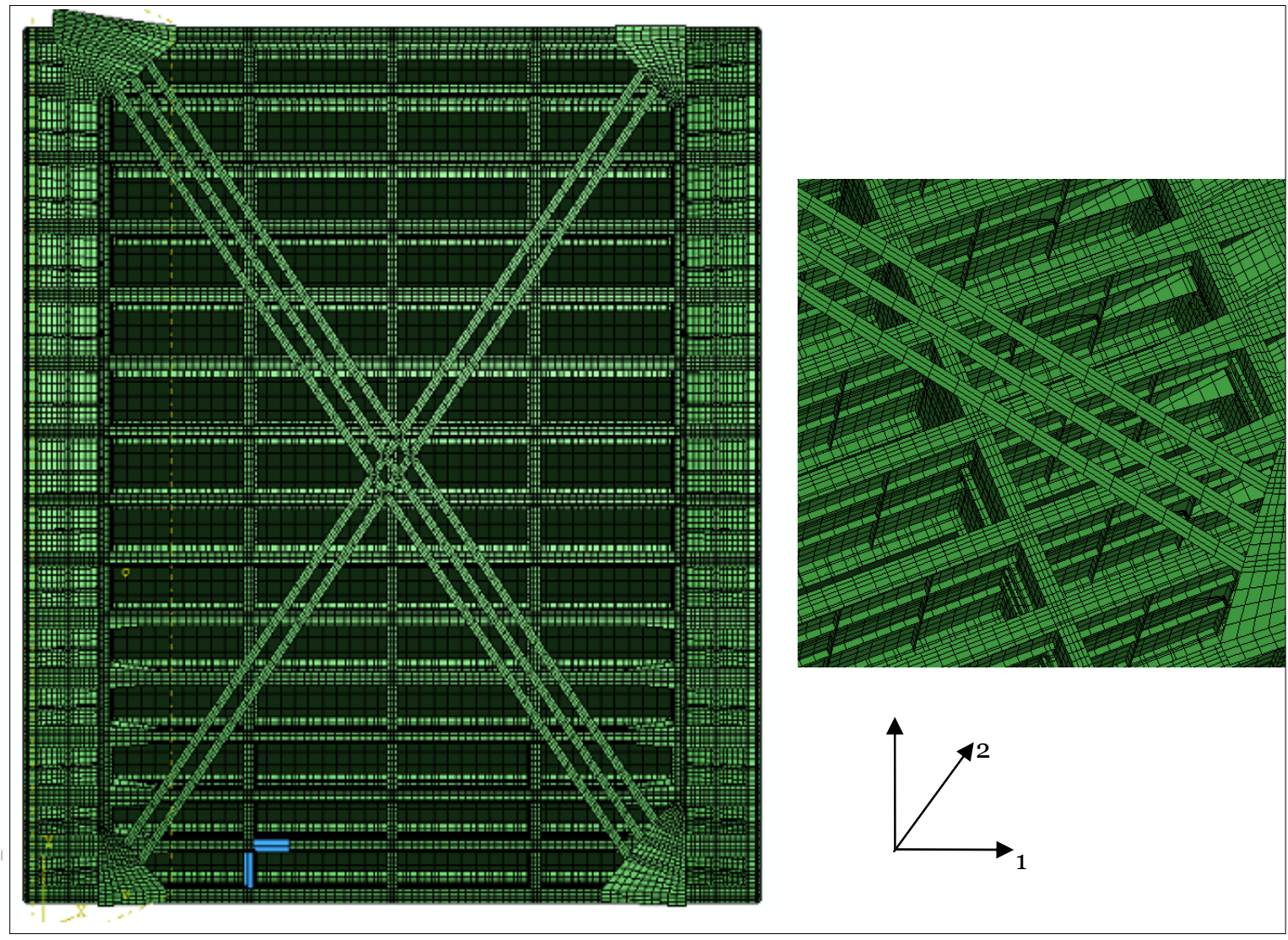




\title{
Numerical Investigation of Miter Gates
}

\author{
Guillermo A. Riveros \\ Information Technology Laboratory \\ U.S. Army Engineer Research and Development Center \\ 3909 Halls Ferry Road \\ Vicksburg, MS 39180-6199 \\ Jorge L. Ayala Burgos, and Jaime Perez \\ Department of Civil Engineering and Surveying \\ University of Puerto Rico at Mayaguez \\ PO Box 9041 \\ Mayaguez, P.R. 00681-9041
}

Final report

Approved for public release; distribution is unlimited.

Prepared for Headquarters U.S. Army Corps of Engineers

Washington, DC 20314-1000 


\begin{abstract}
This report presents results of a three-dimensional (3-D) finite element analysis of a generic miter gate with multiple cracks used to calculate the stress intensity factor using the $J$-integral approach. The model was also used to determine the optimum diagonals prestressing. Stress intensity factors and J-integral approach were validated numerically against closed-form solutions of semi-infinite plates with throughthickness cracks, double-edged cracks, single-edged crack, and cracks growing from round holes. Only a 2 percent difference between the closedform solution and the numerical calculated values was obtained. Additionally, the report shows meshing techniques that facilitated the construction of the complex 3-D model. Finally, results and graphical methods of the parametric analysis to calculate the optimum diagonal prestresses are illustrated.
\end{abstract}

DISCLAIMER: The contents of this report are not to be used for advertising, publication, or promotional purposes. Citation of trade names does not constitute an official endorsement or approval of the use of such commercial products. All product names and trademarks cited are the property of their respective owners. The findings of this report are not to be construed as an official Department of the Army position unless so designated by other authorized documents. 


\section{Contents}

Figures and Tables.......................................................................................................................

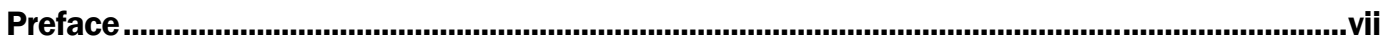

Unit Conversion Factors...........................................................................................................................viii

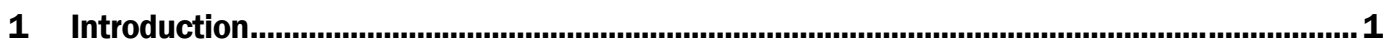

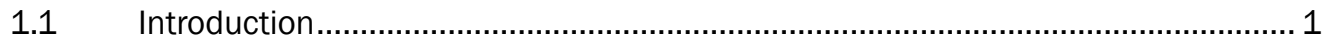

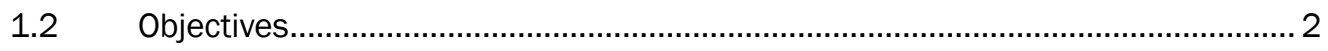

1.3 Research significance.................................................................................. 3

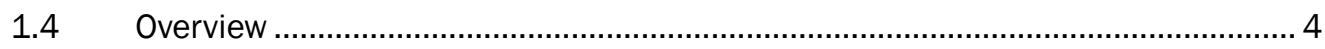

2 Fracture Mechanics and its Applications to Finite Elements in Steel Structures.................. 5

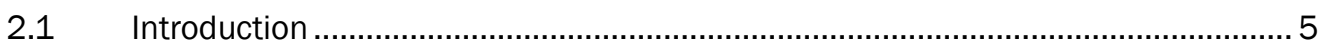

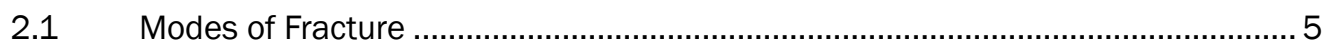

2.2.1 Mode l, the opening mode ............................................................................. 5

2.2.2 Mode II, the sliding or shearing mode.......................................................... 6

2.2.3 Mode III, the tearing mode ................................................................................... 6

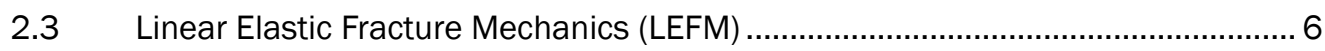

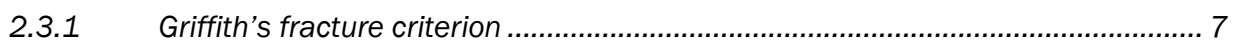

2.3.2 Stress distribution ahead of the crack tip........................................................... 8

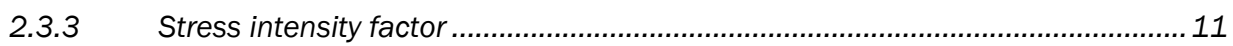

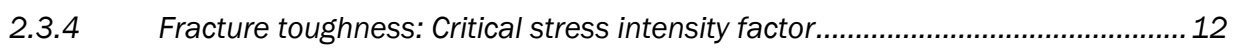

2.3.5 Plastic zone and influence of constraint at the crack tip........................................13

$2.4 \quad$ J-integral ................................................................................................. 13

3 Fracture Mechanics Numerical Solution: Validation of J-integral Approach ......................17

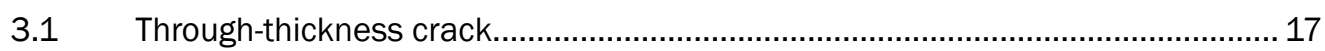

3.2 Double-edge-notched plate ........................................................................20

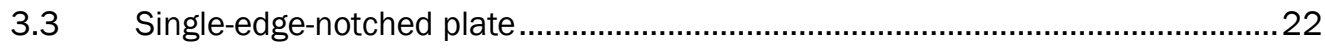

3.4 Cracks growing from round holes.................................................................. 24

4 3-D Finite Element Analysis of Miter Gate With Multiple Cracks............................................27

$4.1 \quad$ Meshing techniques................................................................................. 27

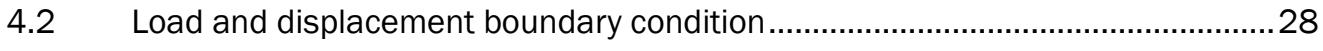

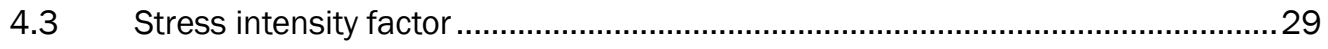

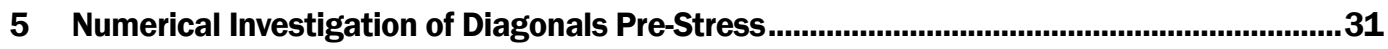

$5.1 \quad$ Diagonal prestressing............................................................................. 32

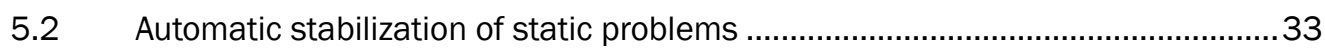

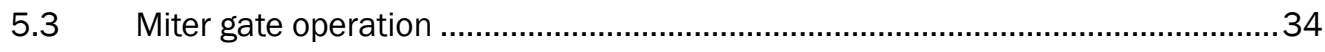

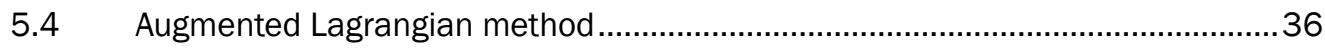

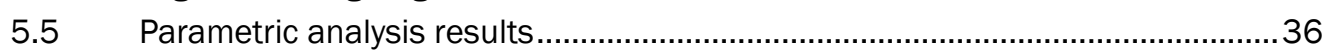




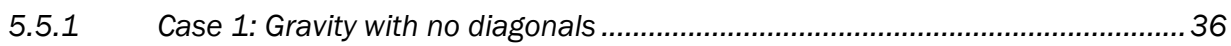

5.5.2 Case 2: Gravity with positive diagonals.............................................................. 39

5.5.3 Case 3: Gravity with positive and negative diagonals .......................................42

5.5.4 Case 4: Gravity with positive, negative diagonals, movement, and

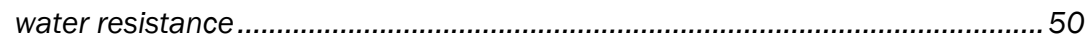

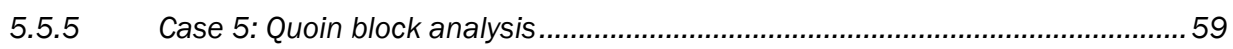

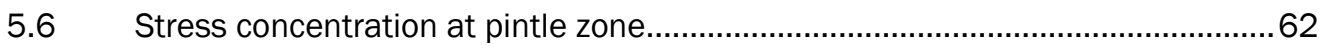

6 Conclusions and Recommendations .................................................................................6

$6.13-D$ finite element analysis of miter gate with multiple cracks ..........................67

$6.2 \quad$ Numerical investigation of diagonals prestress...............................................68

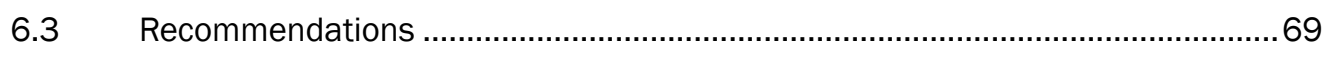

References..............................................................................................................................................70

Report Documentation Page 


\section{Figures and Tables}

\section{Figures}

Figure 1. Diagonal failure.

Figure 2. Cracking in pintle zone. ................................................................................................... 3

Figure 3. Fracture failure modes. (a) Mode I - opening mode; (b) Mode II - sliding or shear mode; (c) Mode III - tearing or out-of-plane shearing mode.

Figure 4. Stress concentration at the crack tip due to (a) circular hole, (b) elliptical hole, and (c) sharp line crack.

Figure 5. Notations for stresses and other geometric parameters. ................................................ 10

Figure 6. Failure stress related to crack size for infinitely wide plate subjected to tension.............. 12

Figure 7. Crack tip coordinate system and typical line integral contour........................................... 14

Figure 8. Plate sketch and dimensions for through-thickness crack ............................................. 18

Figure 9. Through-thickness crack plate finite element mesh and stress contour........................... 18

Figure 10. Plate sketch and dimensions for double-edge-notched plate. .......................................2 20

Figure 12. Plate sketch and dimensions for single-edge-notched plate...........................................23

Figure 13. Single-edge-notched plate finite element mesh and stress contour. .............................. 23

Figure 14. Plate sketch and dimensions for cracks growing from round holes. ................................ 25

Figure 15. Crack before analysis for cracks growing from round holes............................................2 25

Figure 16. 3-D Finite element mesh of as-built miter gate............................................................28

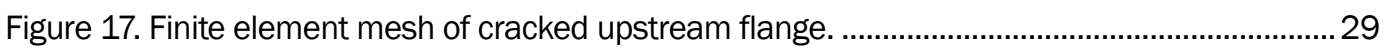

Figure 18. Principal stress contours of the upstream flange................................................................30

Figure 19. 3-D finite element model. ........................................................................................ 31

Figure 20. Free body diagram of the pre-stressed element...........................................................33

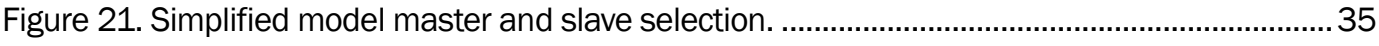

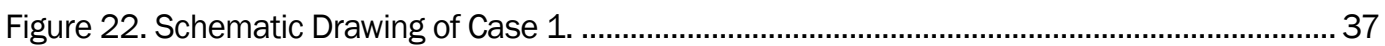

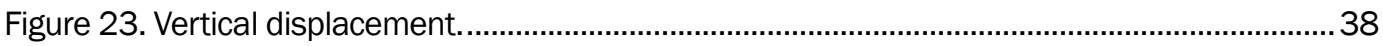

Figure 24. Lateral observed behavior.................................................................................. 38

Figure 25. Lateral displacement............................................................................................ 39

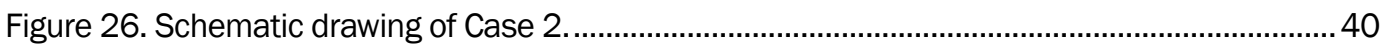

Figure 27. Variation in vertical displacement for the different diagonal prestressing.......................40

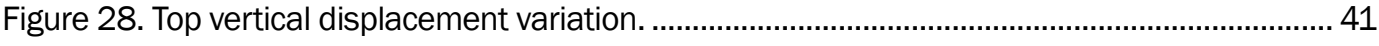

Figure 29. Lateral behavior of the miter gate............................................................................ 43

Figure 30. Relative lateral displacement. ....................................................................................... 43

Figure 31. Schematic drawing of Case 3................................................................................ 44

Figure 32. Vertical displacement variation for the different diagonal prestressing. ....................... 45

Figure 33. Lateral behavior of the miter gate end. ..................................................................... 47

Figure 34. Positive and negative diagonals relation............................................................................ 48

Figure 35. Detailing of the positive and negative diagonal relation...................................................49 
Figure 36. Relative lateral displacement (negative diagonals vary).............................................. 49

Figure 37. Relative lateral displacement (positive diagonals vary)..................................................50

Figure 38. Schematic drawing of Case 4............................................................................. 52

Figure 39. Vertical displacements........................................................................................ 53

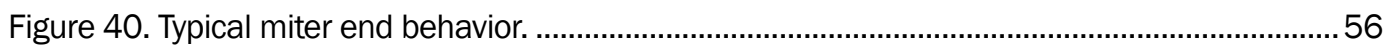

Figure 41. Lateral displacements with different diagonal prestressing combination. ...................... 57

Figure 42. Lateral displacement- different diagonal prestressing combination, gate open............. 57

Figure 44. Relative lateral displacement (negative diagonals vary). ............................................ 58

Figure 45. Relative lateral displacement (positive diagonals vary).................................................59

Figure 46. Schematic of Case 5. ............................................................................................. 60

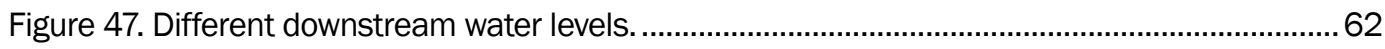

Figure 48. Stress concentration in the pintle zone for cases from top to bottom. .............................63

Figure 49. Stress concentration in the pintle zone for cases from center up and down. .................64

Figure 50. Stress concentration in the pintle zone for cases from bottom to top. ............................64

Figure 51. Stress concentration in the critical zone for cases from bottom to top............................65

Figure 52. Stress concentration in the critical zone for Case Q25B...............................................66

\section{Tables}

Table 1. Correction factors for a finite-width plate containing a through-thickness crack ................19

Table 2. Correction factors for a single-edge-notched plate............................................................ 24

Table 3. Boundary conditions used for the fracture mechanics analysis......................................... 28

Table 4. Validation of the analysis using different values of $\Delta T$.....................................................33

Table 5. Boundary condition for the analyzed structure................................................................... 37

Table 6. Boundary conditions for the analyzed structure................................................................ 40

Table 7. Positive diagonal prestressing. .................................................................................. 41

Table 8. Spatial displacement summary for the top and bottom nodes of the miter gate. .............. 41

Table 9. Boundary condition for the analyzed structure................................................................ 44

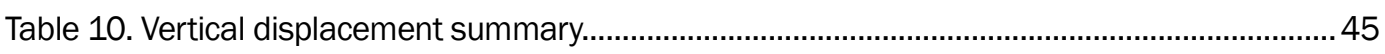

Table 11. Spatial displacement summary for the top and bottom of the miter gate......................... 46

Table 12. Boundary condition for the analyzed structure. ...........................................................52

Table 13. Vertical displacement results................................................................................53

Table 14. Lateral displacement results................................................................................ 54

Table 15. Lateral displacement results for the closing cases.................................................... 55

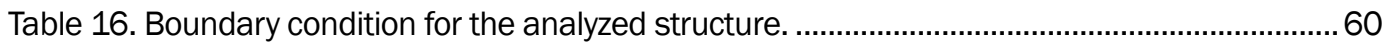

Table 17. Quoin block boundary condition variation.................................................................... 61

Table 18. Summary stresses at pintle zone. ............................................................................ 63

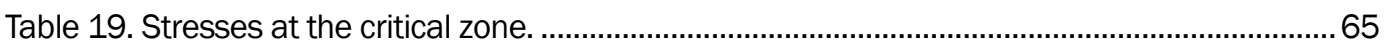




\section{Preface}

This research was conducted under the Navigation Systems Research Program, Work Unit 9K76D4, "Inspection and Condition Assessment of Steel Hydraulic Structures.” Program Manager was James E. Clausner, Associate Technical Director, Coastal and Hydraulics Laboratory (CHL), U.S. Army Engineer Research and Development Center (ERDC), Vicksburg, MS.

This report was prepared by Dr. Guillermo A. Riveros, Information Technology Laboratory (ITL), ERDC, and Jaime Perez and Jorge Ayala, University of Puerto Rico at Mayaguez. The report was prepared under the general supervision of Chris A. Merrill, Chief, Computational Analysis Branch, ITL; Dr. Robert Wallace, Chief, Computational Science and Engineering Division, ITL; and Dr. Reed Mosher, Director, ITL.

At the time of the publication of this report, COL Gary E. Johnston was Commander and Executive Director of ERDC. Dr. James R. Houston was Director. 


\section{Unit Conversion Factors}

\begin{tabular}{|l|c|l|}
\hline Multiply & By & To Obtain \\
\hline degrees Fahrenheit & $($ F-32)/1.8 & degrees Celsius \\
\hline feet & 0.3048 & meters \\
\hline inches & 0.0254 & meters \\
\hline pounds (force) per square inch & 6.894757 & kilopascals \\
\hline pounds (mass) per square foot & 4.882428 & kilograms per square meter \\
\hline
\end{tabular}




\section{Introduction}

\subsection{Introduction}

Steel hydraulic structures maintained by the U.S. Army Corps of Engineers consist primarily of lock and spillway gates, bulkheads, and other closure structures. In recent history there has been ample evidence of unsatisfactory performance of these structures. This evidence has included numerous cases of fatigue cracking caused by welded connections with low fatigue resistance (Markland Lock, Greenup Lock and Dam), poor weld quality, unanticipated structural behavior, or unexpected loading. In the most severe cases at least one catastrophic failure of a bulkhead system nearly resulted in loss of life (Coffeeville Lock, maintenance stoplogs, 1994), and complete replacement of lock gates has been required in at least two other cases (Melvin Price Lock and Upper Mississippi River Lock 27). Miter gates have also been investigated and cracks repaired. Maintenance and repair of fatigue and fracture failures represents a major Operations and Maintenance expenditure for the Corps.

Because of these failures, analytical techniques for employing state-of-theart capabilities for fracture mechanics analysis using finite element modeling have been developed. This effort included the use of commercially available nonlinear finite element programs incorporating J-integral analysis for fracture analysis. The results of J-integral analysis can be directly compared to elastic or elastic-plastic material properties for assessment. These analytical tools can be used for much more accurate and detailed fracture assessments than the Corps currently has the capability to perform and can be used to access the criticality or need to perform repairs.

Detailed finite element fracture analyses employing $J$-integral analysis have the potential to provide a much more accurate fracture assessment. Cost savings may be realized from accurate fracture assessments through avoidance of unnecessary repairs. Detailed fracture analysis can also provide an important investigative tool in assessing the actual loads in a member at the time of failure. 
Recently, there have also been a number of failures of diagonals on miter gates (Figure 1). These appear to be fatigue-induced failures driven by the connection details at the diagonal ends, but some evidence also suggests that the current design guidance results in a much larger prestress in miter gate diagonals than may be required. The high prestress theoretically increases the fatigue of these members and results in increased stress in the miter gate.

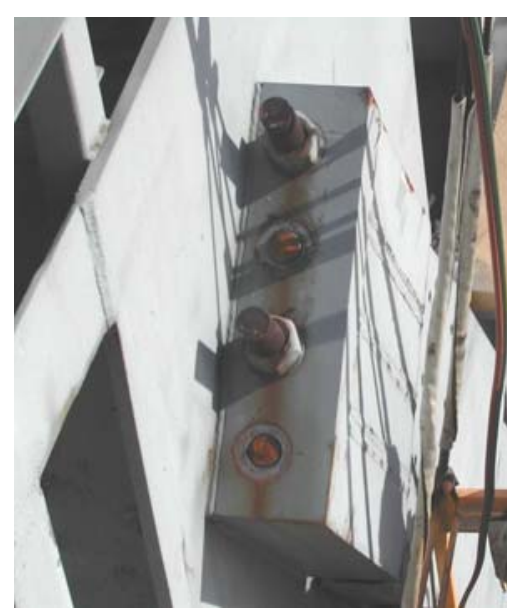

Figure 1. Diagonal failure.

Comprehensive three-dimensional (3-D) finite element analyses have the capability to assess the diagonal prestressing levels, which will provide the initiation for a new design approach. The new techniques will allow the prediction of optimum prestressing levels without compromising the fatigue capacity.

Most recently, a number of gates have experienced cracking problems around the pintle region (Figure 2), in addition to buckling occurring in vertical plates on the miter end sections. The 3 -D finite element modeling will provide the basis to understand the source of the problem and generate appropriate repair procedures.

\subsection{Objectives}

The proposed effort includes the development of analytical techniques for employing state-of-the-art capabilities for fracture mechanics analysis using finite element modeling. This effort includes the use of commercially available nonlinear finite element programs incorporating J-integral analysis for fracture analysis. 


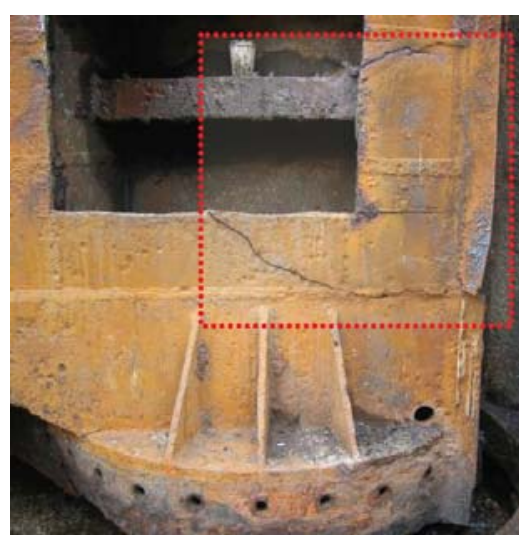

Figure 2. Cracking in pintle zone.

The results of $J$-integral analysis can be directly compared to elastic or elastic-plastic material properties for assessment. These analytical tools can be used for much more accurate and detailed fracture assessments than the Corps currently has the capability to perform. An effort to assess the connection detailing and design of miter gate diagonals is proposed. This effort will include development of analytical models to assess the prestress requirements of diagonals and to develop improved details for diagonal/gate connections. Last, the pintle region cracking and buckling problem will be examined, and recommendations for predicting the problem will be discussed.

\subsection{Research significance}

The Corps requires the inspection of hydraulic steel structures with fracture critical members (FCM) whose failure would result in probable loss of life to ensure structural integrity. Detailed finite element fracture analyses employing J-integral analysis have the potential to provide a much more accurate fracture assessment. The benefits of an accurate fracture assessment may be realized from cost savings through avoidance of unnecessary repairs. Detailed fracture analysis can also provide an important investigative tool in assessing the actual loads in a member at the time of failure. The reassessment of miter gate diagonal design criteria and connection details should lead to more realistic prestress levels in diagonals and could provide the initiation of new design criteria that eliminate the potential of fatigue failures in the diagonal connection. Considering the number of miter gates exhibiting pintle region cracking and buckling, understanding the causes of the problem is not just necessary but essential. 


\subsection{Overview}

Chapter 2 includes a brief review of the basic concepts of linear elastic fracture mechanics. It also presents a detailed explanation of the J-integral approach. Chapter 3 presents the validation of the J-integral computed numerically against closed-form solutions of semi-infinite plates with through-thickness cracks, double-edged cracks, single-edged cracks, and cracks growing from round holes. Details of the numerical models developed in this investigation are presented in Chapter 4. Results from this study along with analysis of these results are presented in Chapter 5 . Conclusions and recommendations for further studies are presented in Chapter 6. 


\section{Fracture Mechanics and its Applications to Finite Elements in Steel Structures}

\subsection{Introduction}

Fracture mechanics is a method of characterizing the fracture behavior in structural parameters, stress, and flaw size, which can be used directly as Barsom and Rolfe stated (1987). They also declared that the science of fracture mechanics can be used to describe quantitatively the trade-offs among stresses, material toughness, and flaw size.

The concepts of fracture mechanics were used in the World War II era to predict the failure of brittle steel materials in boat hulls. Since then, linear elastic fracture mechanics (LEFM) has been increasingly used to predict brittle fracture of high-strength low-toughness materials.

The main purpose is to determine the rates of change of an existing crack, if this crack will grow at a certain load magnitude, and if it does, at what rate and direction. The numerical simulation requires the state of stresses, strain, and displacements present around the crack tip from which it can be predicted if the crack will grow or not, and if it grows, in what direction. For LEFM and the work described herein, the numerical simulation will be used to obtain the stress intensity factor for Mode I. This chapter will describe the basic concepts of LEFM and the method for obtaining the stress intensity factor for Mode I with the J-integral approach.

\subsection{Modes of Fracture}

There are three principal modes of fracture, commonly referred to as the opening mode, the sliding mode, and the tearing mode. The difference between these modes of fracture is in the type of relative displacement between the surfaces of a crack.

\subsubsection{Mode I, the opening mode}

In the opening mode, the instantaneous displacement of two crack surfaces is in opposite directions and perpendicular to the crack surface as shown in Figure 3a. Direct tension and flexural action usually cause structural failure in this mode. 


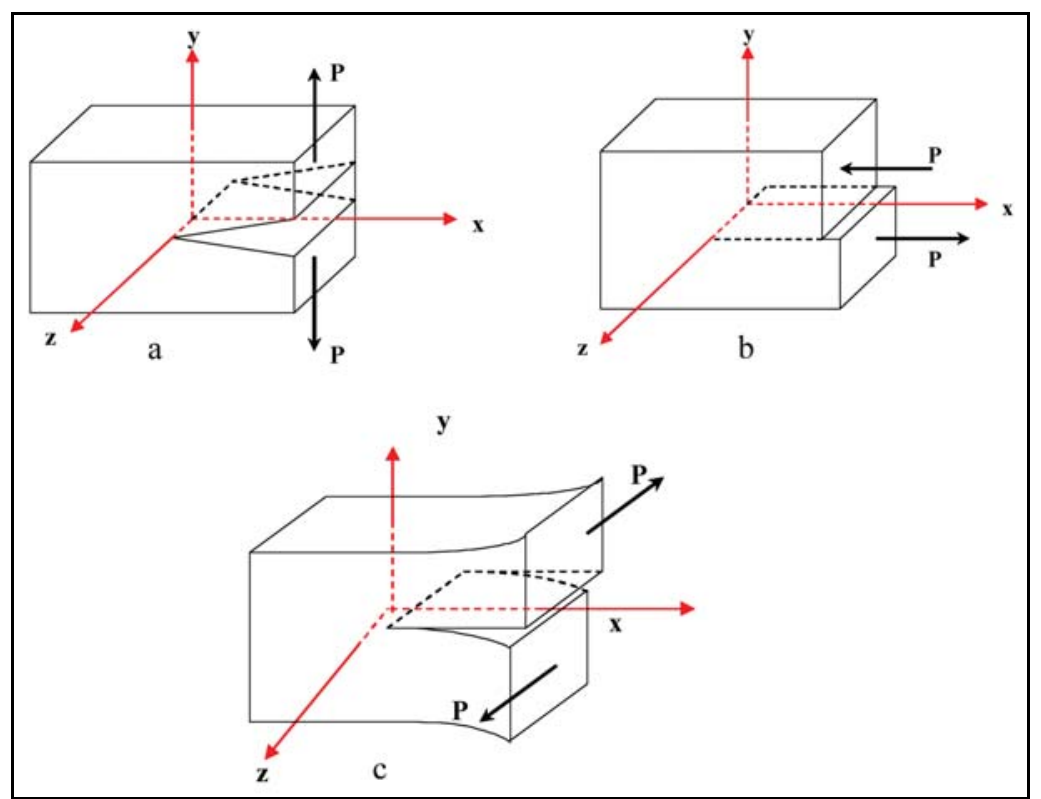

Figure 3. Fracture failure modes. (a) Mode I - opening mode; (b) Mode II - sliding or shear mode; (c) Mode III - tearing or out-of-plane shearing mode.

\subsubsection{Mode II, the sliding or shearing mode}

In the sliding or shearing mode, instantaneous movement of the crack surfaces is in the opposite direction and perpendicular to the crack front line but in the plane of the crack surface. So, plane $x-y$ is plane of symmetry, but cracking with respect to plane $\mathrm{x}-\mathrm{z}$ is antisymmetric. This mode of fracture is usually observed when in-plane shear force is imposed on the structure (Figure 3b).

\subsubsection{Mode III, the tearing mode}

Figure $3 c$ shows the tearing mode. In this mode, instantaneous movements of the two crack surfaces are in opposite directions but in the direction of the crack front line, and in the plane of crack surface, it is antisym-metric with respect to both planes $\mathrm{x}-\mathrm{y}$ and $\mathrm{x}-\mathrm{z}$. Torsion loading causes this mode of fracture.

\subsection{Linear Elastic Fracture Mechanics (LEFM)}

Linear-elastic fracture-mechanics technology is based on an analytical procedure that relates the stress-field magnitude and distribution in the vicinity of a crack tip to the nominal stress applied to the structural member; to the size, shape, and orientation of the crack or crack-like discontinuity; and to the material properties (Barsom and Rolf 1987). 
The fundamental principle of fracture mechanics is that the stress field ahead of a sharp crack in a structural member can be characterized in terms of a single parameter, $K$, the stress intensity factor that has units of psi $\sqrt{\text { in. }}$ This parameter, $K$, is related to both the nominal stress level $\sigma$ in the member and the size of the crack present $a$.

LEFM is the basic theory of fracture, originated by Griffith (1921) and completed by Irwin (1957) and Rice (1968a, 1968b). The LEFM is a highly simplified theory that is applicable to any material as long as certain conditions are met. These conditions are related to the basic ideal situation analyzed in LEFM in which all the material is elastic except in a vanishingly small region (a point) at the crack tip (Bazant and Planas 1998).

\subsubsection{Griffith's fracture criterion}

If the amount of energy supplied to the crack tip for an incremental crack growth is equal to or greater than the amount of energy required for crack growth, then this results in catastrophic crack growth (Anderson 1991). The concept forms the basis of LEFM. The energy supplied to the crack tip, $U$, is usually either the energy released from crack formation or the work done by the applied forces from additional displacement caused by introducing a crack. $W$ denotes the amount of energy absorbed in the creation of new free surfaces as a result of crack propagation. The Griffith criterion for catastrophic crack growth is then given by:

$$
\frac{d U}{d a}>\frac{d W}{d a}
$$

where $d a$ is the incremental crack growth and $d U / d a$ is the energy release rate, $G$. For a center crack plate (crack length $2 a$ ) subjected to far-field tensile stress, $\sigma$, it can be shown that:

$$
G=\frac{d U}{d a}=\frac{\sigma^{2} \pi a}{E}
$$

where $E$ is the modulus of elasticity, and $d W / d a$ is crack resistance, $R$, given by:

$$
R=\frac{d W}{d a}=2 \gamma
$$


where $\gamma$ is the specific surface energy, considered a material property. Consequently, if

$$
\begin{gathered}
\frac{\sigma^{2} \pi a}{E}>2 \gamma \\
\text { or } \\
\sigma>\sqrt{\frac{2 E \gamma}{\pi a}}
\end{gathered}
$$

the crack will grow catastrophically.

The energy release rate, $G$, for Mode I fracture is denoted as $G_{I}$. At incipient catastrophic crack growth, $G_{I}$ equals $G_{I C}$, which is the critical energy release rate $\left(G_{I C}=2 \gamma\right)$. $G_{I C}$ is considered a material property.

\subsubsection{Stress distribution ahead of the crack tip}

In 1898 , Kirsch obtained the stress concentration at the edge of a circular hole as three times the nominal stress (Figure 4a). In 1913, the same problem was solved for a more general case of an elliptical hole by Ingliss (Inglis 1913) (Figure 4b). For that case, the stress concentration factor was obtained as $1+2 * a / b$. A sharp crack in a solid body can be approximated in the limiting case with an elliptical crack where $b \rightarrow 0$ (Figure 4c). The related expression for the stress distribution shows that the normal stress at the crack tip will be infinity for a line crack. 

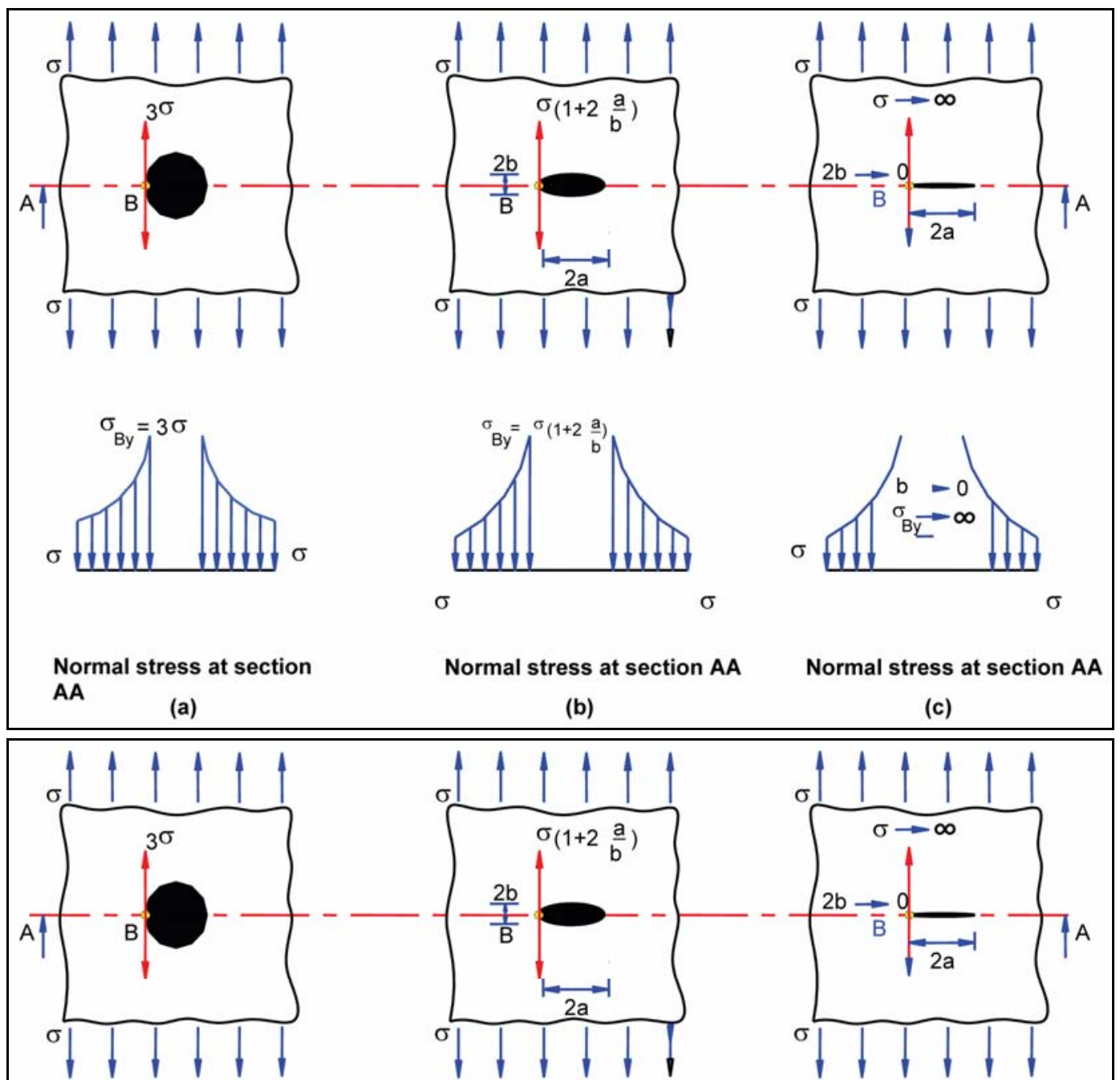

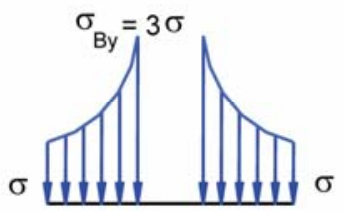

Normal stress at section AA

(a)

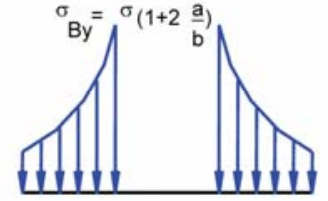

$\sigma$

Normal stress at section AA

(b)

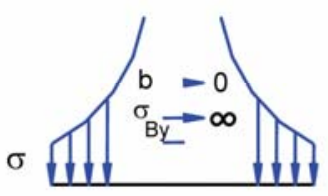

$\sigma$

Normal stress at section AA

(c)

Figure 4. Stress concentration at the crack tip due to (a) circular hole, (b) elliptical hole, and (c) sharp line crack.

Irwin (Irwin 1957) was credited with obtaining mathematical expressions for the stress field near the crack tip. Stress field $\left(\sigma_{i j}\right)$ at the crack tip in each of the principal modes of fracture can be obtained in the form: 


$$
\sigma_{i j}=\frac{K}{\sqrt{2 \pi r}} f_{i j}(\varphi)
$$

where $r$ is the distance from the crack tip and $\varphi$ is the angle of the stress tensor $f_{i j}(\varphi)$, as shown in Figure 5. Equation 2.4 is valid for small values of $r$. The form of $f_{i j}$ depends on the specimen and crack geometry. $K$ in Equation 2.4 is called the stress intensity factor, and equals to $K_{I}, K_{I I}$, or $K_{\text {III }}$ depending on the applicable mode of fracture (I, II, or III, respectively).

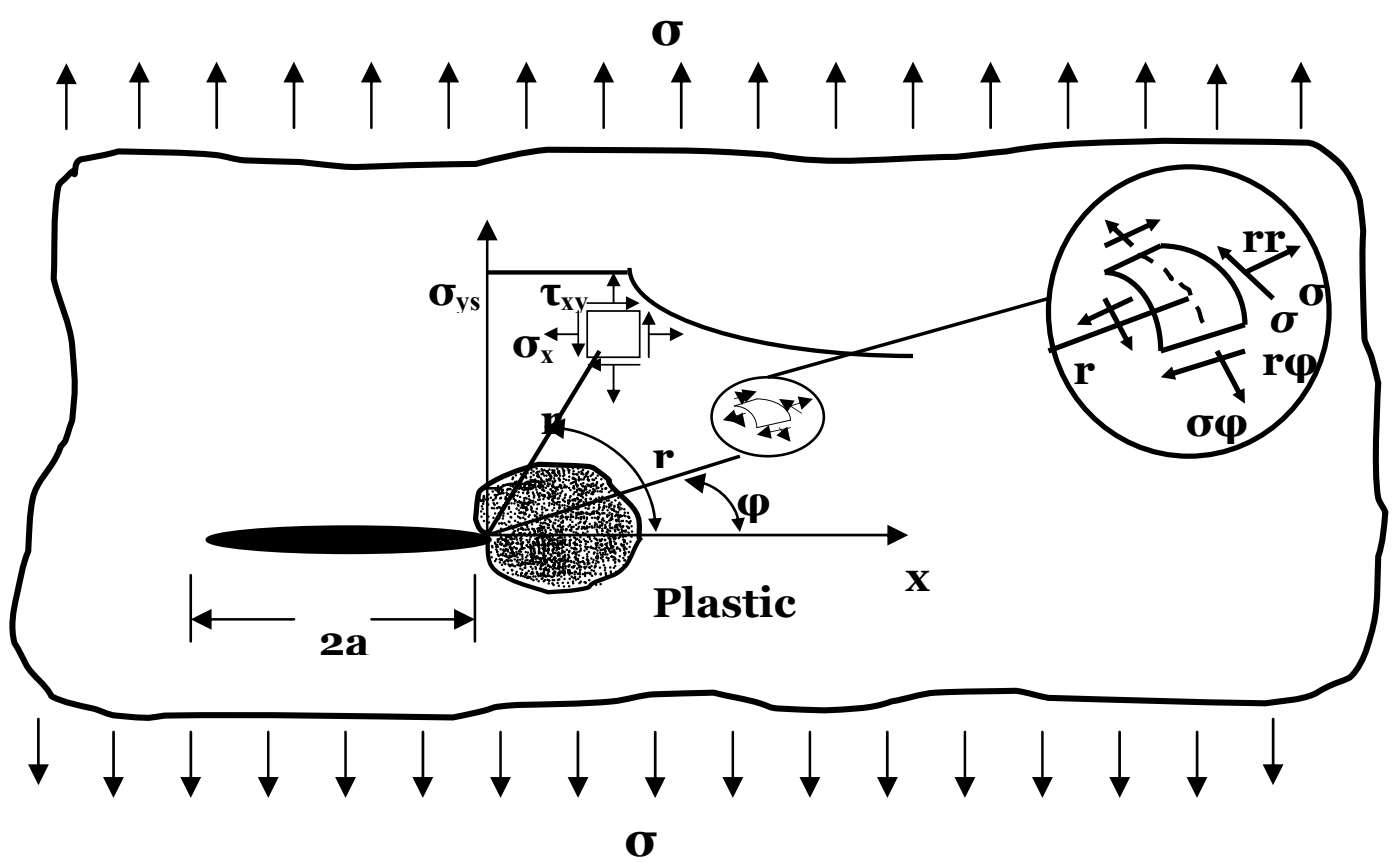

Figure 5. Notations for stresses and other geometric parameters.

Irwin found that the stress and displacement fields in the vicinity of crack tips subjected to the three modes of deformation are given by Equations 2.5, 2.6, and 2.7. Irwin developed these equations using the Westergaard method. Figure 4 shows the stress concentration at the crack tip caused by (a) a circular hole, (b) an elliptical hole, and (c) a sharp line crack. The stress distribution for Mode I fracture (Barsom and Rolfe 1987), can be obtained as:

$$
\sigma_{x x}=\frac{K_{I}}{\sqrt{2 \pi r}} \cos \left(\frac{\varphi}{2}\right)\left[1-\sin \left(\frac{\varphi}{2}\right) \sin \left(\frac{3 \varphi}{2}\right)\right]
$$




$$
\begin{gathered}
\sigma_{y y}=\frac{K_{I}}{\sqrt{2 \pi r}} \cos \left(\frac{\varphi}{2}\right)\left[1+\sin \left(\frac{\varphi}{2}\right) \sin \left(\frac{3 \varphi}{2}\right)\right] \\
\tau_{x y}=\frac{K_{I}}{\sqrt{2 \pi r}} \cos \left(\frac{\varphi}{2}\right) \sin \left(\frac{\varphi}{2}\right) \sin \left(\frac{3 \varphi}{2}\right)
\end{gathered}
$$

At $\varphi=0$ one obtains

$$
\sigma_{y y}=\frac{K_{I}}{\sqrt{2 * \pi * r}}
$$

The distribution obtained for $\sigma_{y y}$ is also shown in Figure 5 .

\subsubsection{Stress intensity factor}

The second major achievement in the theoretical foundation of LEFM was the introduction of the stress intensity factor, $K$, as a parameter for the intensity of stresses close to the crack tip and related to the energy release rate (Bazant and Planas 1998). Ingliss (1913) studied the unexpected failure of naval ships, and Griffith (1921) extended this work using thermodynamical criteria. Using this work Irwin (1957) developed this concept of the stress intensity factor.

The stress intensity factor is a measure of the change in stress within the vicinity of the crack tip. Therefore, it is important to know the crack direction and when the crack stops propagating. The stress intensity factor is compared with the critical stress intensity factor to determine whether or not the crack will propagate.

Dimensional analysis can be used to show that the stress intensity factor for Mode I fracture $K_{I}$ has the following form:

$$
K_{I}=g \sigma \sqrt{\pi a}
$$

where $g$ is a nondimensional function depending on the size and geometry of the crack, size and geometry of the structural component, and the type of loading. For normal cracks, its value ranges between 1 and 2, but may be larger for longer cracks. Functions defined for common geometries and loading conditions are available in published literature (Barsom and Rolfe 1987; Tada et al. 1985). $\sigma$ is the nominal far-field stress and $2 a$ is the crack 
length. If $K_{I}$ is the same for two cracked bodies, then based on the equations, the same stress field will exist at their crack tips. If the two bodies are made of the same material, an identical response is expected. This fact results in the important conclusion that $K_{I}$ can be used as a similitude parameter to compare the response of the same material at the crack tip and also to compare the degree to which materials are influenced by the stress fields.

\subsubsection{Fracture toughness: Critical stress intensity factor}

Another important parameter of the LEFM is the fracture toughness, $K_{I C}$ (the capacity). Fracture toughness is a material fracture property (Swamy 1979). If a plate is loaded (Figure 6) to the failure stress, $\sigma_{f}$, and if $\sigma=\sigma_{f}$ is the value of the nominal far-field stress at failure, then a value of $K_{I}$ associated with $\sigma_{f}$ could be determined and referred to as $K_{I C}$. If this toughness property is available for the material, then the failure state stress could be expressed as (Swamy 1979):

$$
\sigma_{f}=\frac{K_{I C}}{\sqrt{\pi a}}
$$

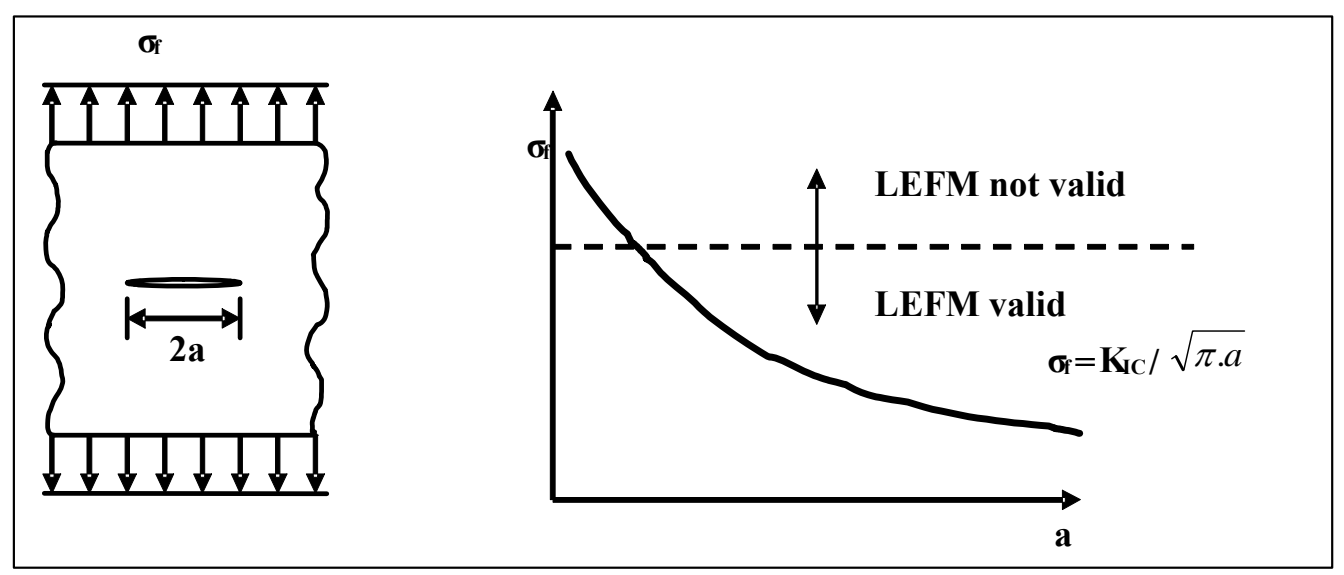

Figure 6. Failure stress related to crack size for infinitely wide plate subjected to tension.

From Figure 6 it can be observed that when the obtained value of $\sigma_{f}$ exceeds the tensile strength of the material, $f_{t}$ (or when $a<a_{c}$, the critical crack length), for small crack length, the LEFM is not valid. The relation between the energy release rate, $G_{I}$, and the stress intensity factor, $K_{I}$, can be shown (Barsom and Rolfe 1987; Bocca et al. 1991) to be of the form: 


$$
G_{I}=\frac{K_{I}^{2}}{E}
$$

where for plane stress conditions $E^{\prime}=E$ and for plane strain conditions $E^{\prime}=E /\left(1-v^{2}\right)$. Where $\mathrm{E}$ is the modulus of elasticity and $v$ is the Poisson ratio. Instead of writing the catastrophic crack growth condition in terms of $G_{I}\left(\right.$ as $\left.G_{I}=G_{I C}\right)$ one may alternatively use the condition $K_{I}=K_{I C}\left(K_{I C}\right.$ can be obtained using Equation 2.10 by substituting $\left.G_{I}=G_{I C}\right)$. $K_{I C}$, and $G_{I C}$ are not loading and crack geometry dependent. Like $G_{I C}, K_{I C}$, also termed the fracture toughness of the material, is a material property.

\subsubsection{Plastic zone and influence of constraint at the crack tip}

Realistically, using elastic theories, the materials cannot be expected to sustain the extremely large stresses predicted at the crack tip. The theoretical shape of the local yield (plastic) zone can be determined using the elastic stress distribution obtained in the vicinity of the crack tip and the yield strength of metals (shaded zone in Figure 5). Elongation in the direction of applied stress is accompanied by negative strains in the other perpendicular directions from the influence of the Poisson's ratio. In other words, an elongation occurs in the applied stress direction and shrinkage in the other direction. Plane stress or plane strain conditions may exist at the crack tip, depending on the type of constraint at the crack tip.

Usually at the surface, the plane stress condition results in a large plastic zone from the low level of constraint. Also, with the large plastic deformation and more energy absorption, there is more resistance to crack growth. Plane strain conditions prevail in the interior of the specimen, where constraints are more severe. A smaller plastic zone with less energy absorption is typical under plane strain conditions of crack growth. The thickness of the specimen, as a result, plays a major role in determining the state of stress at the crack tip.

\subsection{J-integral}

The J-integral was presented by Cherepanov (1967) and by Rice (1968a, 1968b) for two-dimensional (2-D) domains containing cracks. The $\mathrm{J}$-integral is usually used in rate-independent quasi-static fracture analysis to characterize the energy release associated with crack advance. It can be related to the stress intensity factor if the material response is linear. 
Consider a 2-D linear body of linear or nonlinear elastic material free of body forces and subjected to a 2-D deformation field (plane strain, plane stress) so that all stresses $\sigma_{i j}$ depend only on two Cartesian coordinates $(\mathrm{x}, \mathrm{y})$. Suppose the body contains an edge crack as shown in Figure 7.

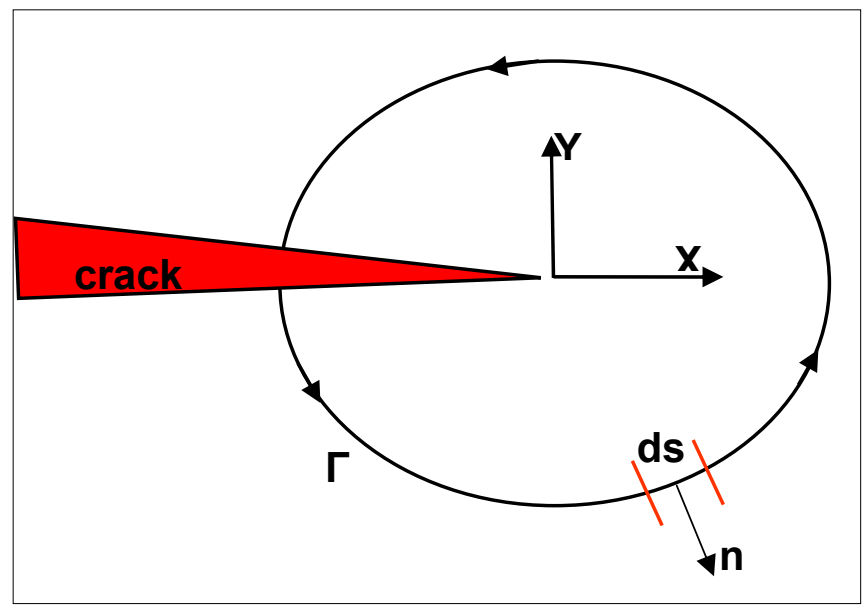

Figure 7. Crack tip coordinate system and typical line integral contour.

Define the strain-energy density $W$ as

$$
W=W(x, y)=W(\varepsilon)=\int_{0}^{\varepsilon} \sigma_{i j} \partial \varepsilon_{i j}
$$

where $\varepsilon=\left[\varepsilon_{i j}\right]$ is the infinitesimal strain tensor. Now, define the J-integral as

$$
J=\int_{\Gamma}\left(W \partial y-T \frac{\partial u}{\partial x} \partial s\right)
$$

As shown in Figure $7, \boldsymbol{\Gamma}$ is the curve surrounding the notch tip, the integral being evaluated counterclockwise starting from the lower surface and continuing along the path $\boldsymbol{\Gamma}$ to the upper surface. In Equation 2.12, $\boldsymbol{T}$ is the traction vector defined according to the outward normal along $\boldsymbol{\Gamma}$, $T_{i}=\sigma_{i j} n_{j}: \boldsymbol{u}$ is the displacement vector, and $\boldsymbol{d} \boldsymbol{s}$ is an element arc length along $\boldsymbol{\Gamma}$. Rice (1968a, 1968b) proved the path-independent concepts and found that for small-scale yielding the stress energy release rate $G$ is equal to the J-integral. Therefore, the stress intensity factor can be evaluated as follows: 


$$
\begin{gathered}
G=\frac{K_{I}^{2}}{E^{*}} \\
J=G=\frac{K_{I}^{2}}{E^{*}} \\
K_{I}=\sqrt{J E^{*}}
\end{gathered}
$$

where:

$E^{*}=\frac{E}{1-v^{2}}$ for plane strain and $E^{*}=E$ for plane stress

For a virtual crack advance $\varphi(p)$ in the plane of a three-dimensional fracture, the energy release rate is given by

$$
J=\int_{A}(p) n \cdot Q \cdot r d A
$$

where $d A$ is a surface element along a vanishing small tubular surface enclosing the crack tip or crack line, $n$ is the outward normal to $d A$, and $r$ is the local direction of virtual crack extension. $Q$ is given by

$$
Q=\left(W I-\sigma \cdot \frac{\partial u}{\partial x}\right)
$$

For elastic material behavior $W$ is the elastic strain energy; for elasticplastic or elasto-viscoplastic material behavior $W$ is defined as the elastic strain energy density plus the plastic dissipation, thus representing the strain energy in an equivalent elastic material. Therefore, the J-integral calculated is suitable only for monotonic loading of elastic-plastic materials. $I$ is the unit matrix.

The stress intensity factors $K_{I}, K_{I I}$, and $K_{I I I}$ are usually used in linear elastic fracture mechanics to characterize the local crack-tip/crack-line stress and displacement fields. They are related to the energy release rate (the J-integral) through

$$
J=\frac{1}{8 \pi} K^{T} \cdot B^{-1} \cdot K
$$


where $K=\left[K_{I}, K_{I I}, K_{I I I}\right]$ are the stress intensity factors and $B$ is called the prelogarithmic energy factor matrix. For homogeneous, isotropic materials $B$ is diagonal, and Equation 2-18 simplifies to

$$
J=\frac{1}{E}\left(K_{I}^{2}+K_{I I}^{2}\right)+\frac{1}{2 G} K_{I I I}^{2}
$$

where $E=E$ for plane stress and $E=E /\left(1-v^{2}\right)$ for plane strain, axisymmetry, and three dimensions. 


\section{Fracture Mechanics Numerical Solution: Validation of J-integral Approach}

The field of fracture mechanics has become the primary approach to control brittle fracture and fatigue failures in structures. An overwhelming amount of research on brittle fracture in structures of all types has shown that numerous factors can contribute to brittle fractures in large welded structures, for example, service temperature, material toughness, connections details, welding residual stresses, fatigue, and constraint. However some primary factors control the susceptibility of a structure to brittle fracture: the material toughness, $K_{I C}$, the crack size $a_{c}$; and the stress level $\sigma$.

The material toughness $\left(K_{I C}\right)$ can be defined as the ability to carry load or deform plastically in the presence of a notch and can be described in terms of the critical stress intensity factor under conditions of plane stress, plain strain, or critical toughness.

The critical stress intensity factor, $K_{I C}$, represents the terminal conditions in the life of a structural component. The total useful life of a component is determined by the time necessary for a crack to initiate and propagate from subcritical dimensions to the critical size, $a_{c}$.

This chapter presents the validation of the J-integral computed numerically against closed-form solutions of semi-infinite plates with throughthickness cracks, double-edge cracks, single-edge cracks, and cracks growing from round holes.

\subsection{Through-thickness crack}

A perfectly rectangular plate of 20 by 40 in. (Figure 8 ) with a center crack of 5.0 in. with a tensile stress of 100.0 psi was analyzed and compared with the closed form solution (Tada et al. 1985). Figure 9 shows the finite element mesh and stress contours for the finite element analysis. 


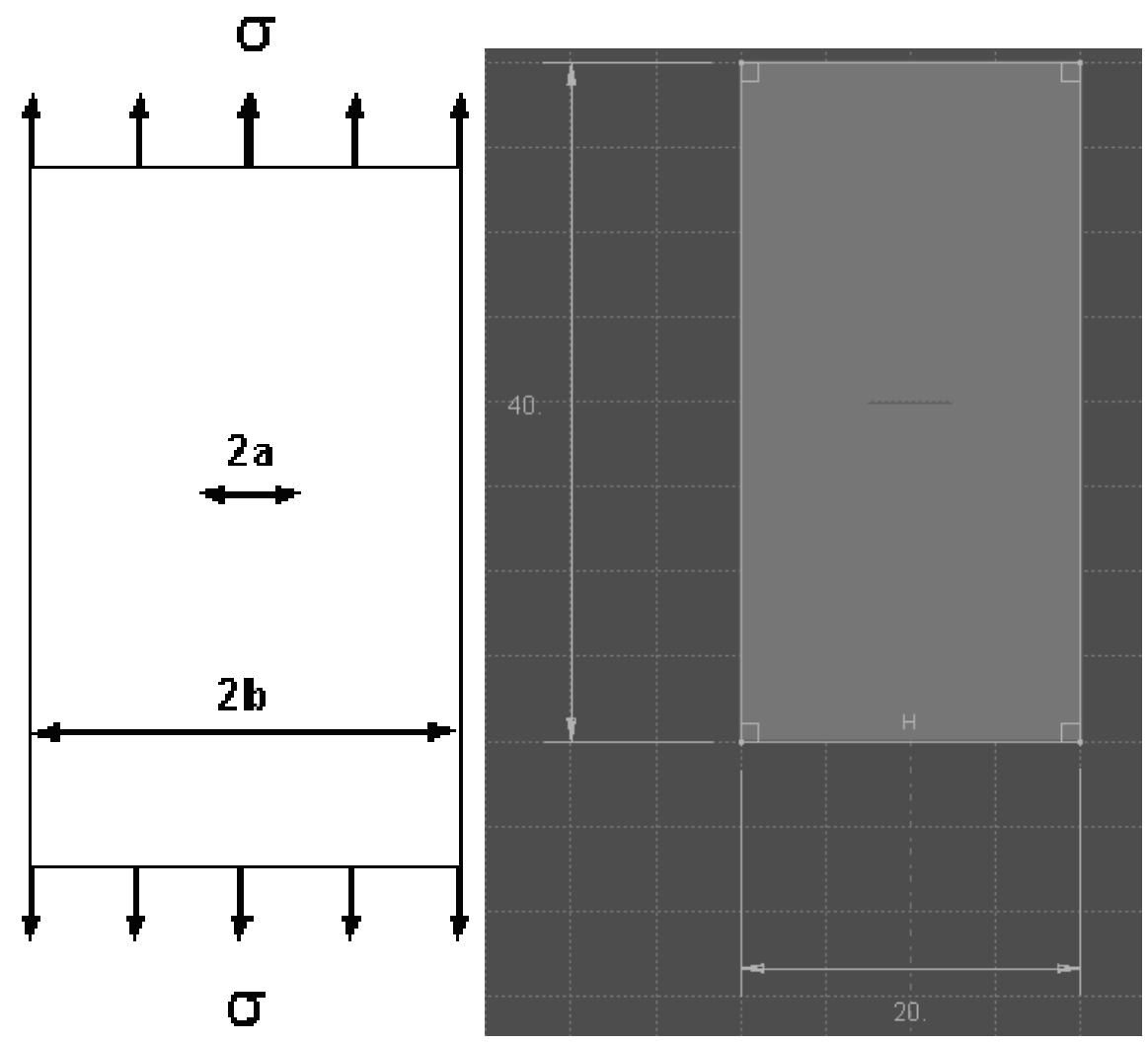

Figure 8. Plate sketch and dimensions for through-thickness crack.

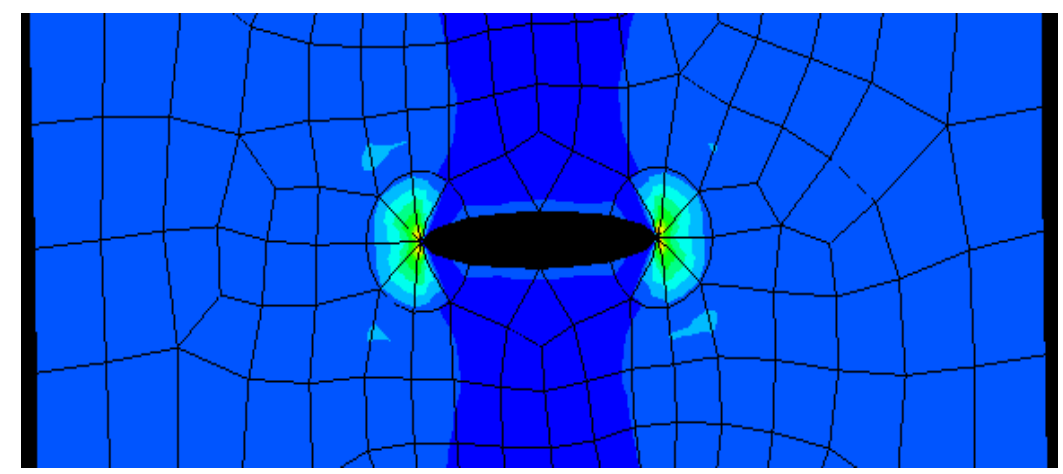

Figure 9. Through-thickness crack plate finite element mesh and stress contour.

The stress intensity factor for an infinite plate subjected to uniform tensile stress, $\sigma$, containing a through-thickness crack of length $2 a$ is:

$$
K_{I}=\sigma \sqrt{\pi a}
$$


with a tangent correction of

$$
\left(\frac{2 b}{\pi a} \tan \frac{\pi a}{2 b}\right)^{1 / 2}
$$

It becomes

$$
K_{I}=\sigma \sqrt{\pi a}\left(\frac{2 b}{\pi a} \tan \frac{\pi a}{2 b}\right)^{1 / 2}
$$

To obtain the correction factor, an interpolation is performed using the values in Table 1 :

$$
\begin{aligned}
& a=2.5^{\prime \prime} \\
& b=10^{\prime \prime} \\
& \frac{a}{b}=\frac{2.5}{10}=0.25
\end{aligned} \quad\left(\frac{2 b}{\pi a} \tan \frac{\pi a}{2 b}\right)^{1 / 2}=1.03
$$

Table 1. Correction factors for a finite-width plate containing a through-thickness crack.

\begin{tabular}{|l|l|l|l|}
\hline $\mathrm{a} / \mathrm{b}$ & $\left(\frac{2 b}{\pi a} \tan \frac{\pi a}{2 b}\right)^{1 / 2}$ & $\mathrm{a} / \mathrm{b}$ & $\left(\frac{2 b}{\pi a} \tan \frac{\pi a}{2 b}\right)^{1 / 2}$ \\
\hline 0.074 & 1.00 & 0.410 & 1.08 \\
\hline 0.207 & 1.02 & 0.466 & 1.11 \\
\hline 0.275 & 1.03 & 0.535 & 1.15 \\
\hline 0.337 & 1.05 & 0.592 & 1.20 \\
\hline
\end{tabular}

Then,

$K_{I}=(100) \sqrt{\pi \cdot 2.5} \cdot(1.03)$

$K_{I}=288.657 p s i \sqrt{\text { in }}$

The results from the finite element evaluation provide a J-integral value of $2.82 \times 10^{-3} \mathrm{psi}$-in. Using Equation 2.14 to determine the stress intensity factor $K_{I}$ gives: 


$$
\begin{aligned}
& J=\frac{K^{2}}{E} \\
& J=2.82 \times 10^{-3} p s i-i n \\
& E=30 \times 10^{6} p s i \\
& K=\sqrt{J \cdot E}=\sqrt{2.82 \times 10^{-3} \cdot 30 \times 10^{6}} \approx 290.86 \mathrm{psi} \sqrt{\mathrm{in}}
\end{aligned}
$$

The results show a difference of less than 1 percent between the numerical and closed-form solutions.

\subsection{Double-edge-notched plate}

A perfect rectangular plate of 20 by 40 in. (Figure 10) with double edge cracks of 2.5 in. with a tensile stress of 100.0 psi was analyzed and compared with the closed-form solution. Figure 11 shows the finite element mesh and stress contours for the finite element analysis.

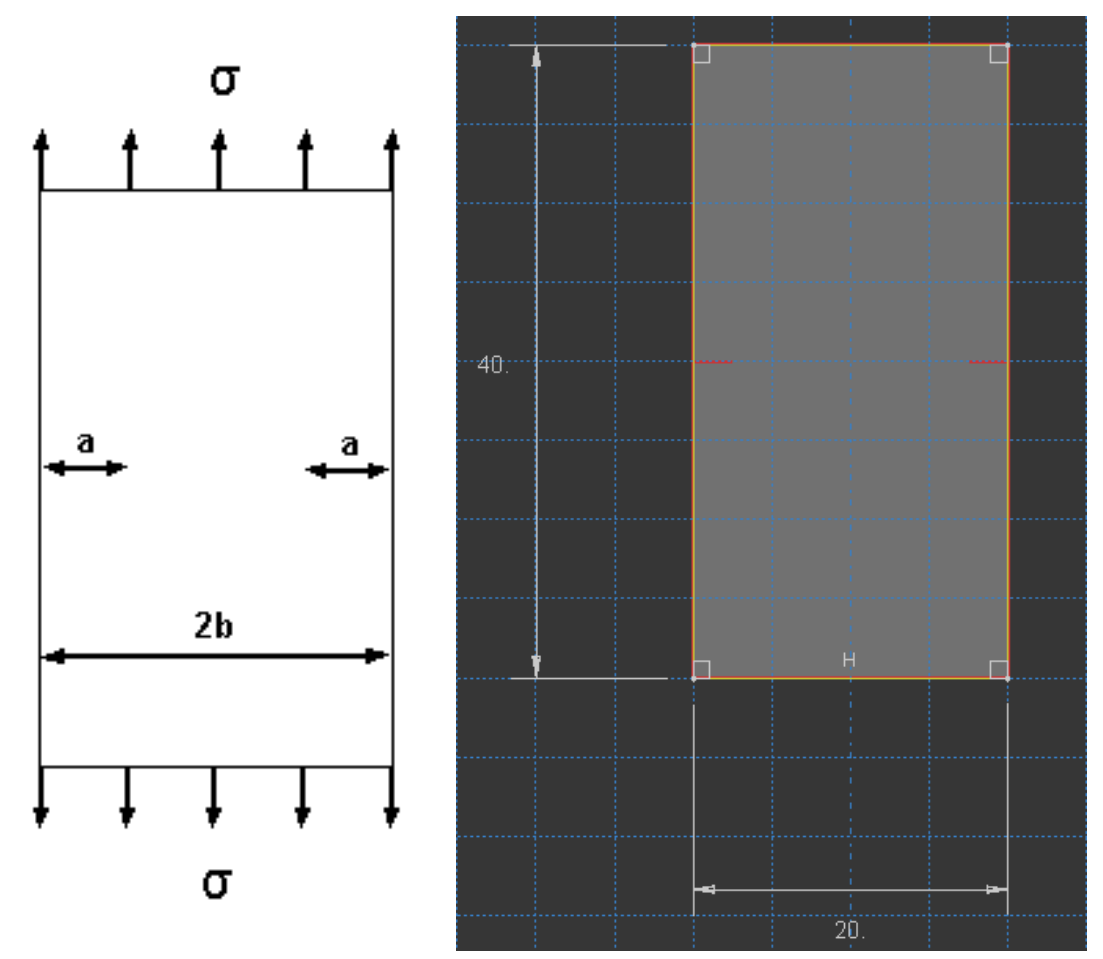

Figure 10. Plate sketch and dimensions for double-edge-notched plate. 


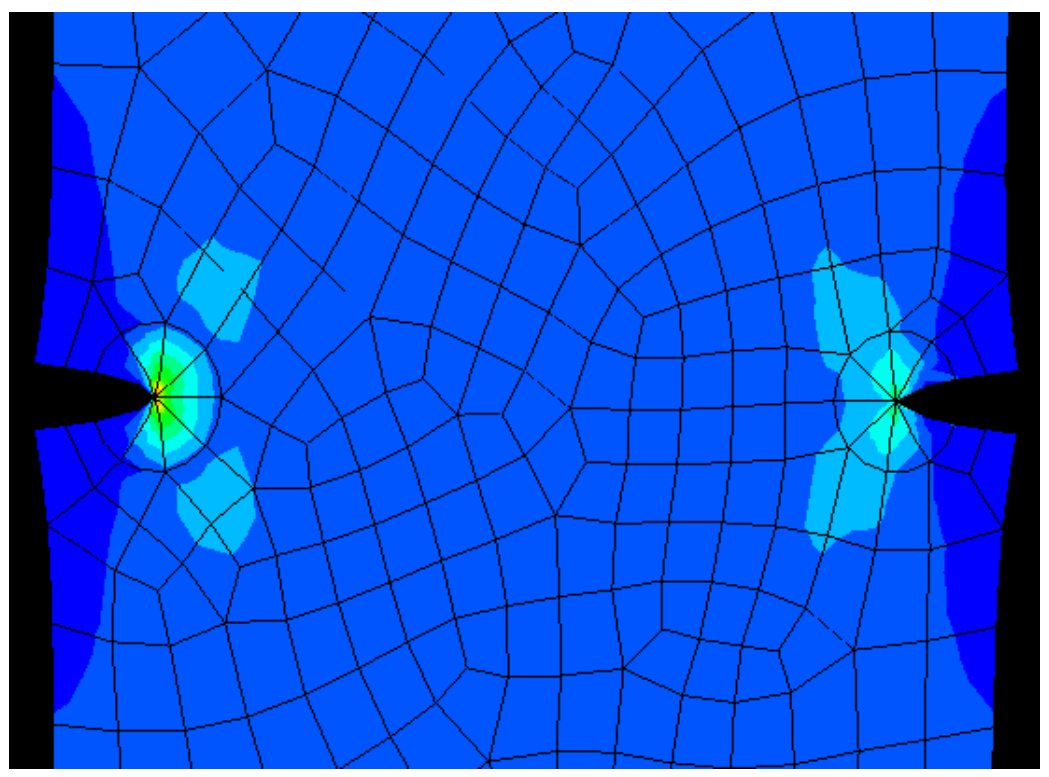

Figure 11. Double-edge-notched plate finite element mesh and stress contour.

The stress intensity factor for double-edge-notched infinite plate that is subjected to a uniform tensile stress is given by $K_{I}=1.12 \sigma \sqrt{\pi a}$, where the constant 1.12 represents a free surface correction factor for edge notches that are perpendicular to the applied tensile stress. For this example,

$a=2.5 \mathrm{in}$.

$K_{I}=1.12 \sigma \sqrt{\pi a}$

$K_{I}=1.12(100) \sqrt{2.5 \cdot \pi}$

$K_{I}=313.88 p s i \sqrt{i n}$.

The results from the finite element evaluation provide a $J$-integral value of $3.26 \times 10^{-3} \mathrm{psi}$-in. for the left edge crack and $3.18 \times 10^{-3} \mathrm{psi}-\mathrm{in}$. for the right edge crack. For this example a similar value of the $J$-integral would be expected for both cracks; however, because of the lack of mesh symmetry the values differ. It is important to point out that the $\mathrm{J}$-integral is directly proportional to the strain energy density of those finite elements inside the contour path chosen; therefore, the lack of mesh symmetry will vary the resultant J-integral as shown in this example. Then using Equation 2.14 to determine the stress intensity factor $K_{I}$ produces less than 1 percent 
difference is observed between the mean value of the stress intensity factor obtained from the finite element analysis and the closed-form solution.

$J=\frac{K^{2}}{E}$

$J=3.26 \times 10^{-3} p s i-$ in

$E=30 \times 10^{6} p s i$

$K=\sqrt{J \cdot E}=\sqrt{3.26 \times 10^{-3} \cdot 30 \times 10^{6}} \approx 312.73 \mathrm{psi} \sqrt{\mathrm{in} .}$ for the left crack and:

$J=3.18 \times 10^{-3} p s i-i n$

$E=30 \times 10^{6} \mathrm{psi}$

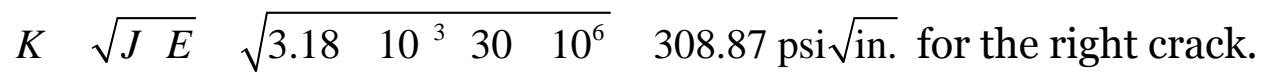

\subsection{Single-edge-notched plate}

For this example, a plate with the same 40 by 20 in. dimensions as that of the previous examples is used (Figure 12). A single-edge crack of $2.5 \mathrm{in.}$ was induced at the left edge of the plate and the plate was loaded with 100 psi in tension as shown in Figure 12. Figure 13 shows the finite element mesh and stress contours for the finite element analysis.

The stress-intensity-factor equation for a semi-finite single-edge notched specimen is given by Equation 3.5:

$$
K_{I}=1.12 \sigma \sqrt{\pi a} \cdot k\left(\frac{a}{b}\right)
$$

This function has an additional correction factor to account for bending stresses caused by lack of symmetry in the single-edge-notched specimen. 


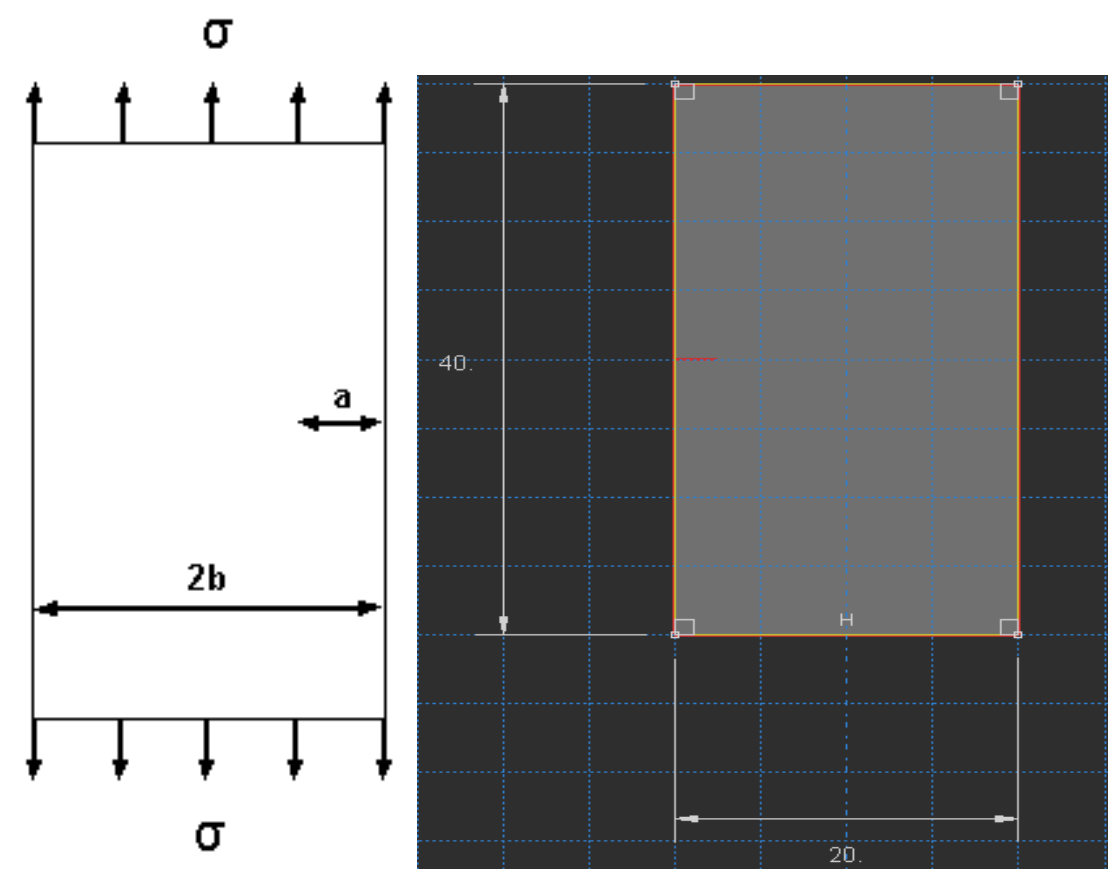

Figure 12. Plate sketch and dimensions for single-edge-notched plate.

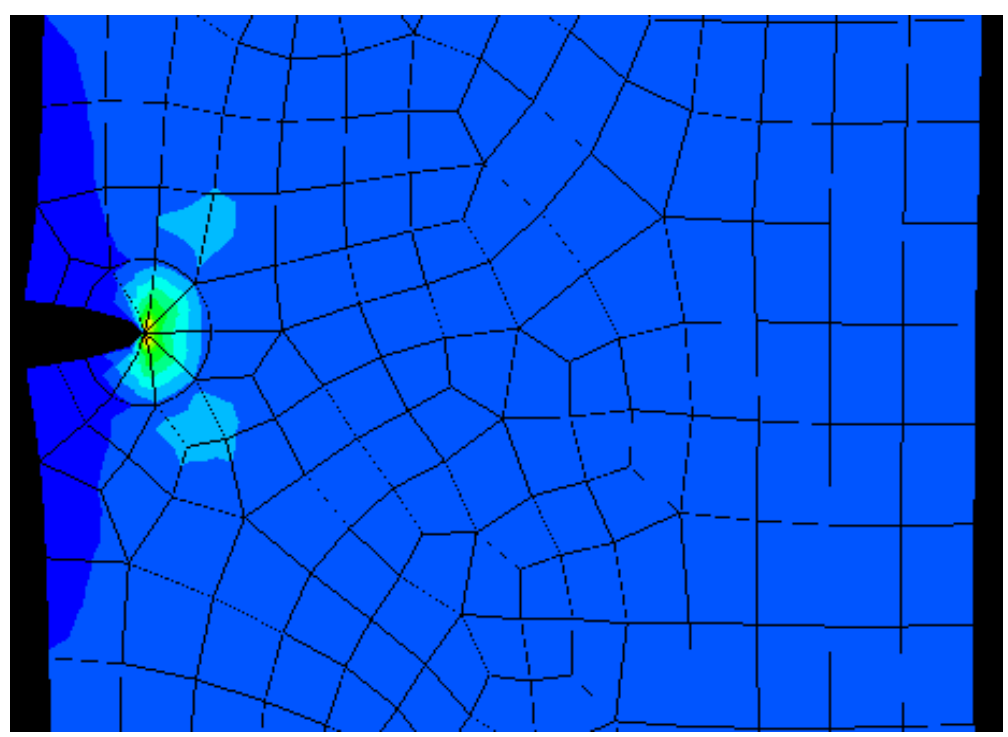

Figure 13. Single-edge-notched plate finite element mesh and stress contour.

To obtain the correction factor, an interpolation is performed using the values in Table 2:

$$
\begin{aligned}
& a=2.5 \mathrm{in.} \quad k\left(\frac{a}{b}\right)=1.11 \\
& b=10 \mathrm{in.} \\
& \frac{a}{b}=\frac{2.5}{10}=0.25
\end{aligned}
$$


Table 2. Correction factors for a single-edge-notched plate.

\begin{tabular}{|l|l|l|l|}
\hline $\mathrm{a} / \mathrm{b}$ & $\mathrm{k}(\mathrm{a} / \mathrm{b})$ & $\mathrm{a} / \mathrm{b}$ & $\mathrm{k}(\mathrm{a} / \mathrm{b})$ \\
\hline 0.10 & 1.03 & 0.60 & 1.50 \\
\hline 0.20 & 1.07 & 0.70 & 1.69 \\
\hline 0.30 & 1.15 & 0.80 & 1.91 \\
\hline 0.40 & 1.22 & 0.90 & 2.20 \\
\hline 0.50 & 1.35 & 1.00 & 2.55 \\
\hline
\end{tabular}

Then,

$$
\begin{aligned}
& K_{I}=1.12(100) \sqrt{\pi \cdot 2.5} \\
& K_{I}=348.406 \mathrm{psi} \sqrt{\mathrm{in} .}
\end{aligned}
$$

The results from the finite element evaluation provide a J-integral value of $3.92 \times 10^{-3}$ psi-in. Using Equation 2.14 to determine the stress intensity factor $\mathrm{K}_{\mathrm{I}}$, gives

$$
\begin{aligned}
& J=\frac{K^{2}}{E} \\
& J=3.92 \times 10^{-3} p s i-i n \\
& E=30 \times 10^{6} p s i \\
& K=\sqrt{J \cdot E}=\sqrt{3.92 \times 10^{-3} \cdot 30 \times 10^{6}} \approx 342.93 \mathrm{psi} \sqrt{\mathrm{in} .}
\end{aligned}
$$

Once again, a difference of less than 1 percent is observed between the stress intensity factor from the finite element analysis and the closed-form solution.

\subsection{Cracks growing from round holes}

For this example, a rectangular plate $40 \mathrm{in}$. long $(h=40 \mathrm{in}$.) and $20 \mathrm{in}$. wide ( $b=20$ in.) with a 5.0-in.-radius hole and two 1.0-in. edge cracks extending toward the longitudinal edges of the plate were introduced (Figure 14). The plate was loaded with 100.0 psi in tension. Figure 15 shows the finite element mesh and stress contours for the finite element analysis. 


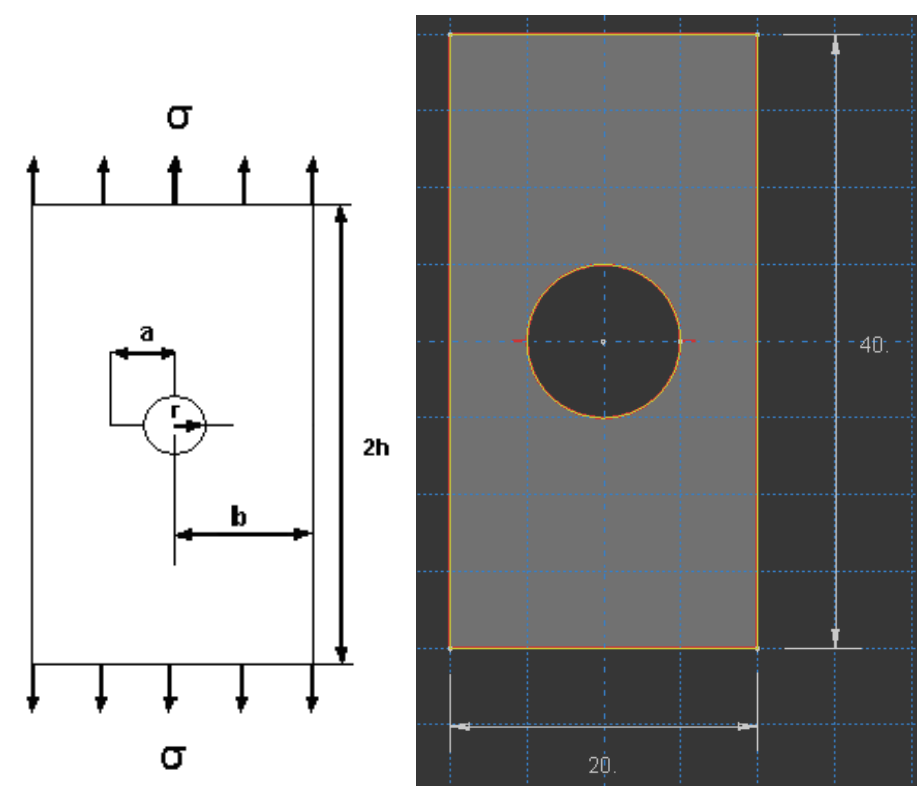

Figure 14. Plate sketch and dimensions for cracks growing from round holes.

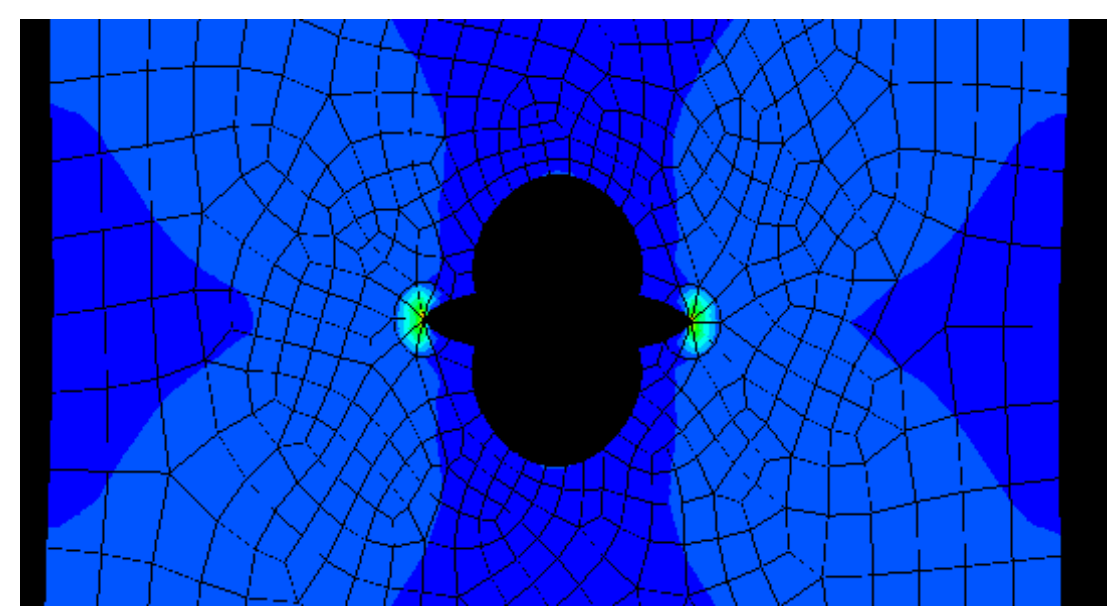

Figure 15. Crack before analysis for cracks growing from round holes.

The stress intensity factor for cracks growing from a circular hole in an infinite plate is given by:

$$
K=\sigma \sqrt{\pi a} \cdot F\left(\frac{a}{b}, \frac{R}{b}, \frac{h}{b}\right)
$$


Where for our example,

$$
\begin{array}{llll}
a=6 \text { in. } & h=20 \mathrm{in} . & & R=5 \mathrm{in} . \\
b=10 \mathrm{in} . & b=10 \mathrm{in} . & b=10 \mathrm{in} . & \sigma=100 \mathrm{psi} \\
\frac{a}{b}=\frac{6}{10}=0.6 & \frac{h}{b}=\frac{20}{10}=2.0 & & \frac{a}{b}=\frac{5}{10}=0.5
\end{array}
$$

The value for $F\left(\frac{a}{b}, \frac{R}{b}, \frac{h}{b}\right)$ is obtained from Tada et al. (1985) as 1.5, then,

$$
K=\sigma \sqrt{\pi a} \cdot F\left(\frac{a}{b}, \frac{R}{b}, \frac{h}{b}\right)=100 \sqrt{\pi \cdot 6}(1.5)=308.28 \mathrm{psi} \sqrt{\mathrm{in}}
$$

The results from the finite element evaluation provide a J-integral value of $3.05 \times 10^{-3}$ psi-in. Using Equation 2.14 to determine the stress intensity factor $K_{I}$, gives

$$
\begin{aligned}
& J=\frac{K^{2}}{E} \\
& J=3.05 \times 10^{-3} \text { psi-in. } \\
& E=30 \times 10^{6} \text { psi } \\
& K=\sqrt{J \cdot E}=\sqrt{3.05 \times 10^{-3} \cdot 30 \times 10^{6}} \approx 302.49 \mathrm{psi} \sqrt{\mathrm{in}} .
\end{aligned}
$$

For this example, a difference of less than 2 percent was observed between the stress intensity factor from the finite element analysis and the closedform solution. 


\section{3-D Finite Element Analysis of Miter Gate With Multiple Cracks}

This chapter will provide an overview of how to develop complex 3-D finite element meshes of the as-built structures. It will also give an example of how to mesh around a crack tip to determine the J-integral. It concludes by showing the calculation of the stress intensity factor and comparing it against the material toughness $\left(K_{I C}\right)$.

\subsection{Meshing techniques}

Historically the finite element mesh generation has been one of the most time-consuming issues during a finite element analysis. It is even more complex if a 3-D model is to be analyzed. In the last couple of years new meshing techniques have been developed to construct meshes of as-built structures easily. These techniques allow the modeler to include the actual details of the structures without the need for simplification and assumptions. Figure 16 shows the 3 -D mesh of an as-built miter gate. The inset provides a magnification of the bottom right corner of the gate. It becomes clear that advanced meshing techniques are necessary to generate all the details shown in Figure 16 that will result in more accurate results.

The three steps to generate the more detailed finite element mesh are as follows:

- A 3-D CAD drawing of the as-built structure is developed.

- Once the drawing has been generated, an Initial Graphics Exchange Specifications (IGES) file with trimmed surfaces is created. Most of the commercial CAD packages have the capability to generate IGES files.

- The IGES file is imported into the finite element application and the mesh is generated.

With this process all the structural components are easily modeled in the CAD package instead of in the finite element mesh application. This utilizes the strengths of both types of software; the CAD program to create the complex geometry and the finite element program to generate the analytical mesh automatically, making the meshing inexpensive. 


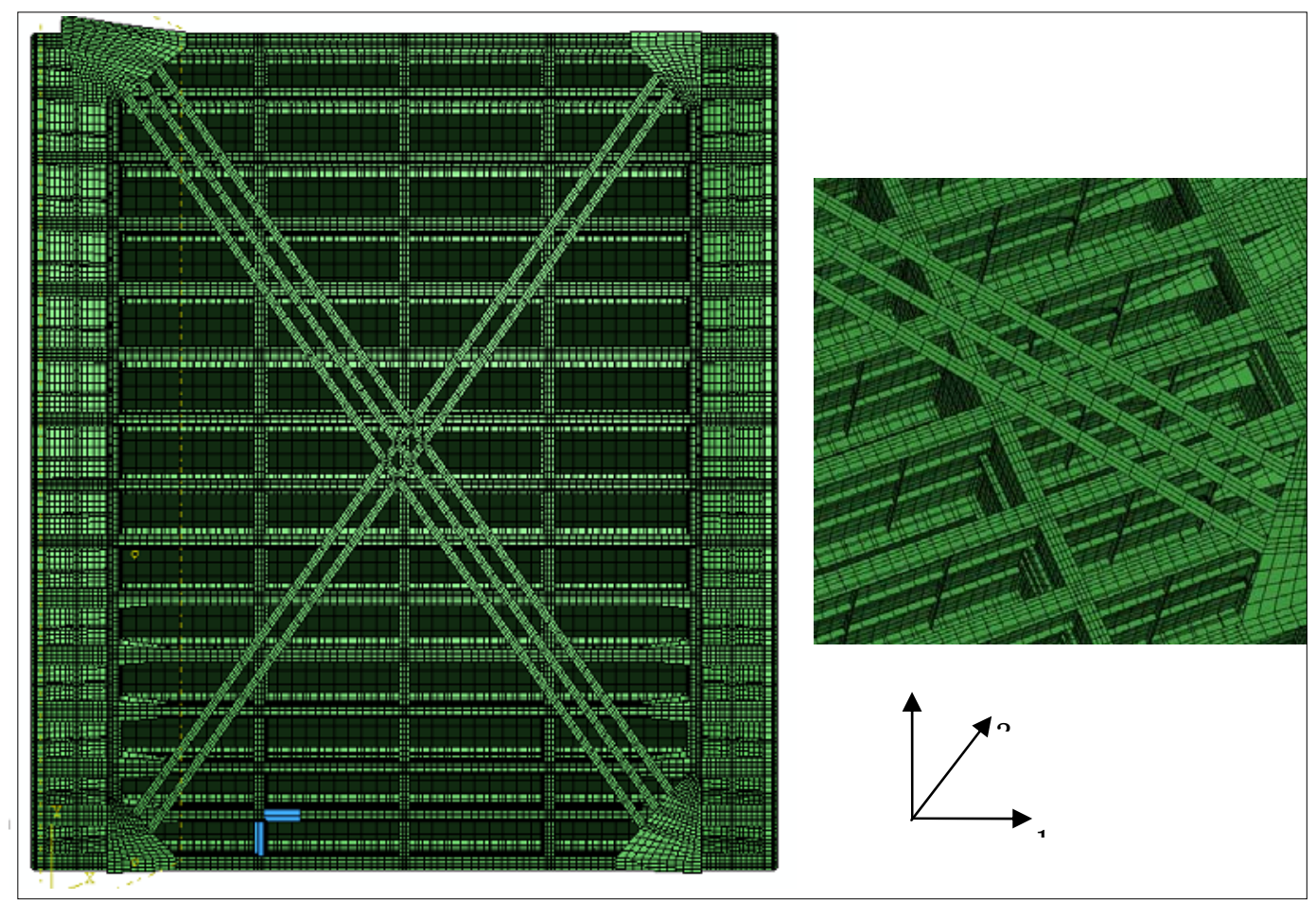

Figure 16. 3-D Finite element mesh of as-built miter gate.

For this example the finite element mesh has 364,736 nodes and 123,193 shell elements. Each shell element has a quadratic formulation with five degrees of freedom per node. The total number of degrees of freedom for this model is 1.823 million.

\subsection{Load and displacement boundary condition}

For this example the load boundary condition was a hydrostatic head of $61.5 \mathrm{ft}$, and the displacement boundary conditions restrained the miter and quoin ends to move along the three principal axes. The movement along the vertical axis at the pintle was also restricted, while the movement along the longitudinal and transverse direction (1 and 2) was restrained at the gudgeon. Table 3 summarizes the boundary conditions used for this analysis.

Table 3. Boundary conditions used for the fracture mechanics analysis.

\begin{tabular}{|l|l|l|l|l|l|l|l|}
\hline Gate Component & U1 & U2 & U3 & UR1 & UR2 & UR3 & CSYS \\
\hline Gugeon pin & 0 & 0 & --- & --- & --- & --- & Global \\
\hline Pintle & ---- & ---- & 0 & --- & --- & --- & Global \\
\hline Quoin block & 0 & 0 & 0 & --- & --- & --- & Local \\
Miter block & 0 & 0 & 0 & -- & -- & -- & Local \\
\hline
\end{tabular}




\subsection{Stress intensity factor}

The downstream flange of a vertical diaphragm is shown in Figure 17a, and a horizontal girder downstream flange is shown in Figure 17b. These flanges meshes contained artificial diagonal cracks. The meshing required to calculate the $\mathrm{J}$-integral is as follows:

- The crack tip must be meshed with a ring of quarter-point triangular elements.

- All the other elements outside the ring can be quadratic elements.

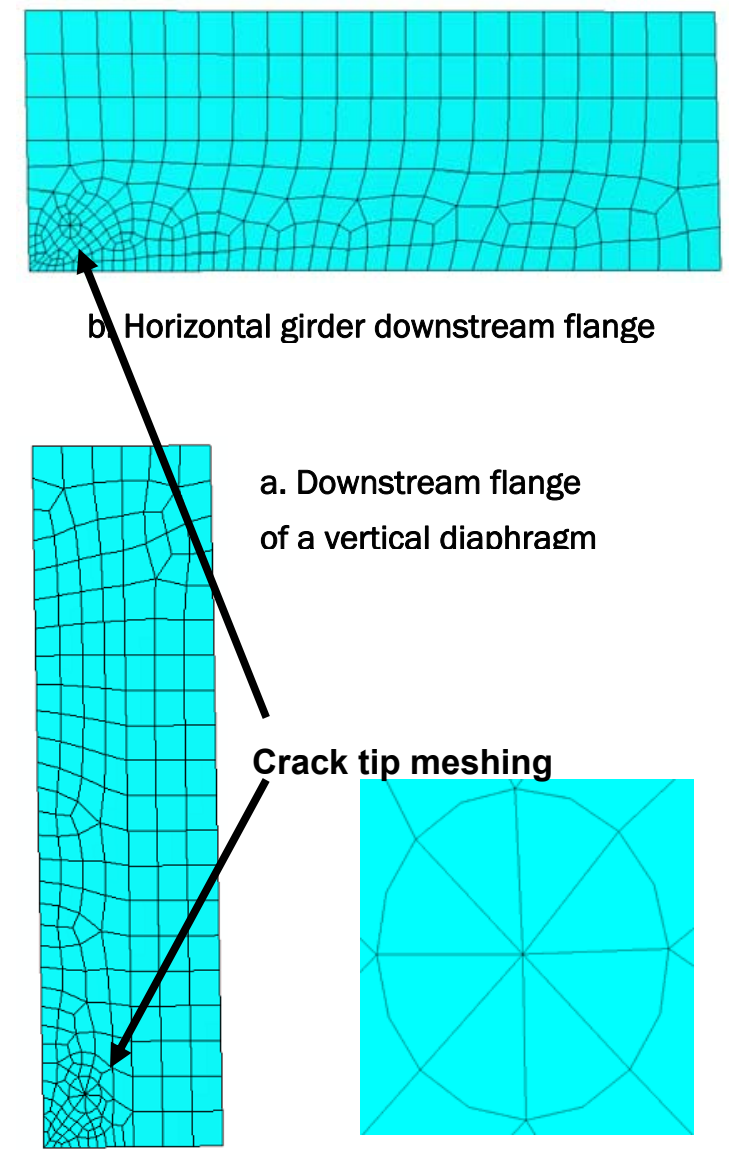

Figure 17. Finite element mesh of cracked upstream flange.

Figure 18a shows the stress contour of the upstream vertical diaphragm flange. The principal stress at the crack tip is $1,215 \mathrm{psi}$, and the J-integral is 6.91 psi*in. Using Equation 2.15 and solving for $K_{I}$ produced a stress intensity factor of $14.397 \mathrm{psi} \sqrt{\mathrm{in}}$, which is much lower than the fracture toughness of the steel $\left(K_{I C}=50,000 \mathrm{psi} \sqrt{\mathrm{in}}\right.$. $)$. 


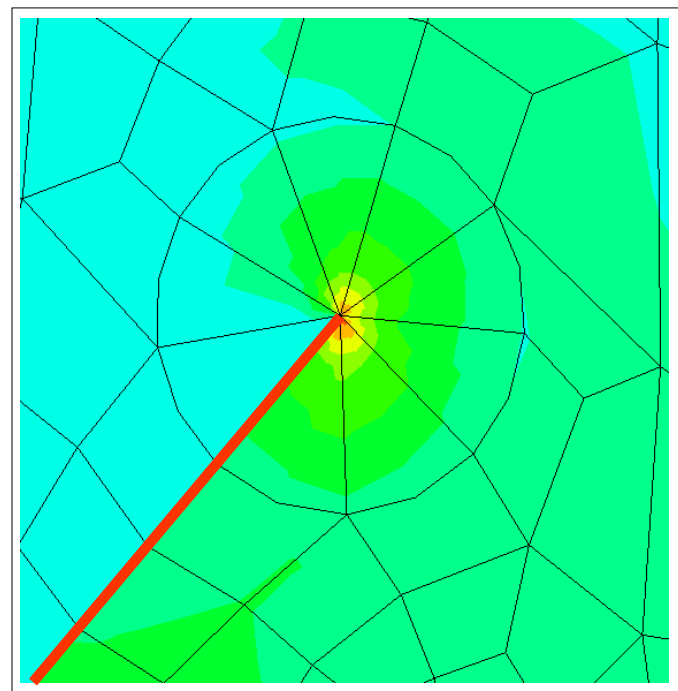

a. Vertical diaphragm

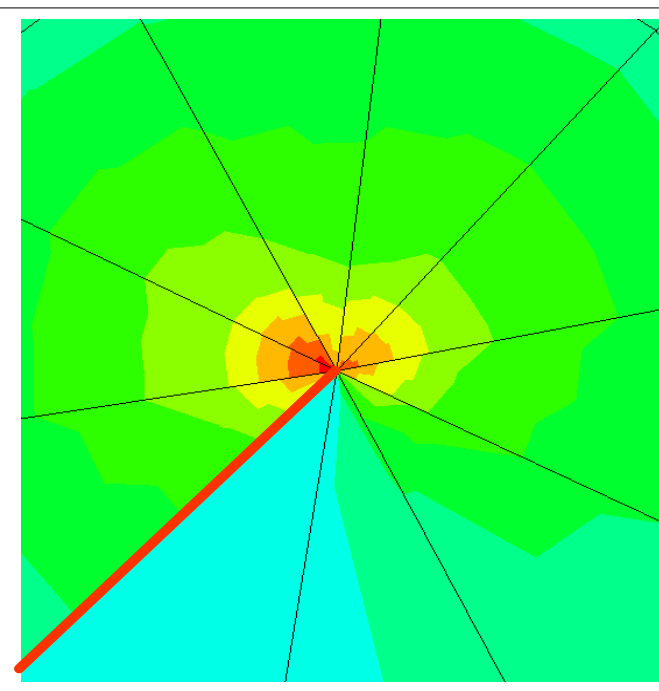

b. Horizontal girder

Figure 18. Principal stress contours of the upstream flange.

Figure $18 \mathrm{~b}$ shows the stress contour of the upstream flange of the horizontal girder. The principal stress at the crack tip is 3,990 psi and the $\mathrm{J}$-integral is $24.66 \mathrm{psi}$ in. Using Equation 2.15 and solving for $K_{I}$ produced a stress intensity factor of $27,202 \mathrm{psi} \sqrt{\mathrm{in}}$., which is much lower than the fracture toughness of the steel $\left(K_{I C}=50,000 \mathrm{psi} \sqrt{\mathrm{in}}\right.$. $)$.

Since the calculated stress intensity factors are less than the fracture toughness of the steel, the cracks on the upstream flanges of the horizontal girder and vertical diaphragm will not propagate. Whether a crack will or will not propagate can, therefore, be predicted accurately. Furthermore, ways of repairing the crack regions numerically can also be studied. 


\section{Numerical Investigation of Diagonals Pre- Stress}

This chapter presents a comprehensive 3-D finite element analysis conducted to assess the diagonal prestressing levels. This analysis will provide the initiation for a new design approach. The new techniques will allow the prediction of optimum prestressing levels without compromising the fatigue capacity.

In recent years there have been a number of failures of diagonals on miter gates (Figure 1). These appear to be fatigue-induced failures driven by the connection details at the diagonal ends, but some evidence also suggests that the current design guidance results in a much larger prestress in miter gate diagonals than may be required. The high prestress theoretically increases the fatigue of these members and results in increased stress in the miter gate.

A series of parametric analysis were carried out using the 3-D finite element models shown in Figure 19. The model consisted of 3-D shell elements with 6 degrees of freedom (Figure 19).
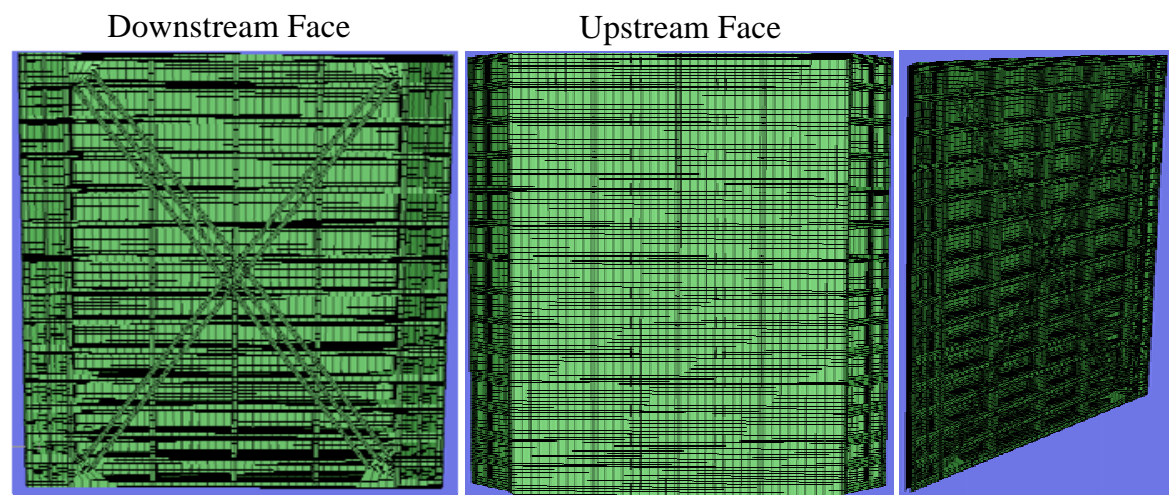

Figure 19. 3-D finite element model.

The following parametric cases were performed:

1. Gravity with no diagonals: gravity analysis of the miter gate without diagonals.

2. Gravity with positive diagonal: gravity analysis of the miter gate including only the positive diagonal. A variation of the diagonal prestressing was also 
analyzed in order to obtain displacement versus diagonal prestressing curves.

3. Gravity with positive and negative diagonals: gravity analysis of the miter gate including the positive and negative diagonals. Variation in the diagonal prestressing was also carried out.

4. Gravity with positive and negative diagonals, hydrostatic resistance pressure, and movement: analysis of the miter gate including the positive and negative diagonals, the hydrostatic resistance pressure, and the movement of the gate were evaluated. Diagonal prestressing, hydrostatic resistance pressure loads, and movement of the gate with different diagonals prestressing were also conducted.

5. Quoin block analysis: gate in closed position with upper and lower pools. A typical combination of diagonal prestressing was used in the analysis. The prestressing combination was $20 \mathrm{ksi}$ in the positive diagonal and $25 \mathrm{ksi}$ in the negative diagonal. These analyses account for deterioration in the quoin block area.

\subsection{Diagonal prestressing}

A method to produce the same effect of the diagonal prestressing in the finite element model when using plate elements was evaluated. In order to represent the pre-stress in the diagonals using the finite element code, a thermal gradient $(\Delta T)$ of the diagonals was used. To determine the sign of the change in temperature, a shell element was created to model a bar. The bar was assumed to be fixed at its ends. To compare the results obtained with the model, a theoretical solution of the problem was used. The theoretical formula for a fully restrained element is:

$$
\sigma=-E \alpha(\Delta T)
$$

Where $E$ is Young's modulus of elasticity, a measures the percentage change in the length per degree temperature (Equation 5.2). In equation 5.2, $L_{o}$ is the original length and $\Delta L$ is the change in length after temperature gradient $(\Delta T)$ is applied. For steel $\alpha=6.5 \mathrm{e}-6 /{ }^{\circ} \mathrm{F}$.

$$
\alpha=\frac{\left(\frac{\Delta L}{L_{o}}\right)}{\Delta T}
$$


Figure 20 presents a free body diagram of the pre-stressed element. In order to produce a tensile stress in the member, a negative $\Delta T$ is required. The negative $\Delta T$ produces contraction (shortening) in the element, this contraction in a restrained element produce stresses similar to the ones produced by the prestressing force in the miter gate.

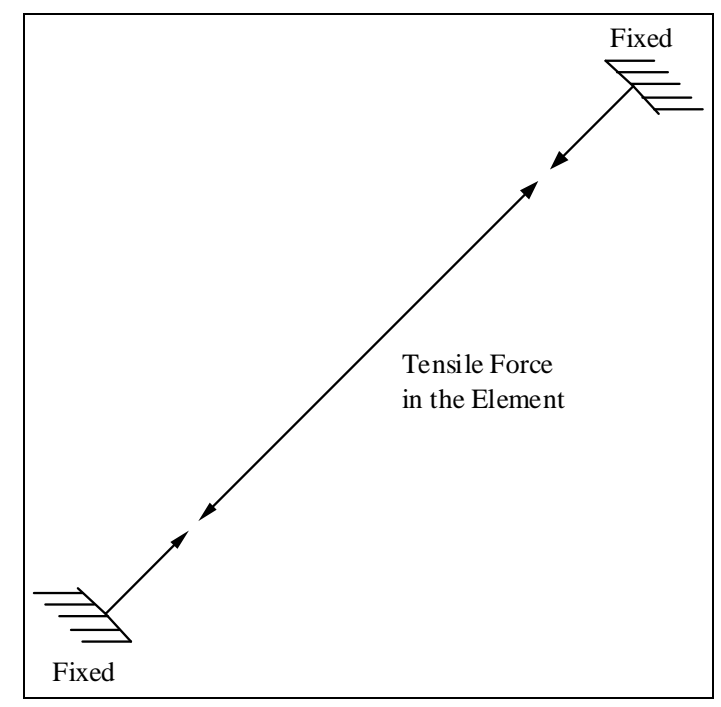

Figure 20. Free body diagram of the prestressed element.

A 2- by 2- in. steel section with $E=30 \times 10^{6} \mathrm{psi}$ and different temperature gradients was used. The theoretical and finite element results with different temperature gradients are compared in Table 4.

Table 4. Validation of the analysis using different values of $\Delta T$.

\begin{tabular}{|c|c|c|}
\hline \multirow{2}{*}{$\Delta T$} & \multicolumn{2}{|c|}{$\sigma, \mathrm{ksi}$} \\
\cline { 2 - 3 } & & $\begin{array}{l}\text { Finite Element } \\
\text { Theodel }\end{array}$ \\
\hline-20 & 3.9 & 3.9 \\
\hline-40 & 7.8 & 7.8 \\
\hline-60 & 11.7 & 11.7 \\
\hline-80 & 15.6 & 15.6 \\
\hline
\end{tabular}

\subsection{Automatic stabilization of static problems}

In finite elements the analyses that include nonlinearities can experience instabilities. The instabilities may be of a geometrical nature such as buckling or a material nature such as material softening. If the instabilities manifest themselves in a global load-displacement response with a 
negative stiffness, the problem can be treated as a buckling or collapse problem. But if the instability is localized, a local transfer of strain energy from one part of the model to neighboring parts occurs; and global solution methods may not work properly. These problems have to be solved either dynamically or with the aid of artificial damping. The commercial code used provides an automatic mechanism for stabilizing unstable quasi-static problems through the automatic addition of volume proportional damping to the model. Viscous forces with the form $F_{v}=c M v$ where $c$ is a damping factor, $M=$ artificial mass matrix calculated with unity density, and $v=\Delta u / \Delta t$ is the vector of nodal velocity, are added to the global equilibrium equations $P-I-F_{v}=0$ where $P$ is the external force, and $I$ is the internal force.

Because of the complexity of the model, localized nonlinearities can occur without affecting the global stability of the structure. For that reason this automatic stabilization mechanism was activated in the parametric analysis. The value used for the damping factor was the default value of 0.0002 .

\subsection{Miter gate operation}

During gate operation the boundary conditions are located in the pintle and gudgeon pin. These boundary conditions do not restrict the gate from having a rigid body rotation around the axis connecting the pintle and gudgeon pin. To induce a rotation in the gate three alternatives were evaluated: (1) applied rotation to the pintle, (2) applied angular velocity to the pintle, and (3) a concentrated force in the location of the operation point. The load conditions for each alternative were the self-weight of the gate, prestressing in the diagonals, and the water resistance pressure obtained from code recommendations, $30 \mathrm{psf}$ (Headquarters, U.S. Army Corps of Engineers 1994). The analysis reveals that the three methods induce rotation in the gate.

The applied rotation in the pintle and the angular velocity cases generated required rotary motion in the gate. However, the relative displacements between the top and bottom of the gate induced by the operating force were not achieved. The third alternative (concentrated force) produced a more realistic behavior of the gate when in operation; however, because the rotation cannot be specified, the total rotation depends on the step time. To reproduce the required rotation during the gate operation, the 
rigid body rotation had to be restrained. To restrain the rotation of the gate, contact surfaces were created. The contact surfaces act as a restriction in the model, stopping the gate at the desired locations. In order to verify the effectiveness of the method, a simplified model was created with the same boundary condition of the real structure. In this model a 60 - by $40-\mathrm{ft}$ plate was used to represent the gate and two plates were used to act as restricting walls. Figure 21 presents a view of the model rotating between the restricting elements.

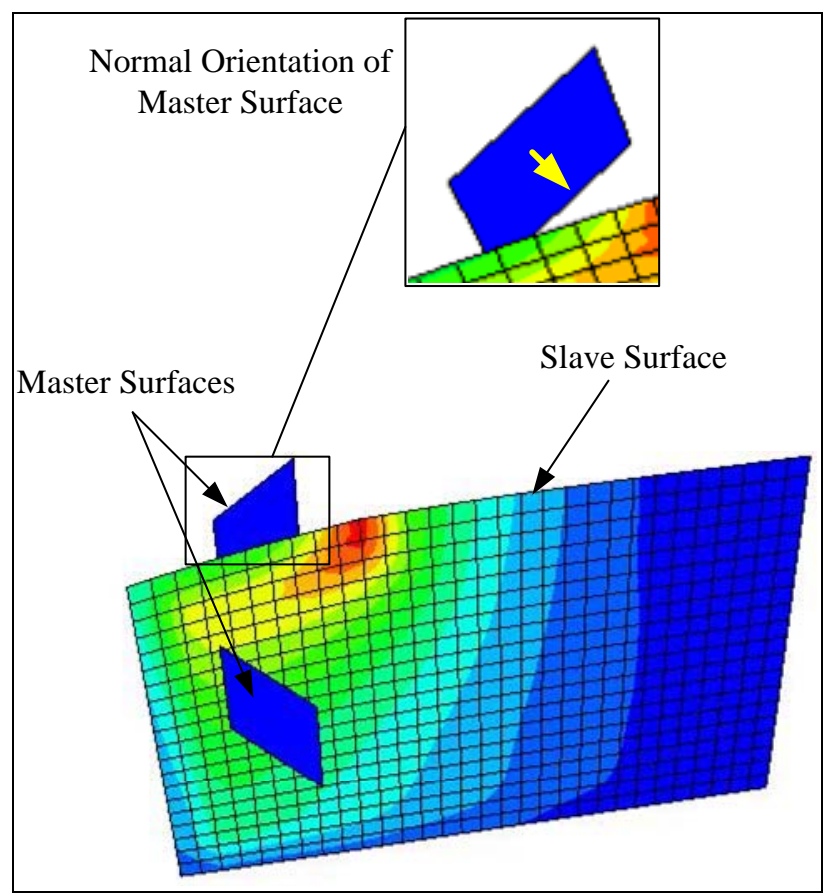

Figure 21. Simplified model master and slave selection.

To make the gate stop at the desired location a surface-to-surface contact interaction between the surfaces was specified. Surface-to-surface contact interactions describe contact between two deformable surfaces or between a deformable surface and a rigid surface. The finite element program defines contact between two bodies in terms of two surfaces that may interact; these surfaces are called a "contact pair." The contact surfaces are defined as master and slave surfaces. The surface of the stiffer body should be chosen as the master surface, and the slave surface should always be attached to deformable bodies.

The master surface normal always has to be in the direction of the contact surface. In this case the master surfaces are the two shell elements located outside of the model and the slave surface is the gate (Figure 21). 
After the selection of the master and slave surfaces, a contact property needs to be defined. The relationship of default contact pressure over closure used by the code is the "hard" contact model. This model assumes that the surfaces transmit no contact pressure unless the nodes of the slave surface contact the master surface. There is no limit to the magnitude of contact pressure that can be transmitted when the surfaces are in contact. That means that the slave surface cannot penetrate the master surface. Because the surfaces make contact in a localized area, the mechanical property used was "normal behavior." The small sliding formulation was specified in the analysis because the master and slave surfaces are in contact in a specific area. The formulation assumes that the surfaces may undergo arbitrarily large rotations but that a slave node will interact with the same local area of the master surface throughout the analysis. The formulation used in this simplified model was implemented with success in the miter gate 3-D model to produce the desired behavior.

\subsection{Augmented Lagrangian method}

To permit some penetration of the slave surface into the master surface, the augmented Lagrangian method was used. If a slave node penetrates the master surface by more than 0.1 percent of the characteristic interface length, the contact pressure is augmented and another series of iterations is executed until convergence is once again achieved. Only when the penetration tolerance requirement is satisfied will the solution be accepted. This method may require additional iterations in some cases; however, this approach is sometimes useful for numerical reasons because it can make the resolution of contact conditions easier.

\subsection{Parametric analysis results}

This section presents the parametric analysis results for the different analyzed cases. The vertical and lateral displacements were measured in the miter gate end in the top and bottom locations for all the cases. The results presented herein summarize the relevant findings in the different cases performed.

\subsubsection{Case 1: Gravity with no diagonals}

This analysis was carried out to study the behavior of the miter gate when subjected to the self weight (gravity effects) only. Figure 22 shows a schematic drawing of this case. The boundary conditions used are 
presented in Table 5. Because the pintle and the gudgeon pin restrict one end of the miter gate, the results demonstrate that the gate behaves like a cantilever beam, producing tension in the gudgeon pin zone and compression at the pintle zone. Figure 23 shows the vertical displacement of the miter end. During the gravity analysis the results revealed a twist in the miter gate end. The quoin end of a miter gate is held vertical by the pintle and gudgeon pin, leaving the miter end free to twist out of vertical alignment. This twist is produced because the center of gravity and the shear center are not in the same vertical plane. This difference in its vertical planes produces an eccentricity that produces a load-displacement (P-Delta) effect in the structure. Figure 24 presents the observed behavior with more details. The lateral displacement for this case is presented in Figure 25 .

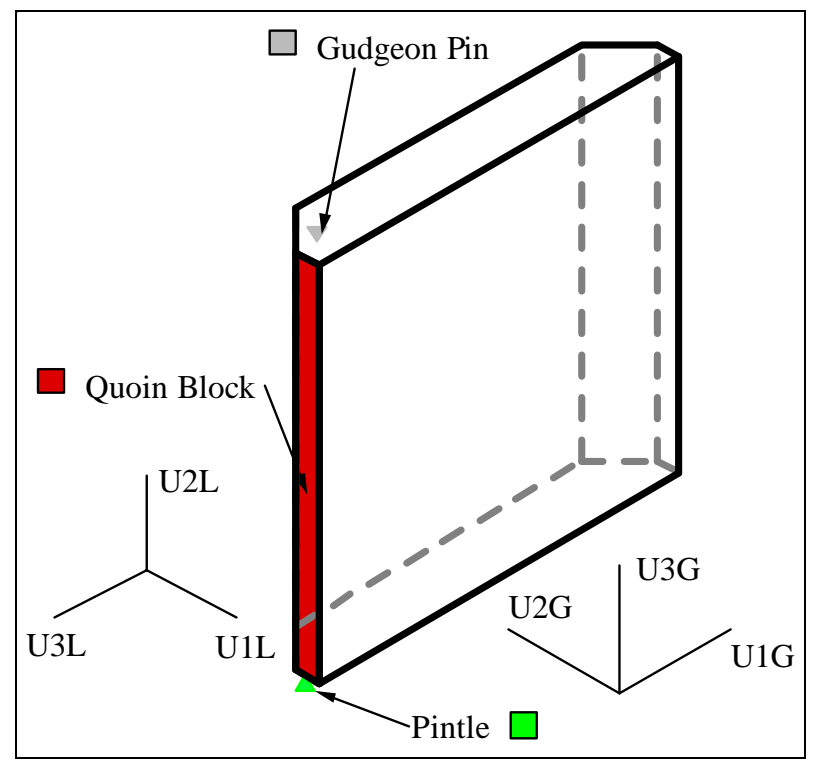

Figure 22. Schematic Drawing of Case 1.

Table 5. Boundary condition for the analyzed structure.

\begin{tabular}{|l|l|l|l|l|l|l|l|}
\hline $\begin{array}{l}\text { Gate } \\
\text { Component }\end{array}$ & U1 & U2 & U3 & UR1 & UR2 & UR3 & CSYS \\
\hline Gudgeon pin & 0 & 0 & --- & --- & --- & --- & Global \\
\hline Pintle & 0 & 0 & 0 & 0 & 0 & --- & Global \\
\hline $\begin{array}{l}\text { Quoin block } \\
\text { Miter block }\end{array}$ & ---- & --- & 0 & --- & --- & --- & Local \\
\hline
\end{tabular}




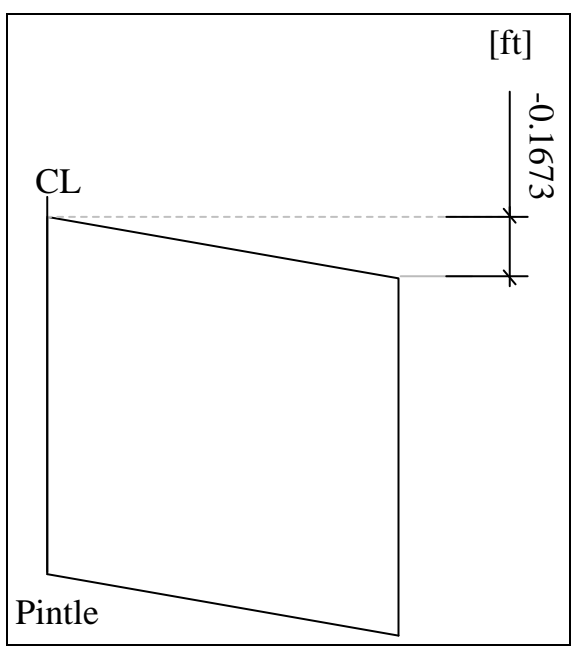

Figure 23. Vertical displacement.

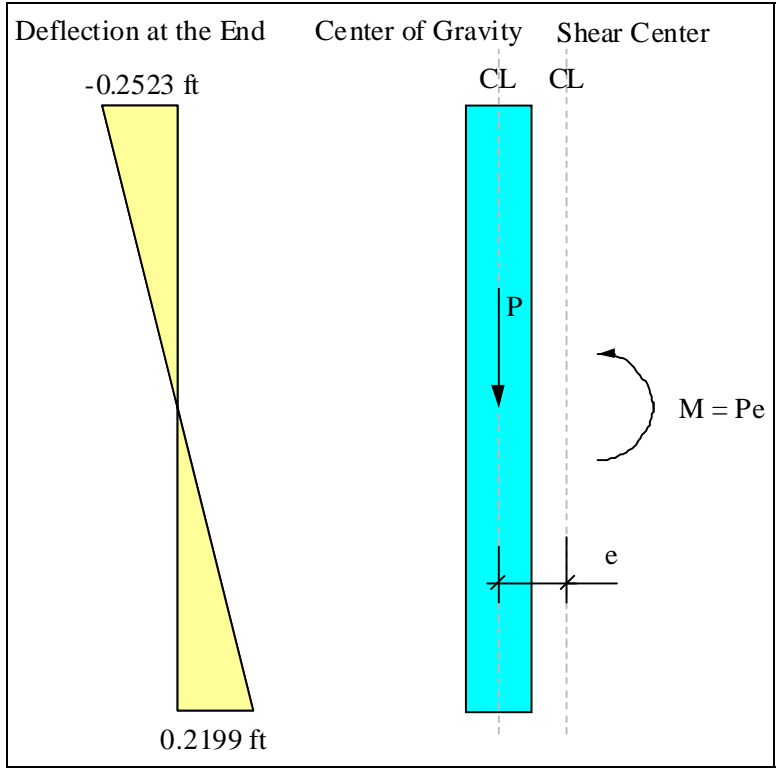

Figure 24. Lateral observed behavior. 


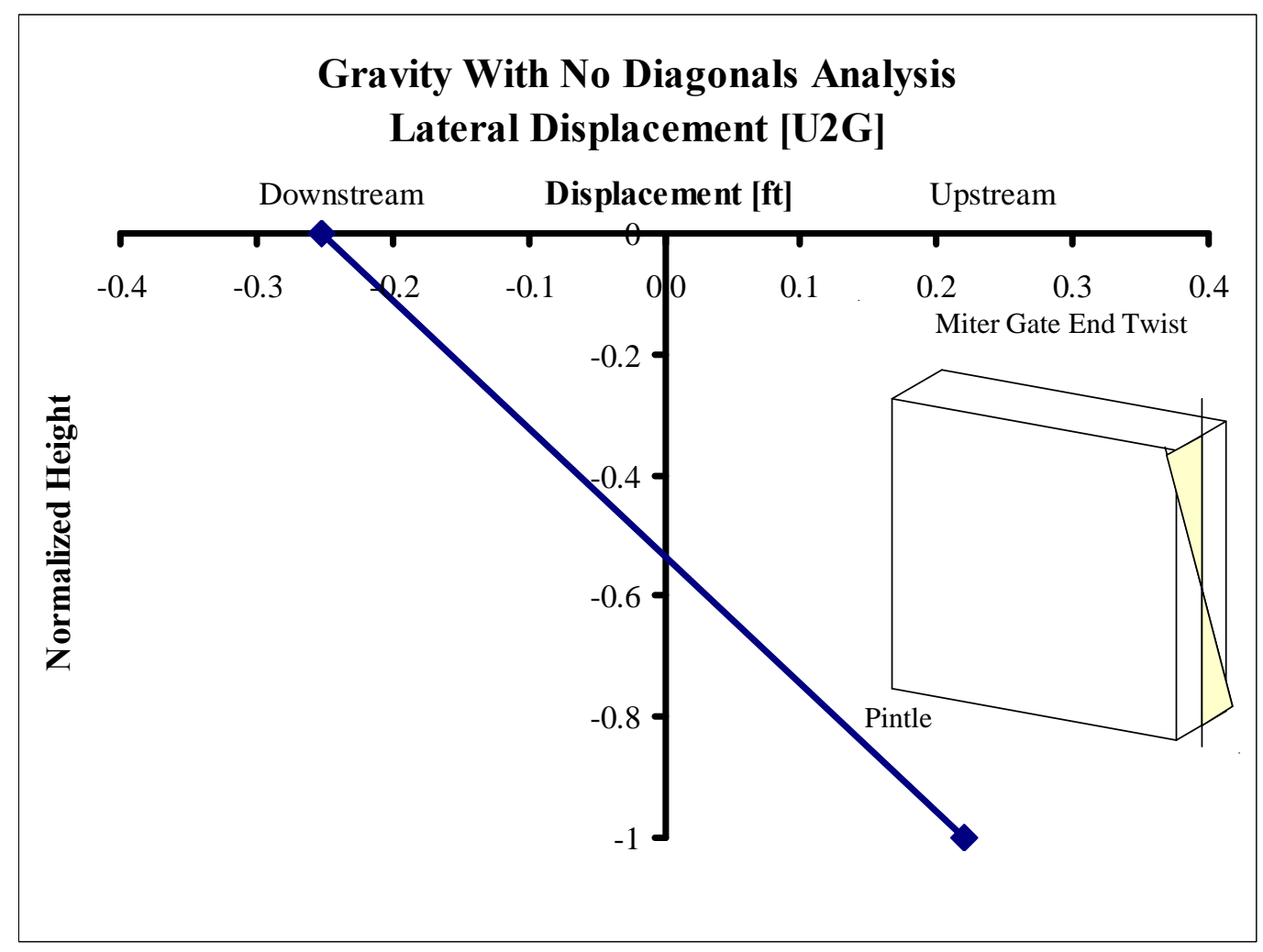

Figure 25. Lateral displacement.

\subsubsection{Case 2: Gravity with positive diagonals}

To study the effects of the positive diagonal in the structure, a series of analyses were conducted including the gravity loads with different positive diagonal prestressing. Figure 26 presents a schematic drawing of the structure used in this case. The boundary conditions used are presented in Table 6. The data presented in Figures 27 and 28 and Table 8 correspond to top (Point A) and bottom (Point B) nodes at the miter end. Table 7 shows the different diagonal pre-stressing combinations used for the positive diagonal. Table 8 summarizes the spatial displacements obtained for the different diagonal prestressing used in the analysis.

Vertical displacement:

The analysis demonstrated that the structure experienced a negative vertical displacement (downward displacement) because of the self weight of the miter gate. To reduce the excessive deflection during operation, diagonals were used in the structure. The positive diagonal pulled up the miter gate; thus, the greater the prestressing in the positive diagonals, the smaller the vertical deflection became. 


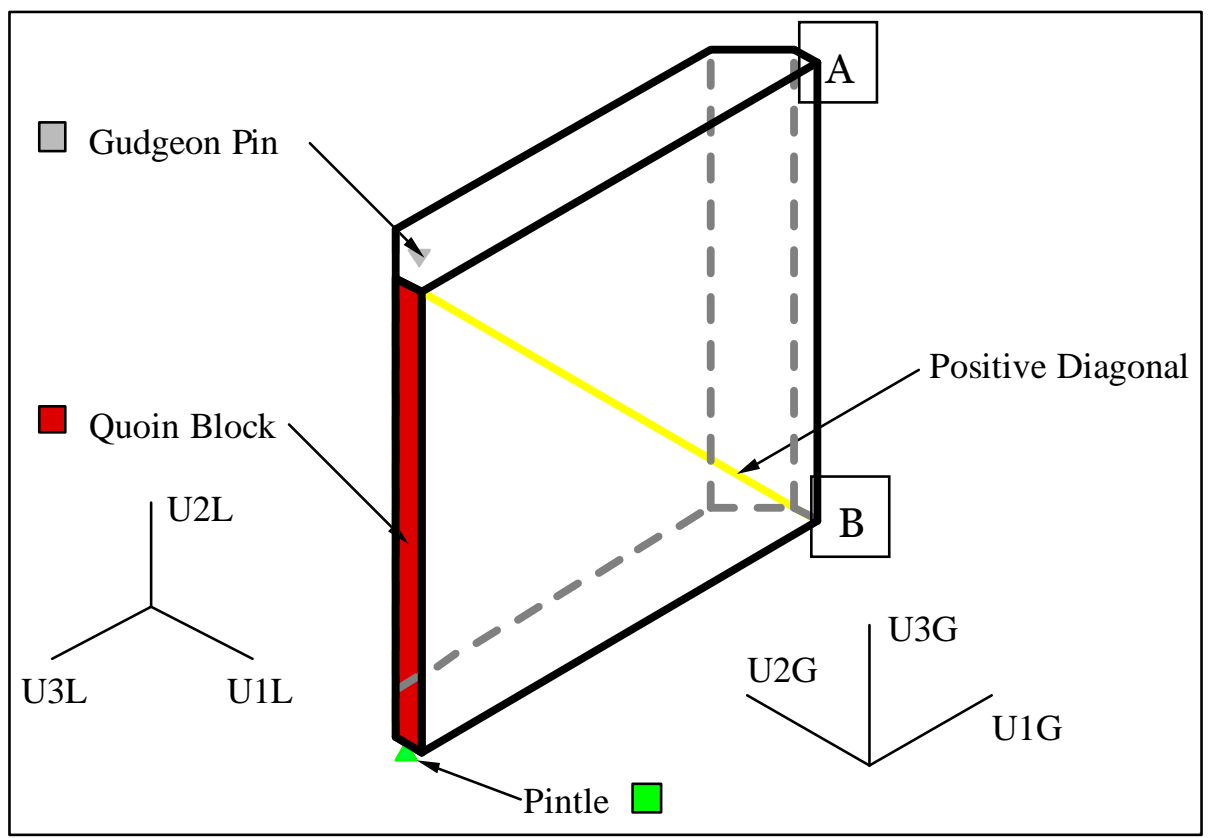

Figure 26. Schematic drawing of Case 2.

Table 6. Boundary conditions for the analyzed structure.

\begin{tabular}{|l|l|l|l|l|l|l|l|}
\hline Gate Component & U1 & U2 & U3 & UR1 & UR2 & UR3 & CSYS \\
\hline Gudgeon pin & 0 & 0 & --- & --- & ---- & --- & Global \\
\hline Pintle & 0 & 0 & 0 & 0 & 0 & --- & Global \\
\hline Quoin & --- & -- & 0 & --- & -- & --- & Local \\
\hline
\end{tabular}

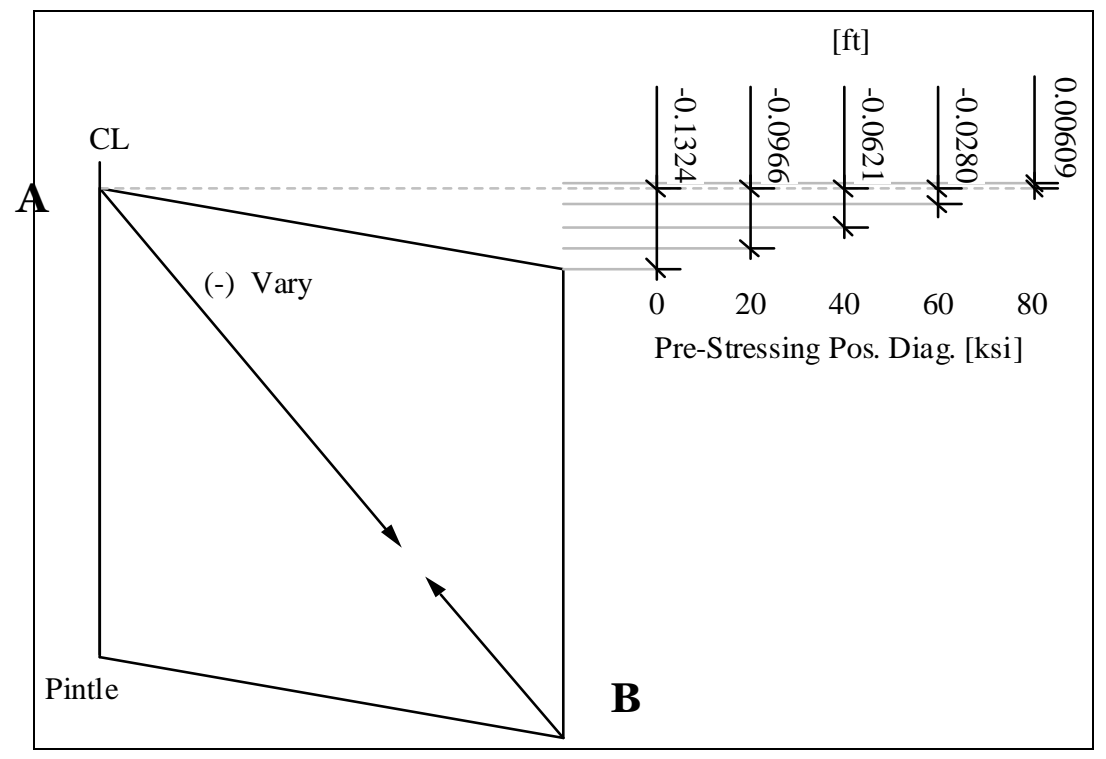

Figure 27. Variation in vertical displacement for the different diagonal prestressing. 


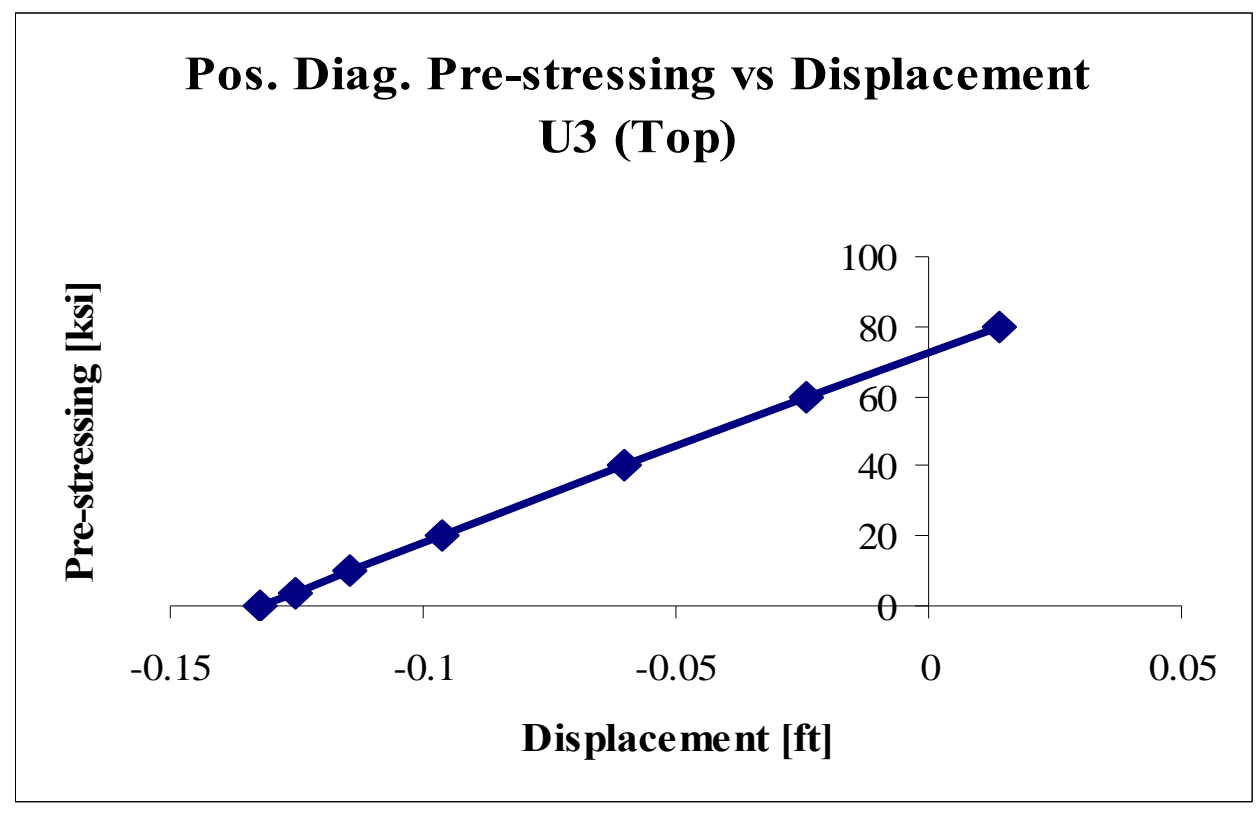

Figure 28. Top vertical displacement variation.

Table 7. Positive diagonal prestressing.

\begin{tabular}{|l|l|}
\hline Case & Diagonal Prestressing, ksi (Positive) \\
\hline 1 & 0 \\
\hline 2 & 20 \\
\hline 3 & 40 \\
\hline 4 & 60 \\
\hline 5 & 80 \\
\hline
\end{tabular}

Table 8. Spatial displacement summary for the top and bottom nodes of the miter gate.

\begin{tabular}{|l|l|l|l|l|}
\hline Displacement. ksi & Node & U1 [ft] & U2 [ft] & U3 [ft] \\
\hline \multirow{2}{*}{0} & Top (A) & 0.00064 & -0.09772 & -0.13240 \\
\cline { 2 - 5 } & Bottom (B) & -0.00457 & 0.08347 & -0.13225 \\
\hline \multirow{2}{*}{40} & Top (A) & 0.00073 & 0.04640 & -0.09660 \\
\cline { 2 - 5 } & Bottom (B) & -0.00678 & -0.04169 & -0.09630 \\
\hline \multirow{2}{*}{60} & Top (A) & 0.00051 & 0.19160 & -0.06210 \\
\cline { 2 - 5 } & Bottom (B) & -0.00927 & -0.16670 & -0.06038 \\
\hline \multirow{2}{*}{80} & Top (A) & -0.00006 & 0.33120 & -0.02802 \\
\cline { 2 - 5 } & Bottom (B) & -0.01207 & -0.29020 & -0.02402 \\
\hline & Top (A) & -0.00089 & 0.48110 & 0.00609 \\
\cline { 2 - 5 } & Bottom (B) & -0.01496 & -0.41680 & 0.01371 \\
\hline
\end{tabular}


The vertical displacement became positive for a certain prestress value. The prestress required to produce zero vertical displacement was greater than the allowable stress of the material, which was $60 \mathrm{ksi}$.

Figure 27 presents the variation in vertical displacement for the different diagonal prestressing. Figure 28 presents in graphical form the vertical displacement variation for the top node in this analysis. Using these graphs the diagonal prestressing in the positive diagonal required to produce zero vertical displacement can be obtained, about $70 \mathrm{ksi}$.

\section{Lateral displacement.}

In this analysis the self weight of the miter gate and the positive diagonal prestressing caused the gate to twist. In this step the positive diagonal contribution to the structure in the lateral displacements was analyzed. The analysis reveals an upstream movement of the top portion of the miter end (Point A) with an increase in the positive diagonal prestressing. The greater the prestressing, the bigger the upstream twist became. Figure 29 presents the observed behavior for the different diagonal prestressing. The gravity produced a downstream movement of the miter end, represented in the curve in which the diagonal prestressing was o ksi, and the positive diagonal prestressing produced an upstream movement of the top portion of the gate end (Point $\mathrm{A}$ ) when the prestressing increased as observed in the plot. Figure 30 shows that a diagonal prestressing of $14 \mathrm{ksi}$ will eliminate any relative displacement between Point A and Point B.

\subsubsection{Case 3: Gravity with positive and negative diagonals}

Case 3 includes the gravity loads and the positive and negative diagonals. Different diagonal prestressing combinations were used in this case. The selected prestressing values were $0,5,10,15,20,25$, and 30 ksi. Figure 31 presents a schematic view of the structure for this case. The boundary conditions used are offered in Table 9. Figures 32-37 and Tables 10 and 11 present a summary of the spatial displacements at the top and bottom of the miter end. 


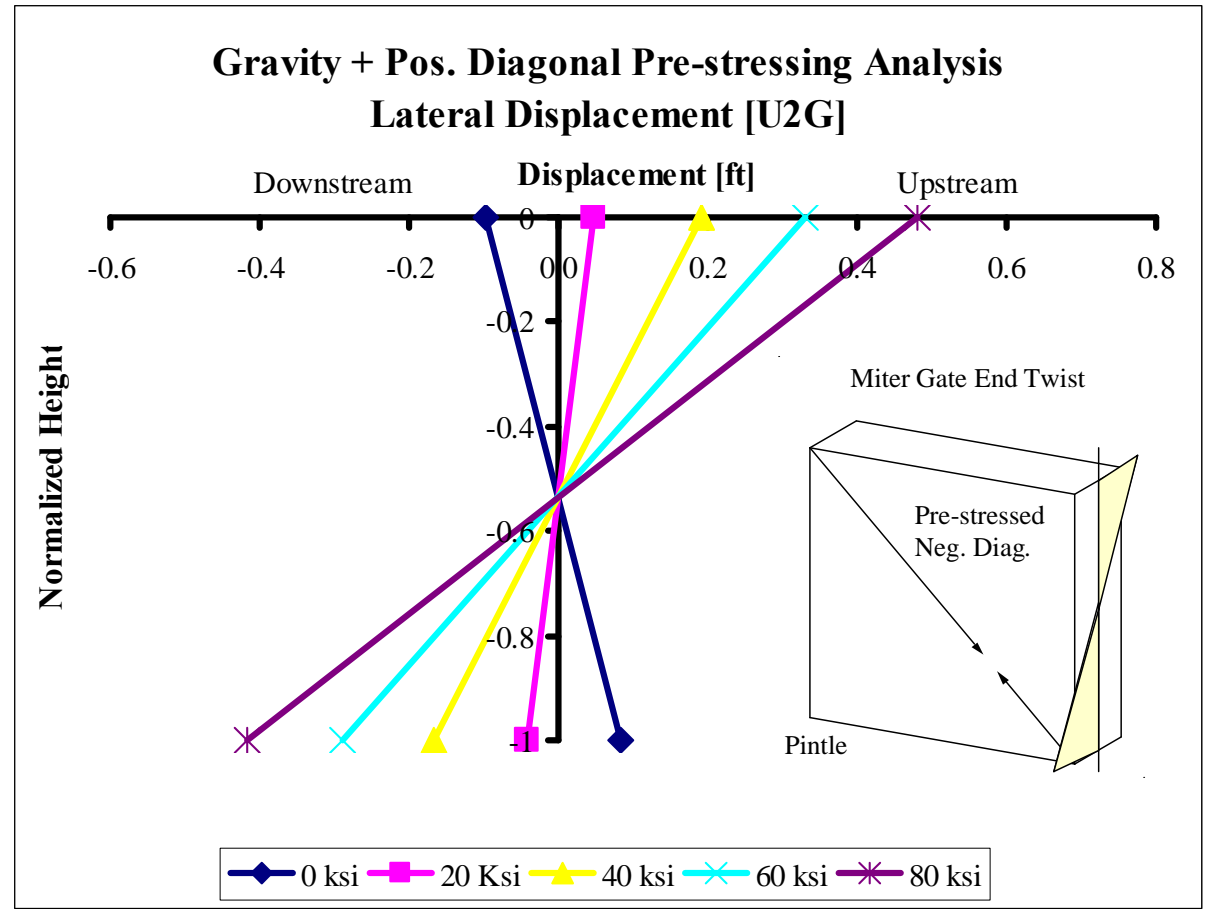

Figure 29. Lateral behavior of the miter gate.

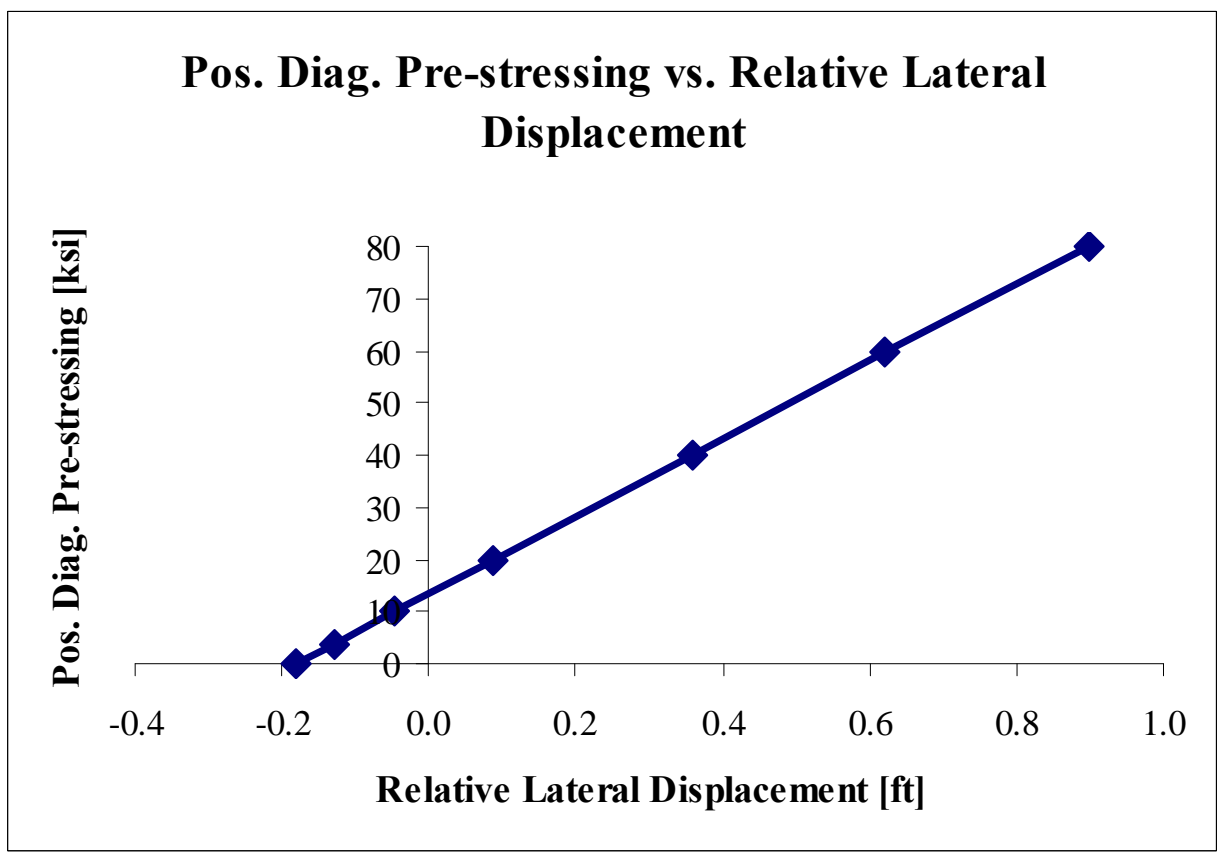

Figure 30. Relative lateral displacement. 


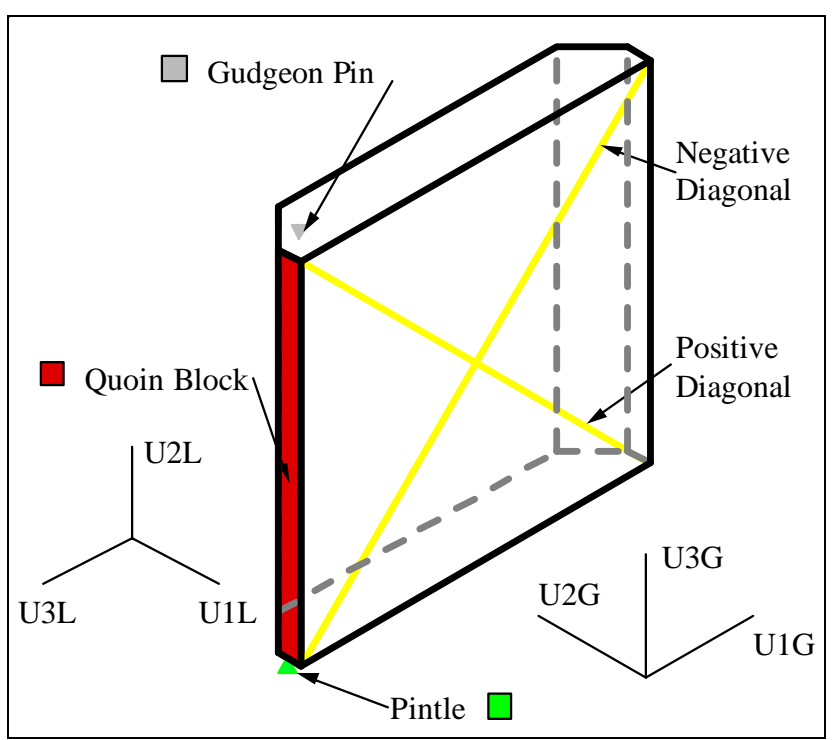

Figure 31. Schematic drawing of Case 3.

Table 9. Boundary condition for the analyzed structure.

\begin{tabular}{|l|l|l|l|l|l|l|l|}
\hline $\begin{array}{l}\text { Gate } \\
\text { Component }\end{array}$ & U1 & U2 & U3 & UR1 & UR2 & UR3 & CSYS \\
\hline Gudgeon pin & 0 & 0 & ---- & --- & ---- & ---- & Global \\
\hline Pintle & 0 & 0 & 0 & 0 & 0 & ---- & Global \\
\hline $\begin{array}{l}\text { Quoin block } \\
\text { Miter block }\end{array}$ & ---- & ---- & 0 & ---- & ---- & ---- & Local \\
\hline
\end{tabular}

Vertical displacement:

The analysis confirmed that the structure had a negative vertical displacement caused by the self weight (gravity loads) of the miter gate. Diagonals helped reduce the excessive deflection during operation. The greater the prestressing in the positive diagonals, the smaller the vertical deflection became. The negative diagonals had the inverse effect: the greater the prestressing in the negative diagonals, the greater the vertical displacement became. Table 10 shows the vertical displacement results for the different diagonal prestressing combinations. Results showed that the minimum vertical displacement of $0.0007 \mathrm{ft}$ occurred with $10 \mathrm{ksi}$ of prestressing in the negative diagonal and $20 \mathrm{ksi}$ in the positive diagonal. Figure 32 presents the variation in vertical displacement of the miter gate end for the different combination of diagonal prestressing. Each series corresponds to a positive diagonal prestressing, and the vertical axis represents the negative diagonal prestressing. The horizontal axis represents the vertical displacement of the miter end. 
Table 10. Vertical displacement summary.

\begin{tabular}{|c|c|c|c|c|c|c|c|c|}
\hline & \multicolumn{7}{|c|}{ Positive Diagonal } \\
\hline & & 0 & 5 & 10 & 15 & 20 & 25 & 30 \\
\hline \multirow{7}{*}{ 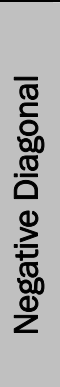 } & 0 & -0.01200 & -0.00606 & -0.00092 & 0.00342 & 0.00775 & 0.01209 & 0.01644 \\
\hline & 5 & -0.01302 & -0.00870 & -0.00440 & -0.00009 & 0.00423 & 0.00857 & 0.01291 \\
\hline & 10 & -0.01649 & -0.01223 & -0.00794 & -0.00363 & 0.00070 & 0.00503 & 0.00938 \\
\hline & 15 & -0.02005 & -0.01578 & -0.01148 & -0.00717 & -0.00285 & 0.00149 & 0.00584 \\
\hline & 20 & -0.02362 & -0.01934 & -0.01505 & -0.01073 & -0.00640 & -0.00207 & 0.00229 \\
\hline & 25 & -0.02719 & -0.02291 & -0.01861 & -0.01429 & -0.00996 & -0.00562 & -0.00127 \\
\hline & 30 & -0.03077 & -0.02648 & -0.02218 & -0.01786 & -0.01352 & -0.00919 & -0.00483 \\
\hline
\end{tabular}

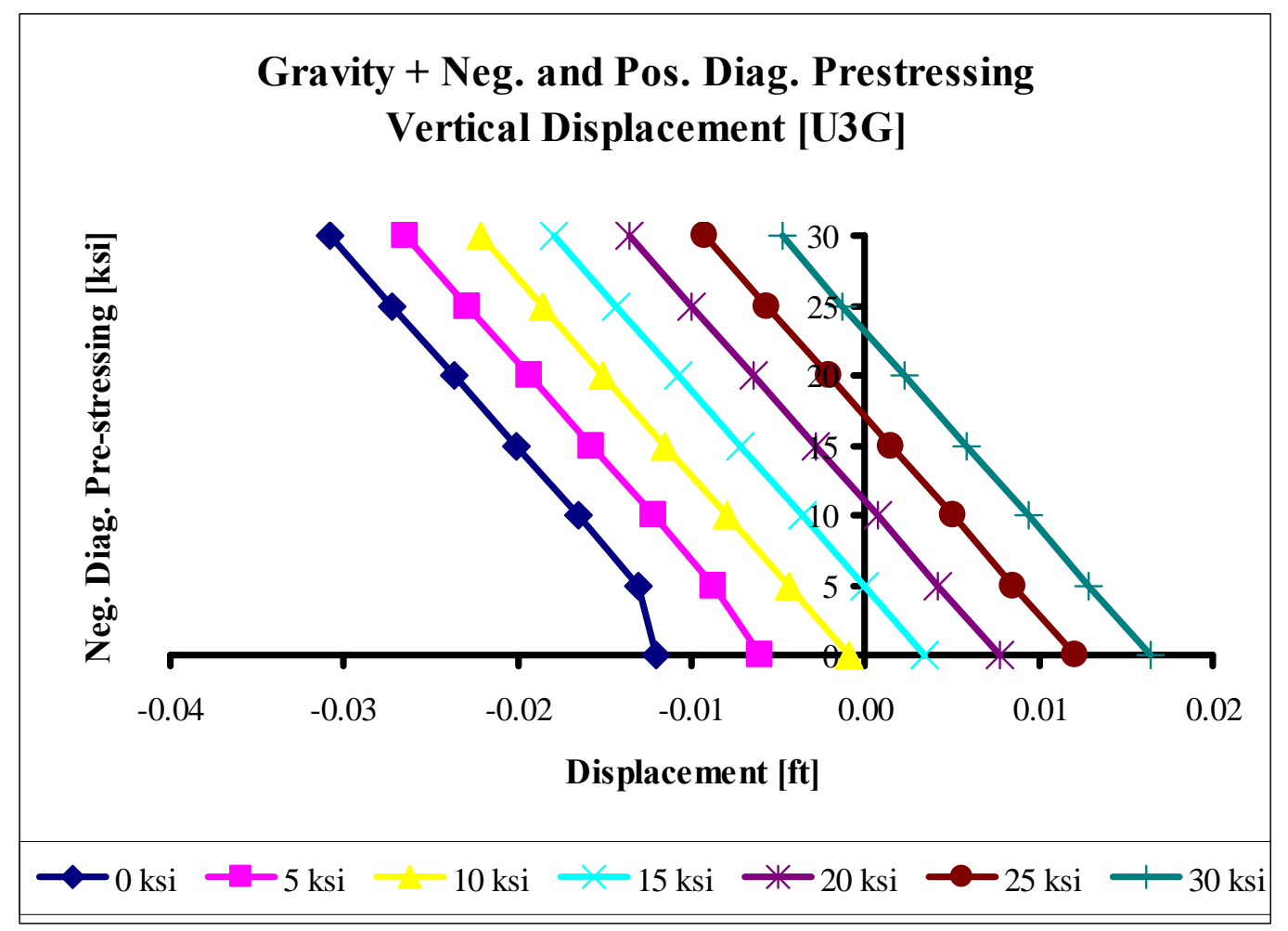

Figure 32. Vertical displacement variation for the different diagonal prestressing.

In Figure 32 the negative diagonal prestressing required to obtain zero vertical displacement is the intersection between the lines with the vertical axis. For example, for $20 \mathrm{ksi}$ of prestressing in the positive diagonal, $11 \mathrm{ksi}$ of prestressing in the negative diagonal is required to have zero vertical displacement in the miter end. 
Lateral displacement:

The positive and negative diagonal prestressing contributions in the lateral displacement were analyzed. The self weight of the miter gate produces a downstream movement of the top portion of the miter end (Figure 25). The positive diagonal prestressing was evaluated in the previous case, and the behavior was an upstream movement of the top portion of the miter end as the prestressing increased, while the bottom portion of the miter gate moved downstream. Table 11 summarizes the lateral displacements obtained for the different positive and negative diagonal prestressing combinations. Figure 33 presents a typical plot of the observed lateral behavior of the miter end with a positive diagonal prestressing of $15 \mathrm{ksi}$, and varying negative diagonal prestressing. Using this plot, the negative diagonal effect in the lateral displacement of the structure can be obtained. The plot shows an initial location of the top portion of the miter end in the upstream position caused by the positive diagonal prestressing of $15 \mathrm{ksi}$.

Table 11. Spatial displacement summary for the top and bottom of the miter gate.

\begin{tabular}{|c|c|c|c|c|c|c|c|c|}
\hline \multirow{2}{*}{\multicolumn{2}{|c|}{ Top }} & \multicolumn{7}{|c|}{ Positive Diagonal } \\
\hline & & 0 & 5 & 10 & 15 & 20 & 25 & 30 \\
\hline \multirow{7}{*}{ 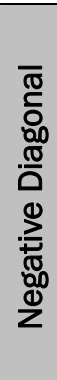 } & 0 & -0.03499 & -0.01057 & 0.00966 & 0.02556 & 0.04140 & 0.05725 & 0.07313 \\
\hline & 5 & -0.03985 & -0.02443 & -0.00872 & 0.00703 & 0.02284 & 0.03866 & 0.05450 \\
\hline & 10 & -0.05863 & -0.04303 & -0.02735 & -0.01161 & 0.00417 & 0.01999 & 0.03583 \\
\hline & 15 & -0.07733 & -0.06173 & -0.04605 & -0.03031 & -0.01452 & 0.00130 & 0.01712 \\
\hline & 20 & -0.09610 & -0.08048 & -0.06479 & -0.04905 & -0.03329 & -0.01743 & -0.00159 \\
\hline & 25 & -0.11490 & -0.09927 & -0.08355 & -0.06780 & -0.05203 & -0.03621 & -0.02035 \\
\hline & 30 & -0.13373 & -0.11806 & -0.10234 & -0.08660 & -0.07081 & -0.05497 & -0.03912 \\
\hline \multirow{2}{*}{\multicolumn{2}{|c|}{ Bottom }} & \multicolumn{7}{|c|}{ Positive Diagonal } \\
\hline & & 0 & 5 & 10 & 15 & 20 & 25 & 30 \\
\hline \multirow{7}{*}{ 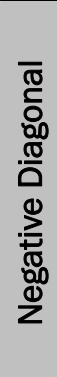 } & 0 & 0.02266 & -0.00208 & -0.02472 & -0.04518 & -0.06568 & -0.08621 & -0.10676 \\
\hline & 5 & 0.02547 & 0.00507 & -0.01527 & -0.03569 & -0.05617 & -0.07669 & -0.09725 \\
\hline & 10 & 0.03488 & 0.01464 & -0.00571 & -0.02614 & -0.04663 & -0.06715 & -0.08772 \\
\hline & 15 & 0.04453 & 0.02425 & 0.00387 & -0.01656 & -0.03705 & -0.05759 & -0.07817 \\
\hline & 20 & 0.05420 & 0.03388 & 0.01349 & -0.00696 & -0.02747 & -0.048 & -0.06859 \\
\hline & 25 & 0.06388 & 0.04353 & 0.02312 & 0.00265 & -0.01786 & -0.03842 & -0.05901 \\
\hline & 30 & 0.07355 & 0.05319 & 0.03276 & 0.01227 & -0.00826 & -0.0288 & -0.04942 \\
\hline
\end{tabular}




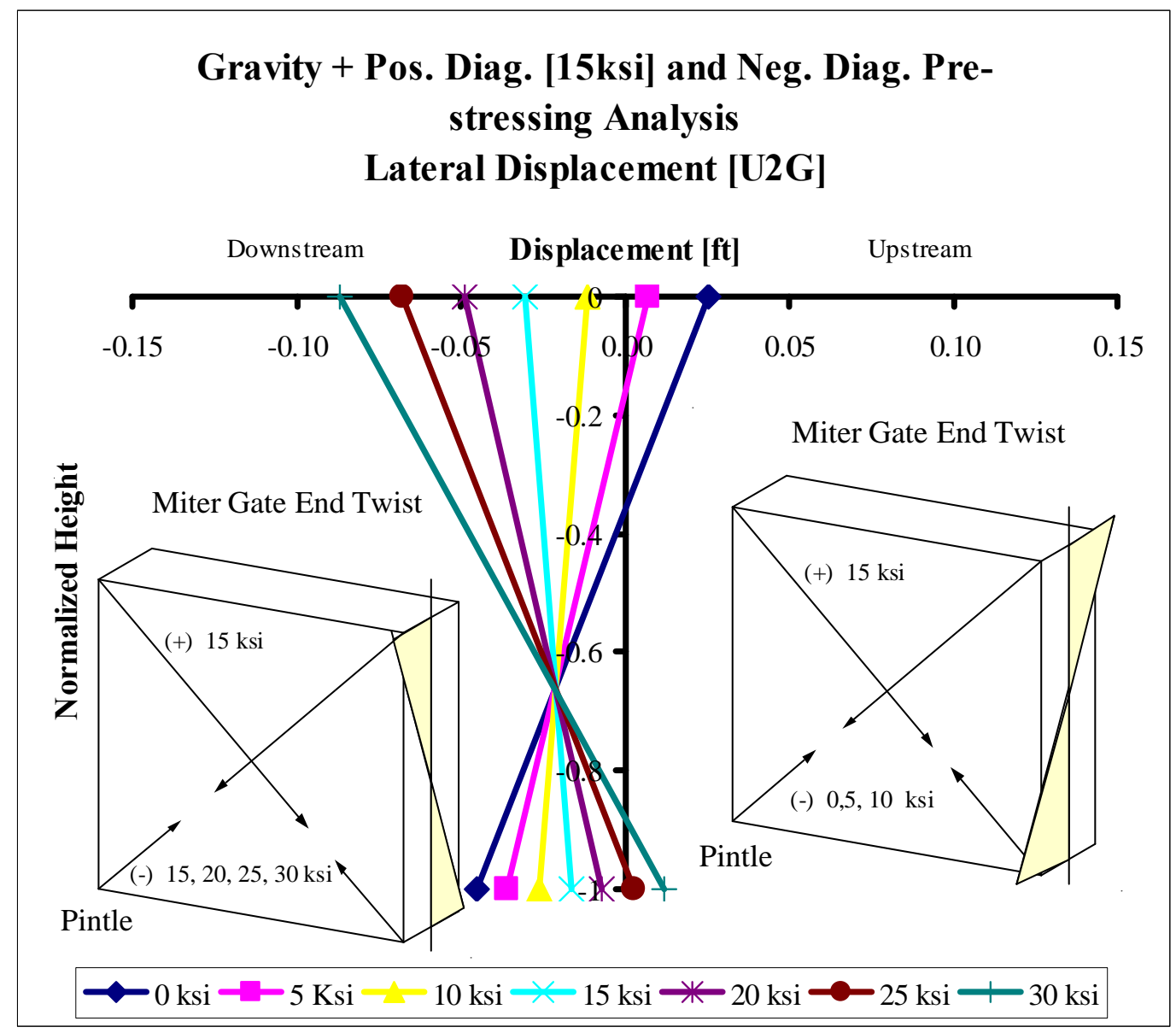

Figure 33. Lateral behavior of the miter gate end.

An increase in the negative diagonal prestressing produces a downstream movement of the top portion of the miter end and an upstream movement of the bottom portion of the miter end. This effect is produced by the prestressing in the positive and negative diagonals. The greater the prestressing, the bigger the twist becomes in that direction.

Figure 34 presents top (TD) and bottom (BD) lateral displacements for all 49 analyses conducted. The plot shows the miter end behavior varying the negative diagonal prestressing as the $y$-axis versus the lateral displacement. Each series corresponds to a constant positive diagonal prestressing. The series with negative slope represents the displacements in the top of the miter end, and the series with positive slope represents the displacements in the bottom of the miter end. 


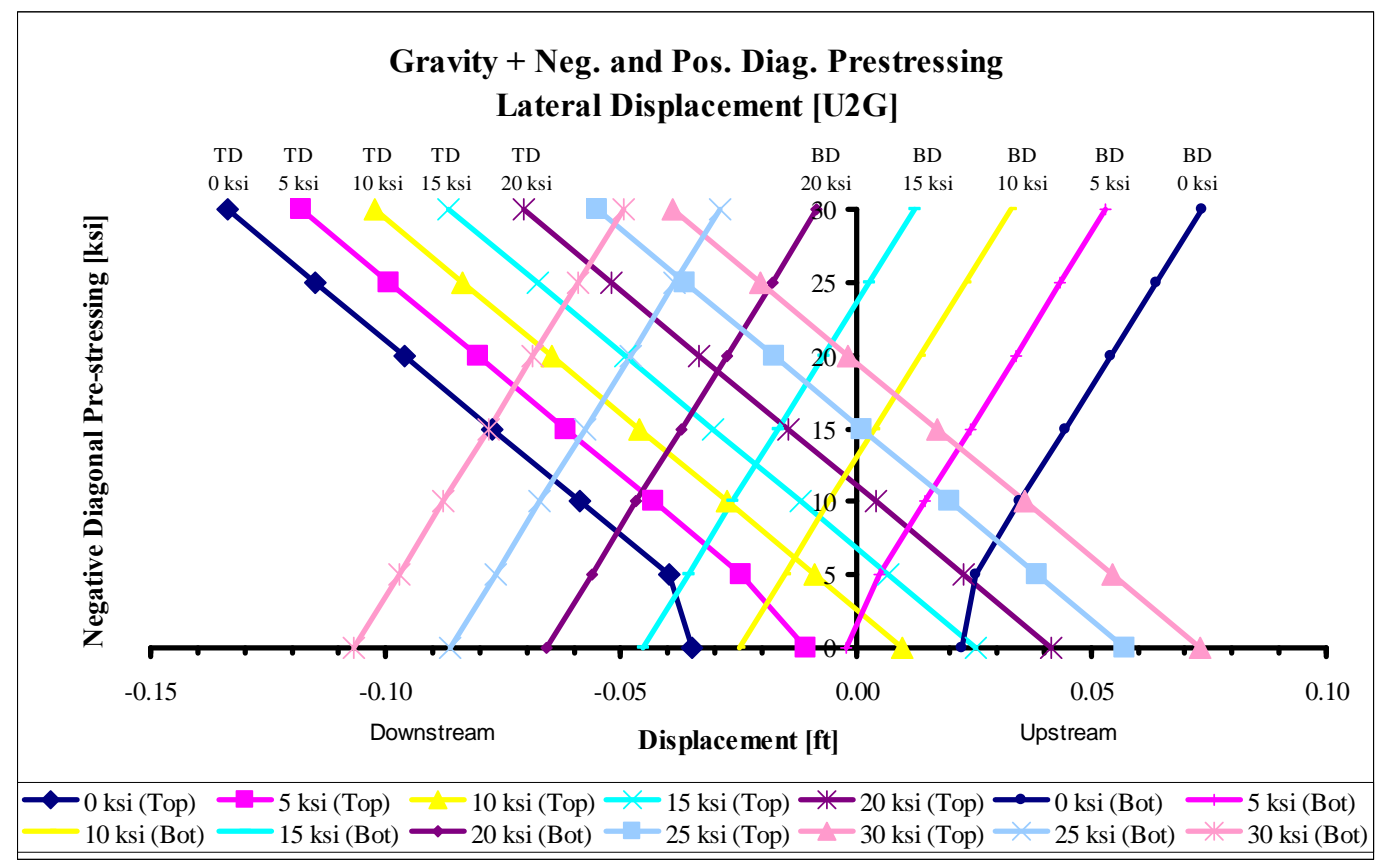

Figure 34. Positive and negative diagonals relation.

From Figure 34 the required positive and negative diagonal prestressing necessary to obtain zero relative displacement between the top and bottom ends is given by the point of intersection of series representing top and bottom displacements for the same positive diagonal prestressing. This point of intersection is associated with a downstream displacement. The downstream displacement occurs because the diagonals are located in the downstream side of the gate, and an increase in the prestressing of the diagonals produces a small rotation of the gate in the downstream direction. This rotation is less than $1 \mathrm{in}$. in all the prestressing combinations. An approximation of the top and bottom displacements can also be obtained for the different combinations of diagonal prestressing. Figure 35 shows that for a negative diagonal prestressing of $15 \mathrm{ksi}$ and a positive diagonal prestressing of $0.0 \mathrm{ksi}$, the top of the gate will displaced $0.077 \mathrm{ft}$ downstream and the bottom will move $0.044 \mathrm{ft}$ upstream. Similar evaluations can be accomplished for different combinations of diagonal prestressing.

Figures 36 and 37 present the relative lateral displacements in which a variation of the negative diagonal is applied with a constant positive diagonal prestressing and when a variation of the positive diagonal is applied with a constant negative diagonal prestressing, respectively. 


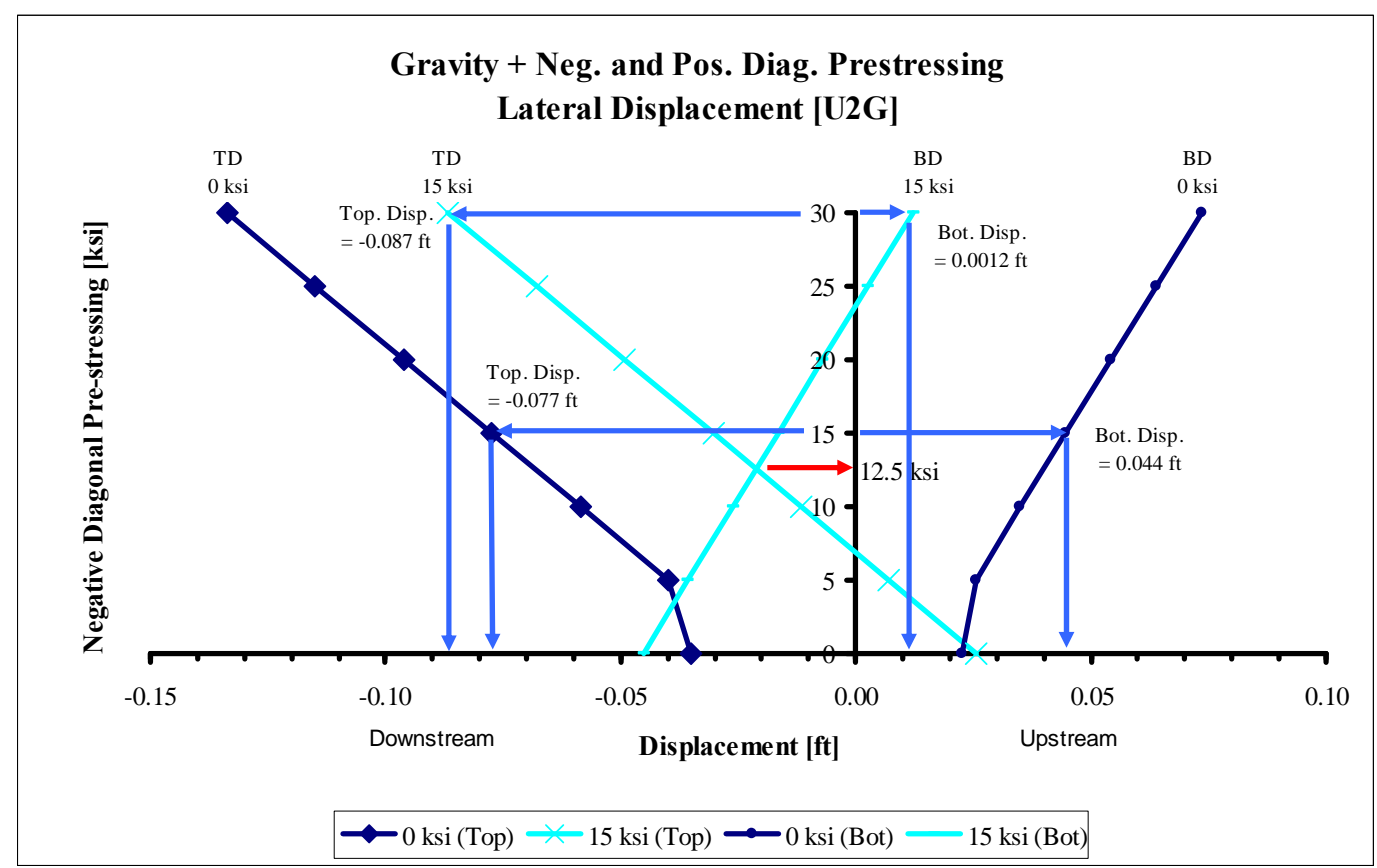

Figure 35. Detailing of the positive and negative diagonal relation.

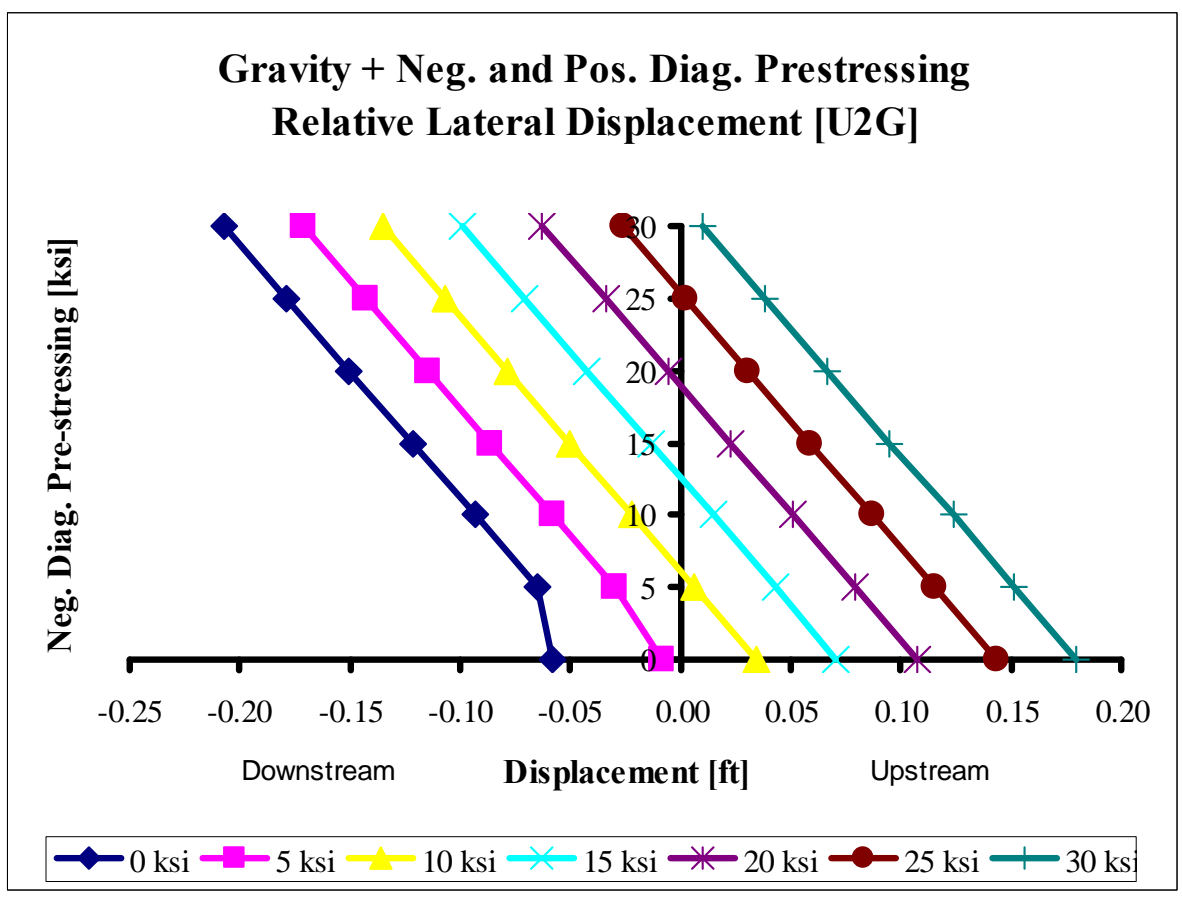

Figure 36. Relative lateral displacement (negative diagonals vary). 


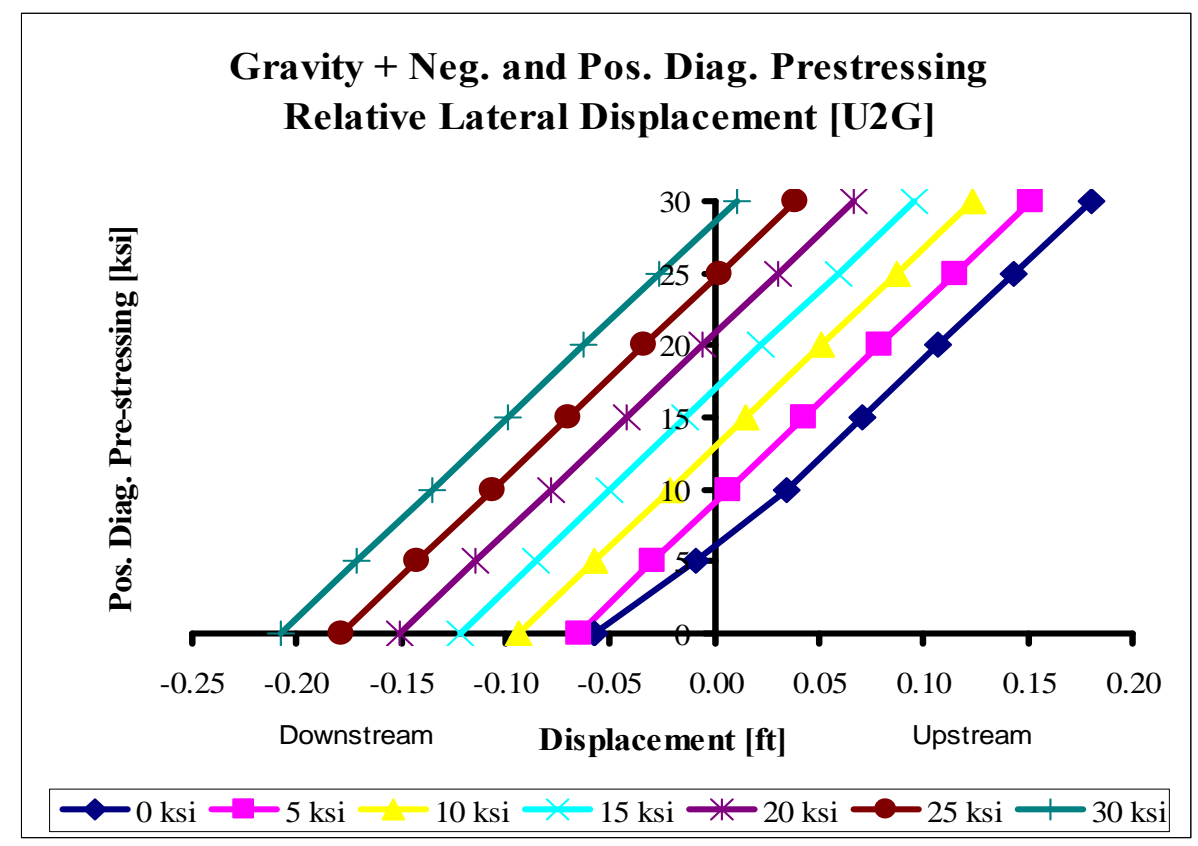

Figure 37. Relative lateral displacement (positive diagonals vary).

These plots can be used to determine the required combination of diagonal prestressing to produce zero relative lateral displacement in the miter end. The series represents the constant diagonal prestressing. Using Figure 36 the series represents the positive diagonal prestressing, and the vertical axis represents the negative diagonal prestressing. When a series intersects the vertical axis, the point of intersection represents the negative diagonal prestressing required to produce zero relative displacement in the miter end. For example from Figure 36 for $15 \mathrm{ksi}$ of prestressing, in the positive diagonal $12.5 \mathrm{ksi}$ of prestressing is required in the negative diagonal to produce zero relative displacement in the gate.

\subsubsection{Case 4: Gravity with positive, negative diagonals, movement, and water resistance}

This parametric case was directed to study the behavior of the gate when it is opening and closing. A total of 16 analyses were performed. In Case 3 the behavior of the gate miter end was evaluated for gravity and different diagonal prestressing. In addition to the previous case, the effects of the water resistance pressures and the gate movement were evaluated. The analysis was divided into two steps, opening the gate and closing the gate. Because the water levels upstream and downstream of the miter gate when the gate is in operation are the same, the analysis considered the resistance pressure produced by the water only when the gate is opening and 
closing. EM 1110-2-2703 (Headquarters, U.S. Army Corps of Engineers, 1994) and EM 1110-2-2105 (Headquarters, U.S. Army Corps of Engineers, 1993) suggest water resistance pressures should be either 30 psf or $45 \mathrm{psf}$ depending on such gate geometrical properties as height and length. For gates similar to the one analyzed in this study the code suggests a value for water resistance pressure of $30 \mathrm{psf}$. The water resistance pressure alone produces downstream movement of the bottom portion of the gate miter end with respect to its neutral axis; the top portion moves in the upstream direction. To induce movement in the gate, a concentrated force was applied at the top of the gate in the operation point of the gate. In order to simulate the gate opening and closing, the concentrated force applied was represented in two steps, one with positive magnitude to open the gate and the other with negative magnitude to close the gate. Because of the large displacements produced for the gate movement, the concentrated force was applied following the rotation of the applied nodes. A concentrated force of 250 to 300 kips is typically applied to open and close this type of gate. In this study the load magnitude used was 250 kips. This load applied in the operation point produced an upstream movement of the top portion of the gate during opening and a downstream movement of the top portion of the gate during closing. Figure 38 shows a schematic drawing of the gate for both steps: opening and closing. Table 12 presents the boundary conditions used for this case.

\section{Vertical displacement:}

The previous analysis confirmed that the self weight of the gate and the prestressing of the different diagonals produce changes in the vertical displacements of the miter end. In this case the vertical behavior of the miter end was evaluated for effects of the water resistance and opening and closing the gate.

The results reveal an upward movement of the gate miter end during opening and a downward movement of the gate end during closing. These values are less than 0.6 in., negligible in comparison with the gate dimensions. 

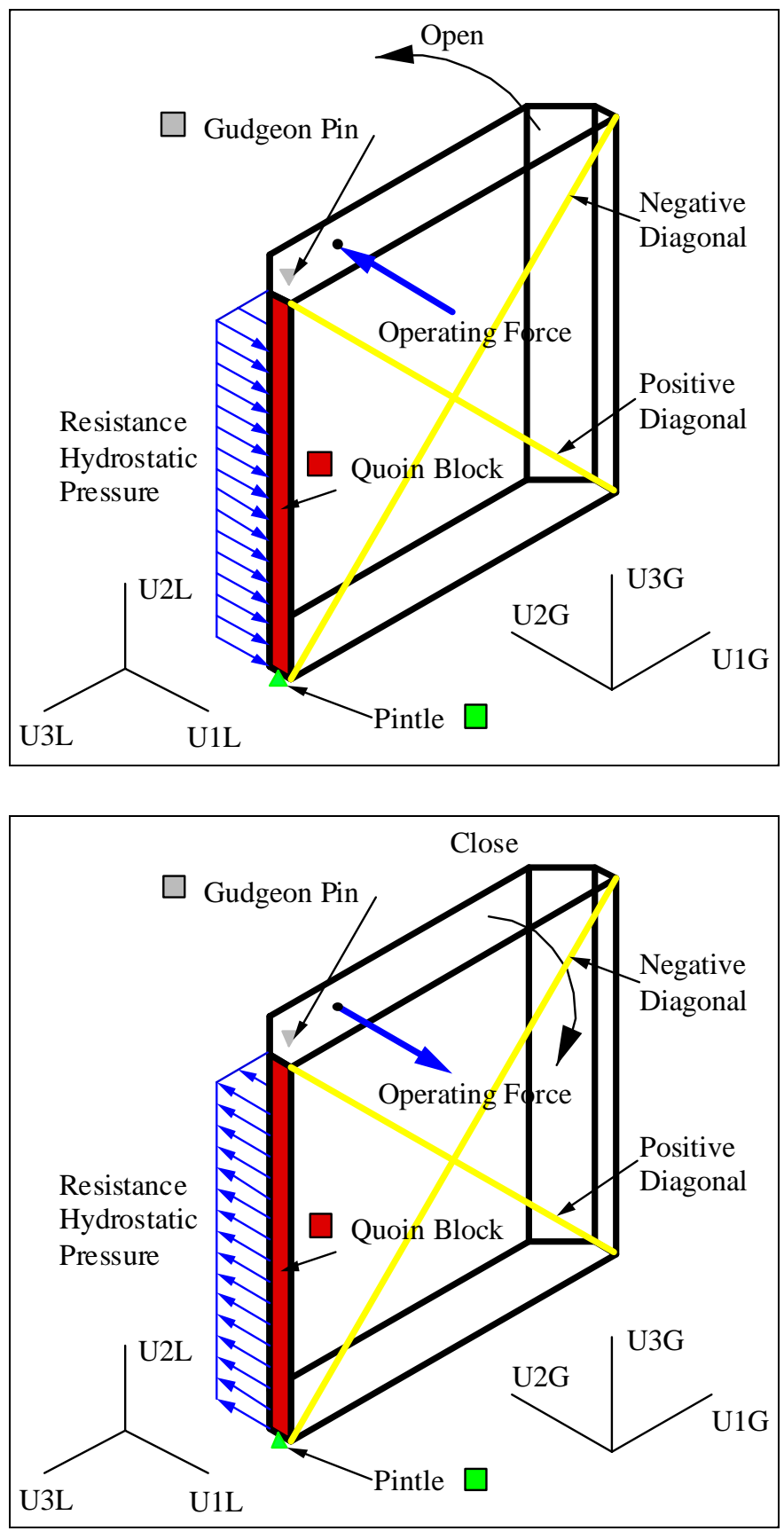

Figure 38. Schematic drawing of Case 4.

Table 12. Boundary condition for the analyzed structure.

\begin{tabular}{|l|l|l|l|l|l|l|l|}
\hline $\begin{array}{l}\text { Gate } \\
\text { Component }\end{array}$ & U1 & U2 & U3 & UR1 & UR2 & UR3 & CSYS \\
\hline Gudgeon pin & 0 & 0 & ---- & --- & ---- & ---- & Global \\
\hline Pintle & 0 & 0 & 0 & 0 & 0 & ---- & Global \\
\hline $\begin{array}{l}\text { Quoin block } \\
\text { Miter block }\end{array}$ & --- & --- & --- & --- & --- & --- & Local \\
\hline
\end{tabular}


Table 13 presents the vertical displacement results for the different diagonal prestressing combinations when the gate was opening and closing. Figure 39 presents the vertical displacements obtained for each diagonal prestressing combination.

Table 13. Vertical displacement results.

\begin{tabular}{|c|c|c|c|c|c|}
\hline & \multicolumn{4}{|c|}{ Positive Diagonal } \\
\hline & & 0 & 10 & 20 & 30 \\
\hline \multicolumn{6}{|c|}{ Opening } \\
\hline \multirow{4}{*}{ 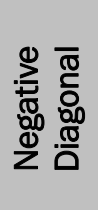 } & 0 & 0.0205 & 0.0221 & 0.0341 & 0.0471 \\
\hline & 10 & -0.0003 & 0.0105 & 0.0234 & 0.0365 \\
\hline & 20 & -0.0132 & -0.0003 & 0.0128 & 0.0259 \\
\hline & 30 & -0.0240 & -0.0110 & 0.0021 & 0.0153 \\
\hline & & \multicolumn{4}{|c|}{ Positive Diagonal } \\
\hline & & 0 & 10 & 20 & 30 \\
\hline \multicolumn{6}{|c|}{ Closing } \\
\hline \multirow{4}{*}{ 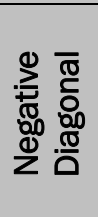 } & 0 & -0.0596 & -0.0360 & -0.0124 & 0.0028 \\
\hline & 10 & -0.0585 & -0.0348 & -0.0209 & -0.0077 \\
\hline & 20 & -0.0578 & -0.0446 & -0.0315 & -0.0184 \\
\hline & 30 & -0.0683 & -0.0553 & -0.0422 & -0.0290 \\
\hline
\end{tabular}

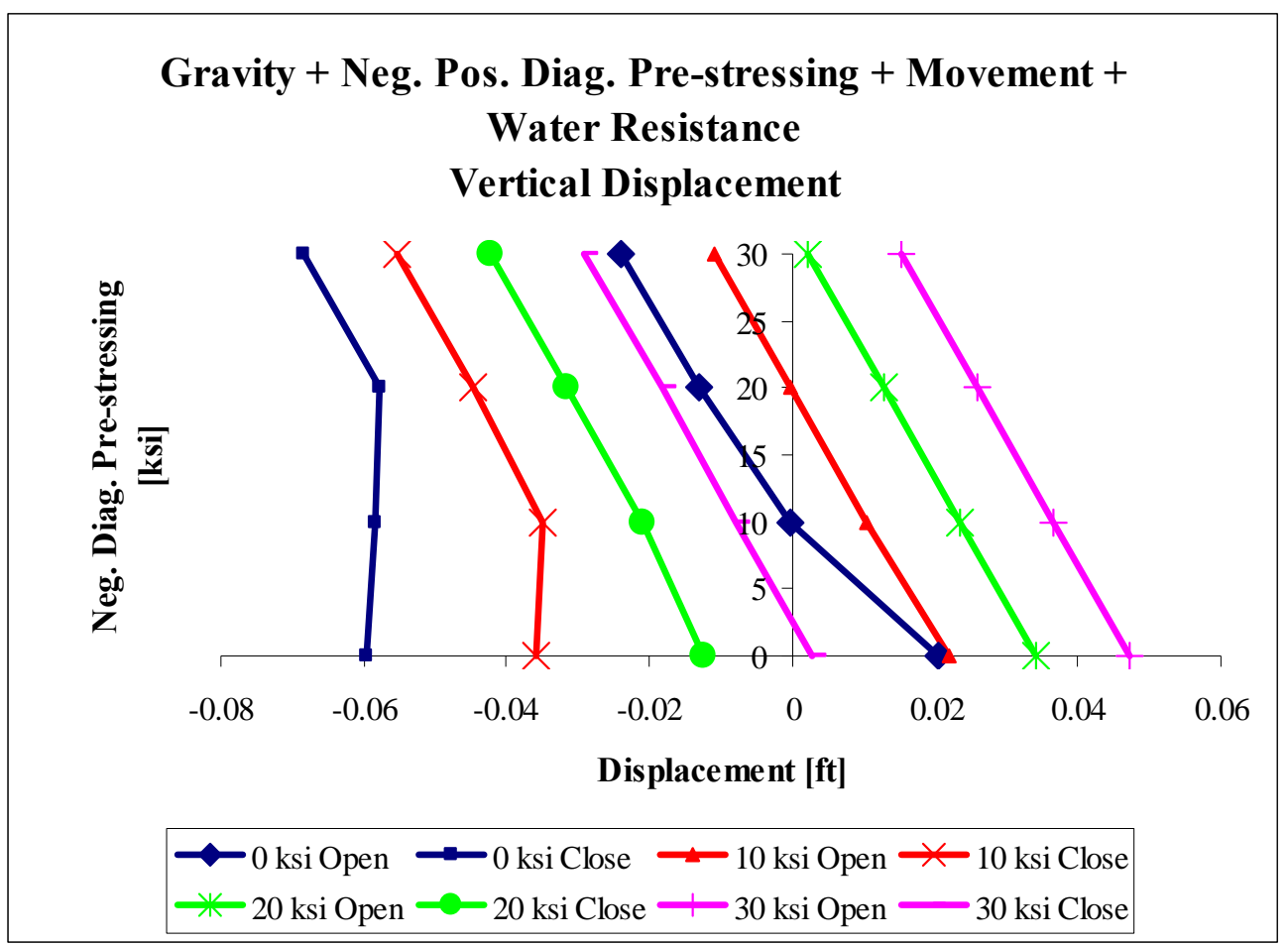

Figure 39. Vertical displacements. 
Lateral displacement:

The boundary conditions of a moving gate are located only in the pintle and gudgeon pin. Therefore, the gate can rotate freely, with the only restriction being the water resistance pressure. The self weight of the miter gate, the positive and negative diagonals prestressing, and the movement of the gate cause it to twist. In these cases the contributions of the positive and negative diagonals when the gate is opening and closing were analyzed. The previous analysis revealed that prestressing the positive diagonals produces a twist in the miter gate, causing the top portion of the miter end to move upstream; and prestressing the negative diagonals produces a downstream movement of the top portion of the miter end. These sets of analysis were conducted to asses the behavior of the miter end when the gate is moving and the contribution of the different combinations of diagonals prestressing.

The incorporation of the gate movement produces an upstream movement of the top portion of the gate when opening and a downstream movement of the top portion of the gate when closing. The critical lateral spatial displacements are summarized in Table 14 for the cases when the gate is opening and in Table 15 for the cases when the gate is closing. These maximum values occur immediately after the operation load is applied.

Table 14. Lateral displacement results.

\begin{tabular}{|c|c|c|c|c|c|}
\hline \multirow[b]{3}{*}{ Top End } & & \multicolumn{4}{|c|}{ Positive Diagonal } \\
\hline & & 0 & 10 & 20 & 30 \\
\hline & & & & & \\
\hline \multirow{4}{*}{ 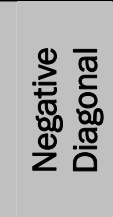 } & 0 & 0.1081 & 0.1164 & 0.1719 & 0.2330 \\
\hline & 10 & 0.0118 & 0.0625 & 0.1234 & 0.1849 \\
\hline & 20 & -0.0472 & 0.0138 & 0.0750 & 0.1368 \\
\hline & 30 & -0.0965 & -0.0353 & 0.0267 & 0.0885 \\
\hline & & \multicolumn{4}{|c|}{ Positive Diagonal } \\
\hline & & 0 & 10 & 20 & 30 \\
\hline \multicolumn{6}{|c|}{ Bottom End } \\
\hline \multirow{4}{*}{ 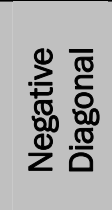 } & 0 & -0.0662 & -0.0713 & -0.1053 & -0.1428 \\
\hline & 10 & -0.0072 & -0.0383 & -0.0756 & -0.1133 \\
\hline & 20 & 0.0289 & -0.0085 & -0.0460 & -0.0838 \\
\hline & 30 & 0.0592 & 0.0216 & -0.0164 & -0.0543 \\
\hline
\end{tabular}


Table 15. Lateral displacement results for the closing cases.

\begin{tabular}{|c|c|c|c|c|c|}
\hline & \multicolumn{4}{|c|}{ Positive Diagonal } \\
\hline & & 0 & 10 & 20 & 30 \\
\hline \multicolumn{6}{|c|}{ Top End } \\
\hline \multirow{4}{*}{ 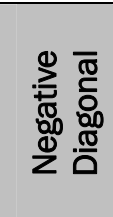 } & 0 & -0.2269 & -0.1217 & -0.0155 & 0.0596 \\
\hline & 10 & -0.2258 & -0.1170 & -0.0519 & 0.0140 \\
\hline & 20 & -0.2236 & -0.1614 & -0.0997 & -0.0384 \\
\hline & 30 & -0.2712 & -0.2096 & -0.1480 & -0.0863 \\
\hline & & \multicolumn{4}{|c|}{ Positive Diagonal } \\
\hline & & 0 & 10 & 20 & 30 \\
\hline \multicolumn{6}{|c|}{ Bottom End } \\
\hline \multirow{4}{*}{ 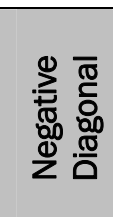 } & 0 & 0.1391 & 0.0746 & 0.0095 & -0.0365 \\
\hline & 10 & 0.1384 & 0.0717 & 0.0318 & -0.0086 \\
\hline & 20 & 0.1371 & 0.0989 & 0.0611 & 0.0235 \\
\hline & 30 & 0.1662 & 0.1285 & 0.0907 & 0.0529 \\
\hline
\end{tabular}

Figure 40 presents a typical curve of the miter end behavior for a positive diagonal prestressing of $20 \mathrm{ksi}$ and various negative diagonal prestressing when the gate is opening and closing. The plot demonstrates the relation between the diagonal prestressing and the opening and closing behavior of the gate. As mentioned in the previous parametric cases, the positive diagonal prestressing forces the top portion of the miter end to move in the upstream direction, and vise versa when the prestressing increases in the negative diagonal.

That implies that an increment in the positive diagonal prestressing produces an upstream movement of the top portion of the gate. This movement then produces a better behavior of the gate when closing because when the gate is closing, the top of the miter gate moves downstream. On the other hand, an increment in the negative diagonal prestressing results in a better behavior of the gate when opening because the lateral displacement produced by the prestressing in the negative diagonal is reduced when the gate opens. This means that the gate will experience a relative lateral displacement when opening and closing, but an adequate diagonal prestressing combination can maintain the lateral displacements between tolerable limits. 


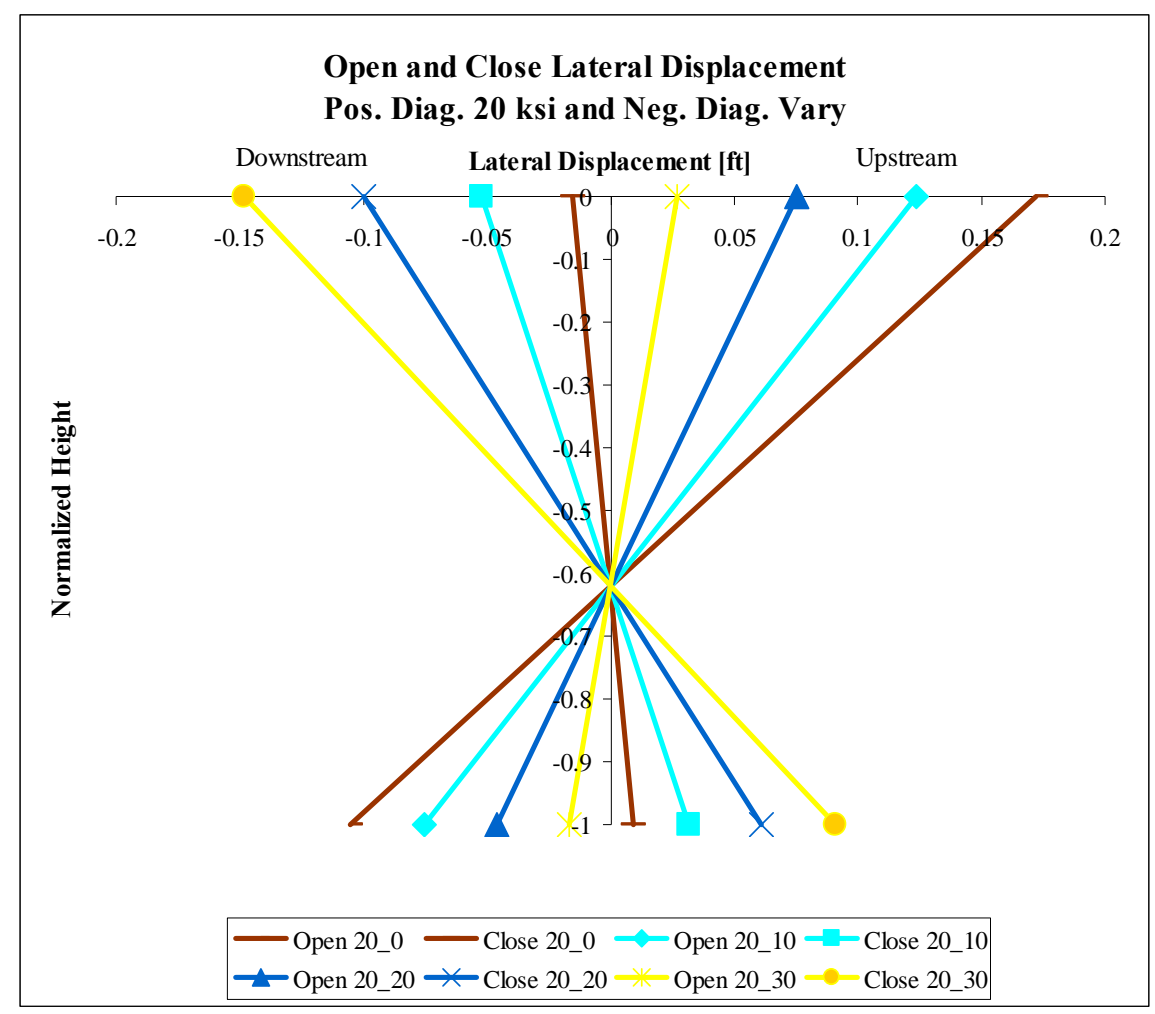

Figure 40. Typical miter end behavior.

Figure 41 summarizes all the lateral displacements for the positive and negative diagonal combinations. In order to obtain the optimal diagonal prestressing combination when the gate opens and closes, a maximum lateral displacement limit had to be defined (tolerance). For example, if this maximum limit is $1.0 \mathrm{in}$. of lateral displacement in the miter end, then based on Figure 41 any diagonal prestressing combination will satisfy the maximum displacements requirement for opening and closing the gate.

Figures 42 and 43 correspond to the opening and closing cases, respectively. The first step is to set the maximum lateral displacement limits in the plot; second; select the diagonal prestressing combinations that satisfy the maximum lateral displacements limits; and third, choose all the prestressing combinations that satisfy the predefined tolerance.

Figure 44 presents the relative lateral displacement of the miter end when the negative diagonal prestressing varies and the positive diagonal prestressing is maintained constant in each series. 


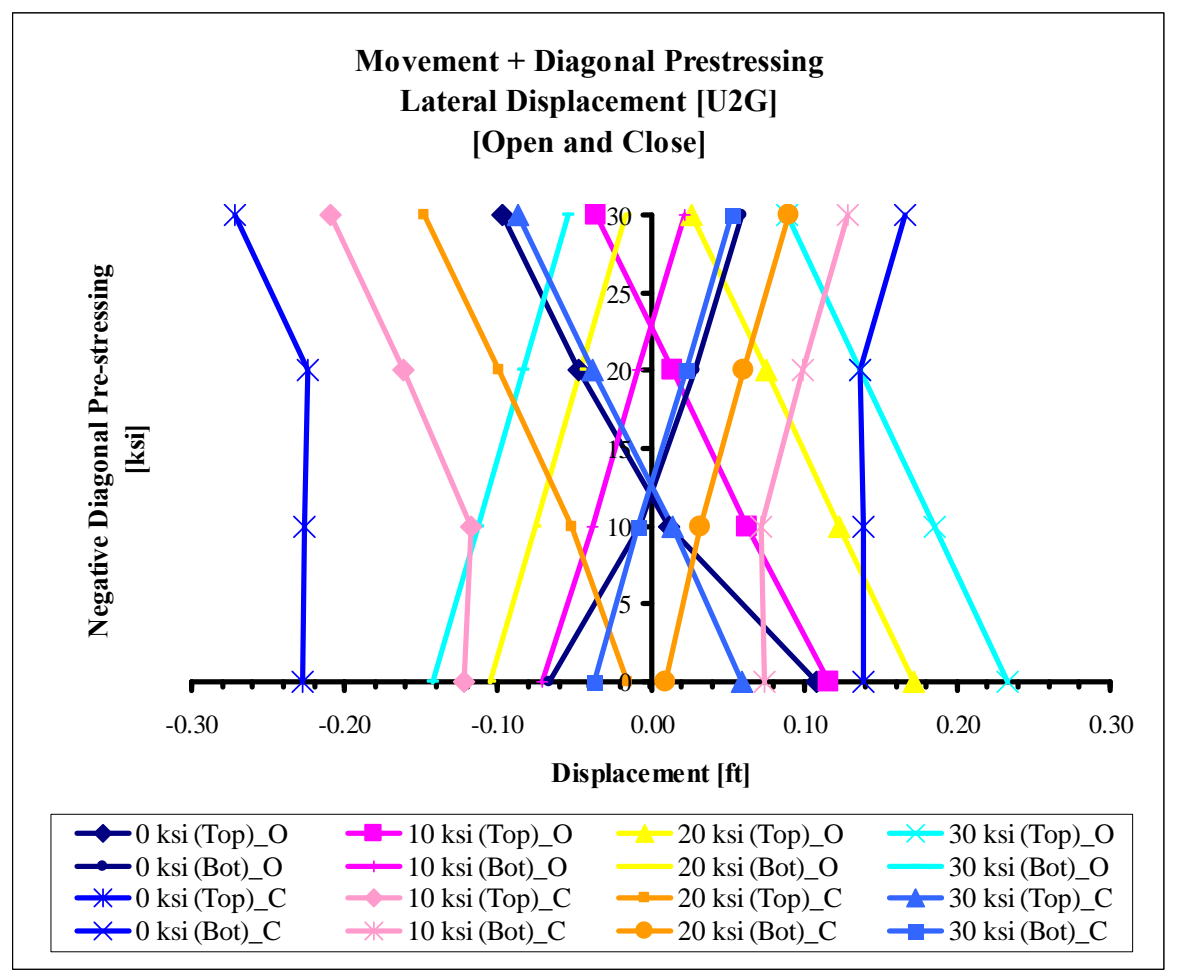

Figure 41. Lateral displacements with different diagonal prestressing combination.

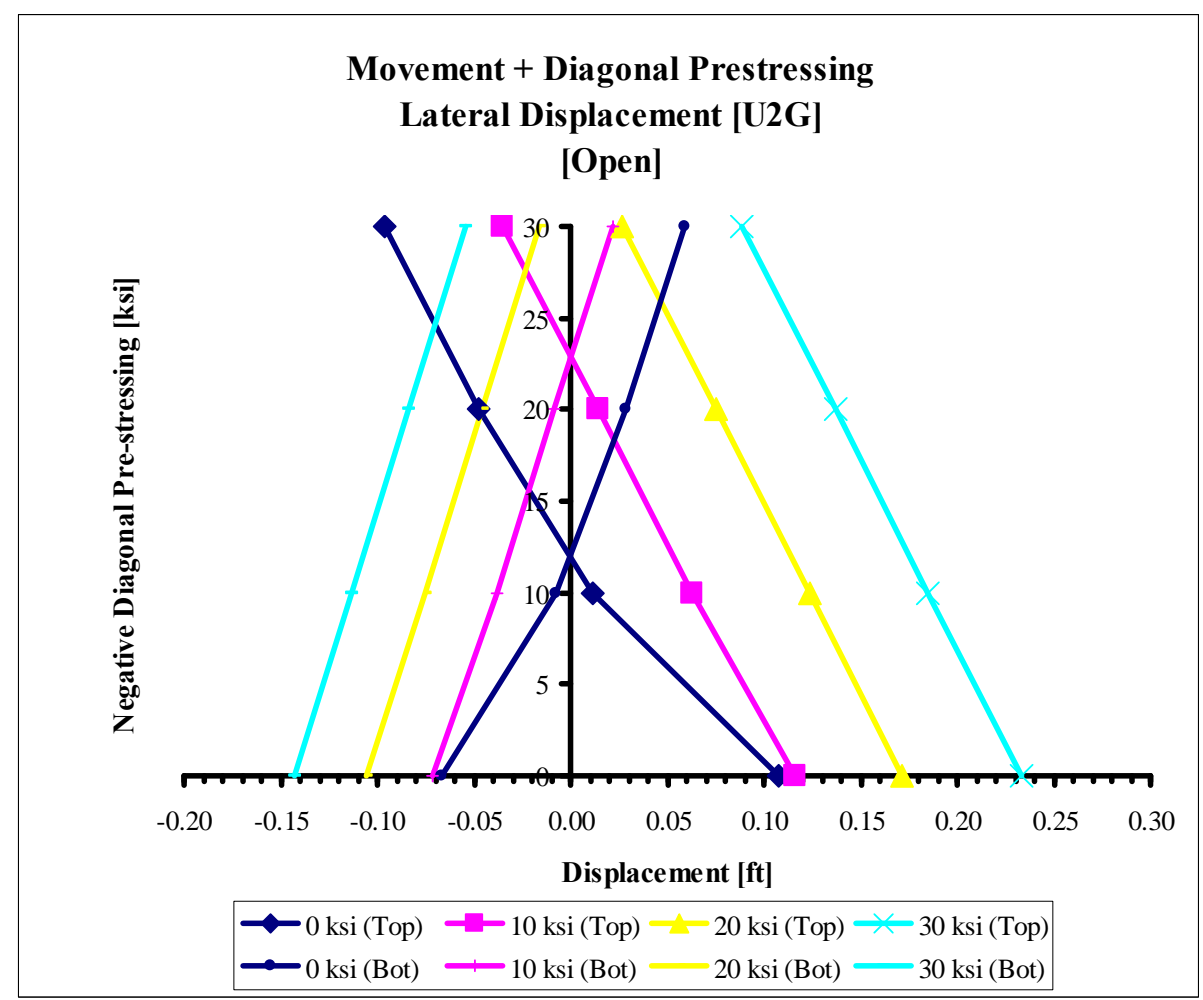

Figure 42. Lateral displacement- different diagonal prestressing combination, gate open. 


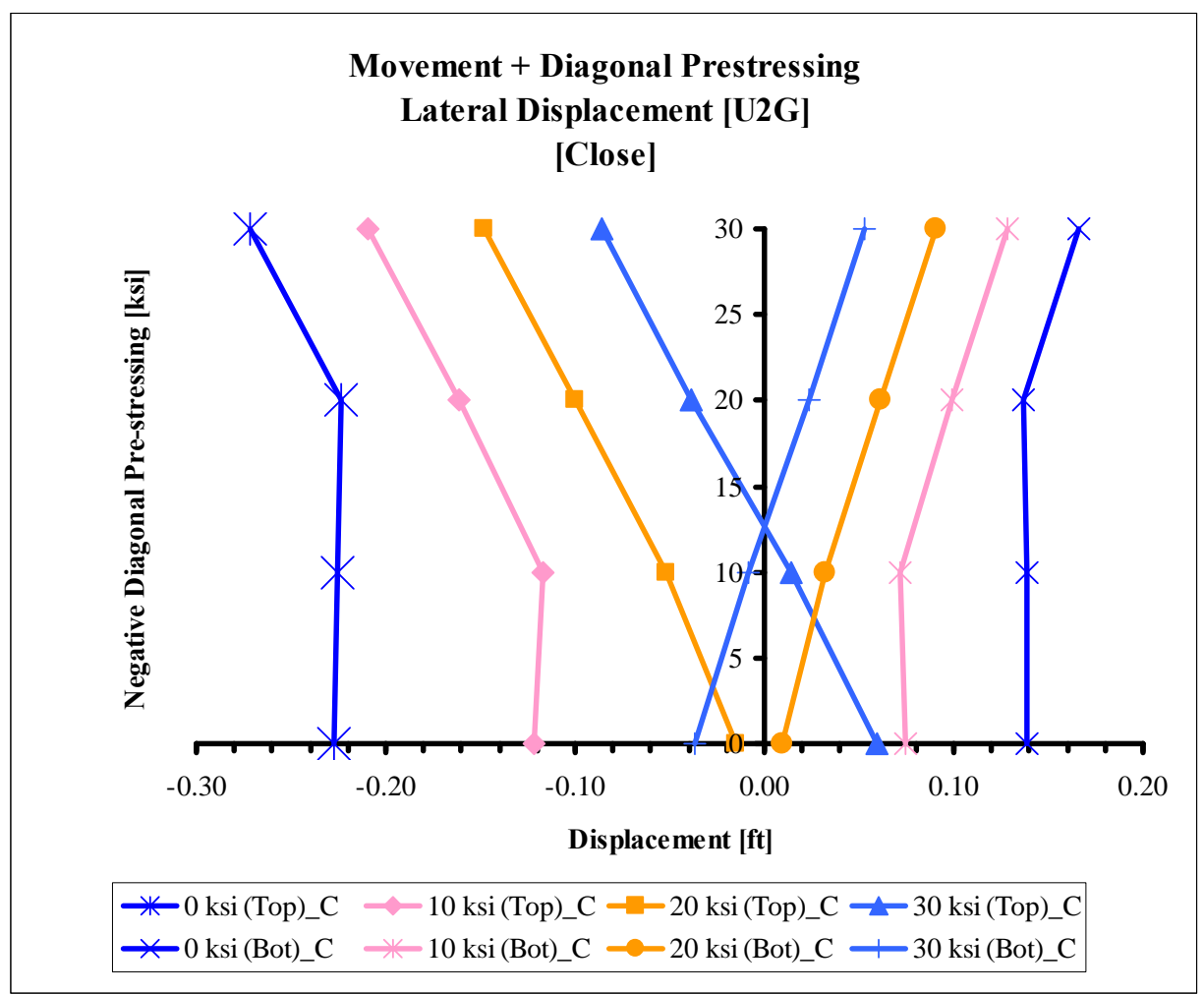

Figure 43. Lateral displacement-different diagonal prestressing combination, gate closed.

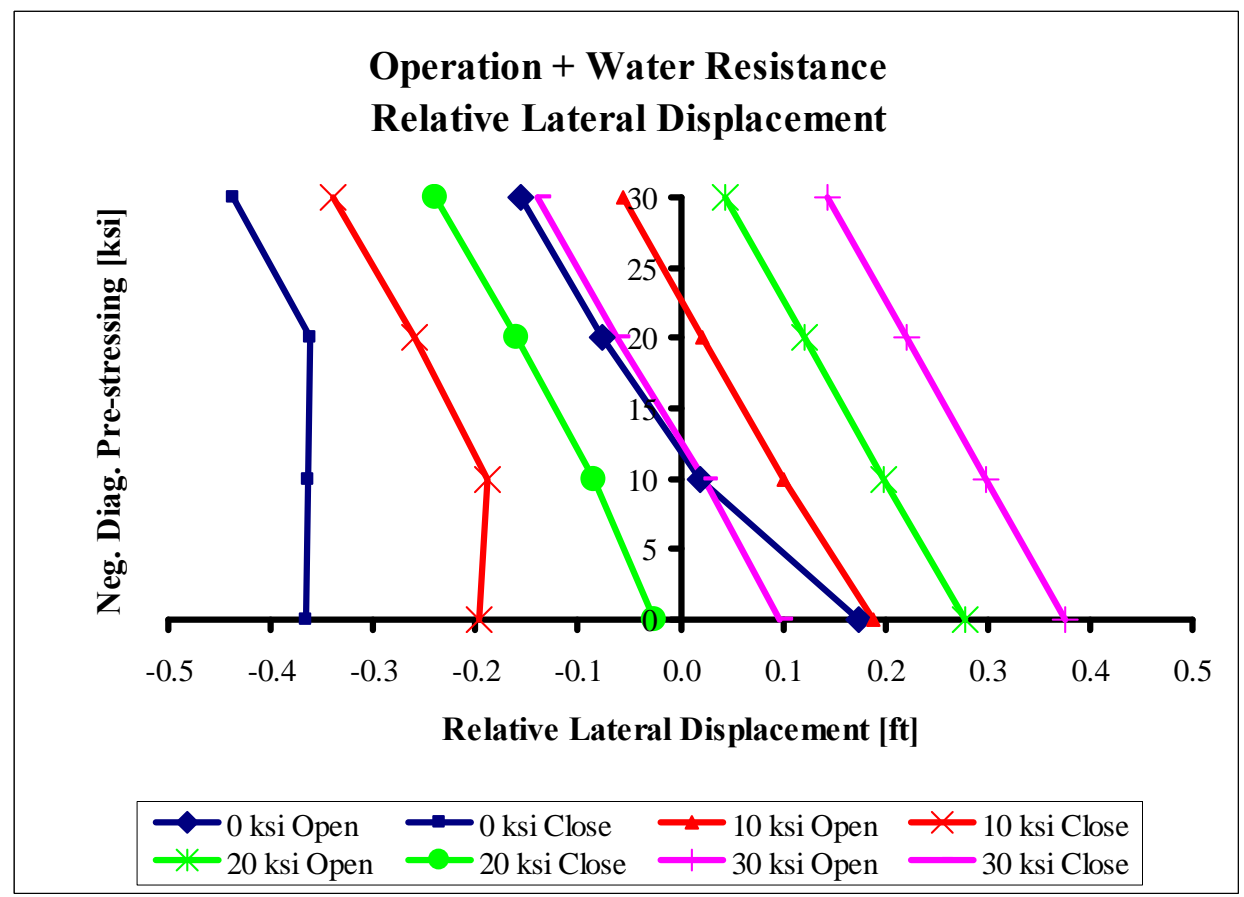

Figure 44. Relative lateral displacement (negative diagonals vary). 
Figure 45 presents the relative lateral displacement when the positive diagonal prestressing varies and the negative diagonal prestressing is maintained constant in each series. These plots can be used to determine the zero relative displacement for a given diagonal prestressing when the gate is opening and closing.

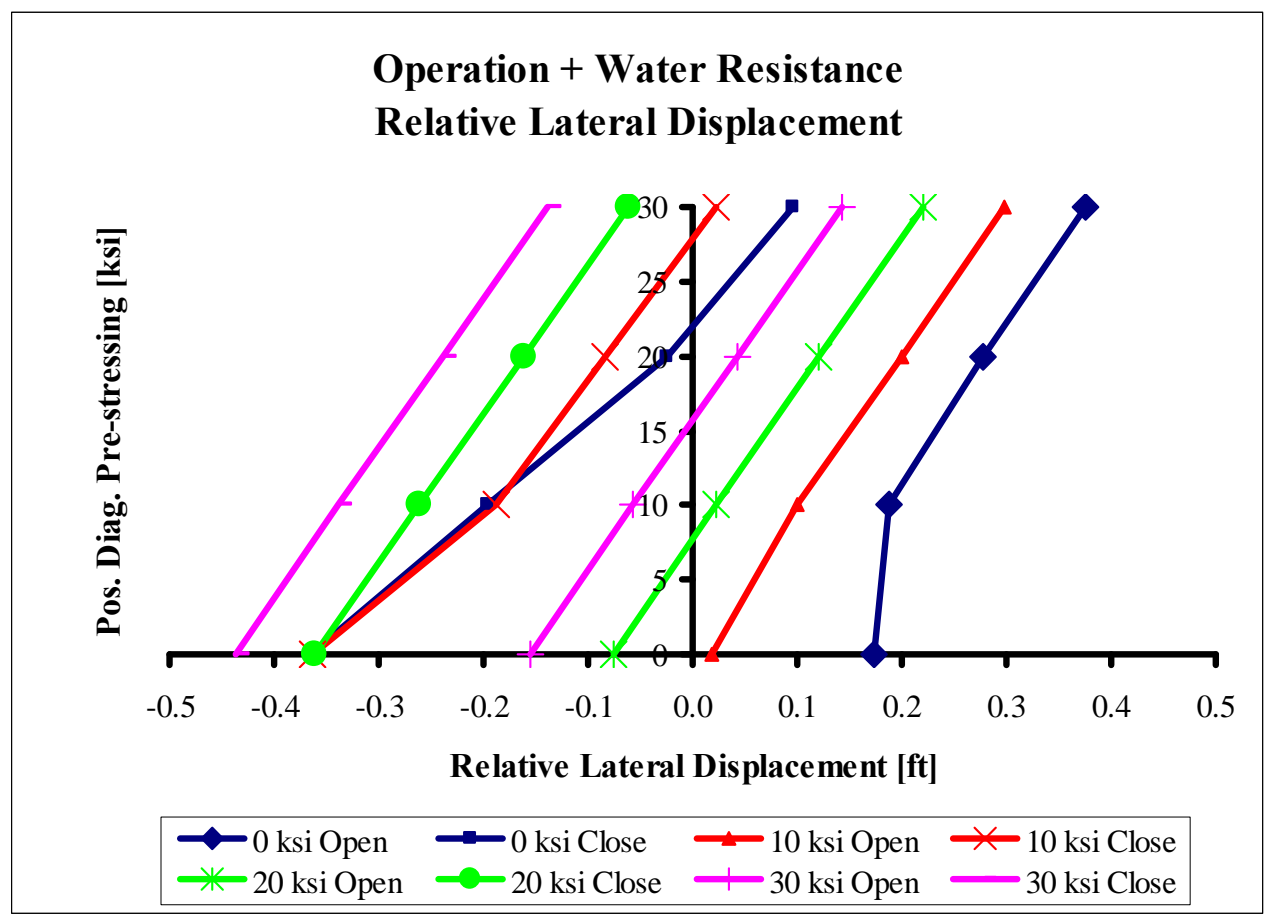

Figure 45. Relative lateral displacement (positive diagonals vary).

\subsubsection{Case 5: Quoin block analysis}

Quoin block will deteriorate during the service live of the structure. The development of the deterioration will cause that the axial loads transfer to the wall be diminished causing an increase of vertical reactions carry by the pintle region. For the analysis a constant value of diagonal prestressing was used. The pre-stressing in the diagonals were $20 \mathrm{ksi}$ for the positive diagonal and $25 \mathrm{ksi}$ for the negative diagonal.

Figure 46 shows a schematic figure for this case, and the assumed boundary conditions for this case are shown in Table 16. The different cases used to simulate the quoin block deterioration are presented and described in Table 17. 


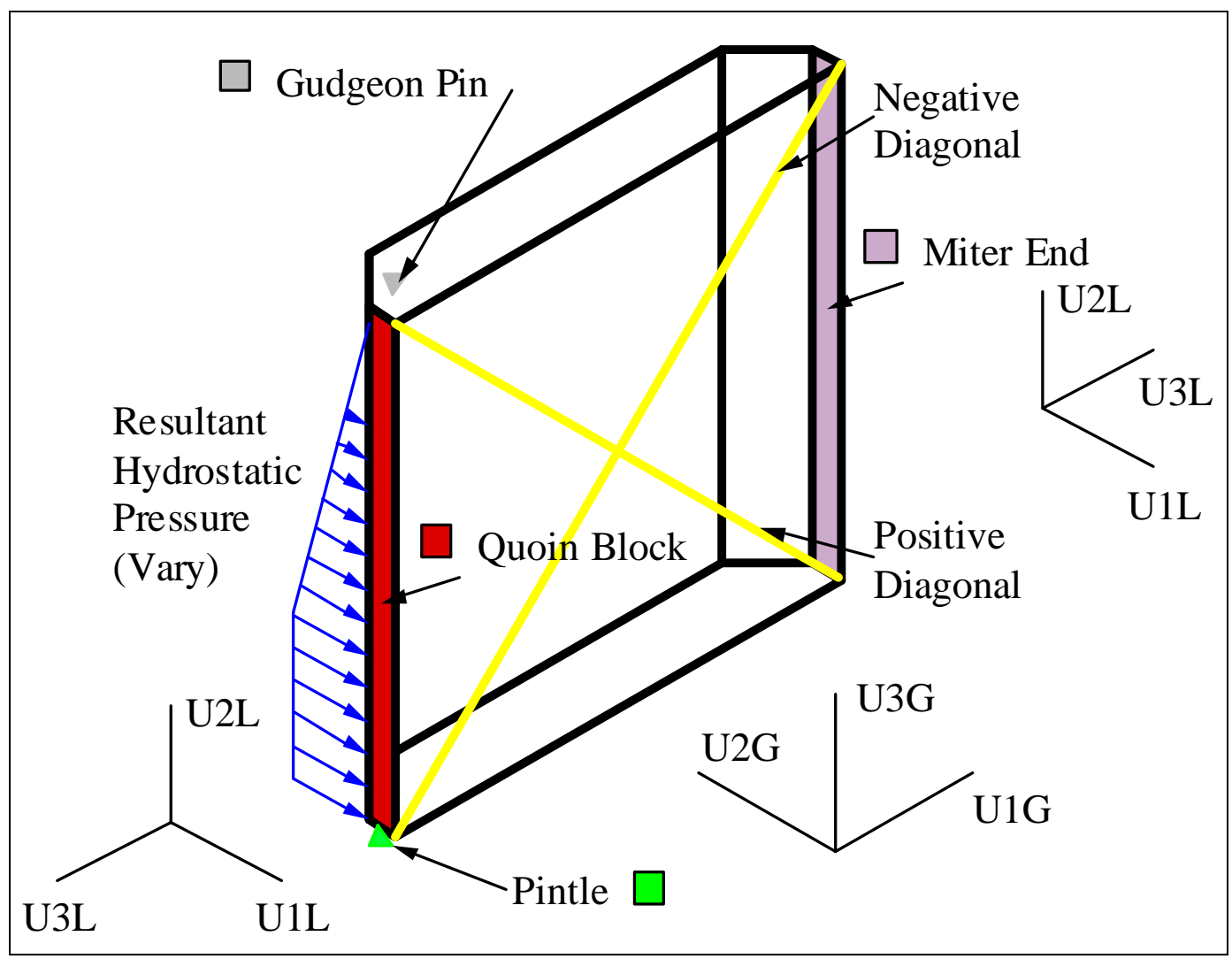

Figure 46. Schematic of Case 5.

Table 16. Boundary condition for the analyzed structure.

\begin{tabular}{|l|l|l|l|l|l|l|l|}
\hline $\begin{array}{l}\text { Gate } \\
\text { Component }\end{array}$ & U1 & U2 & U3 & UR1 & UR2 & UR3 & CSYS \\
\hline Gudgeon pin & 0 & 0 & ---- & --- & ---- & ---- & Global \\
\hline Pintle & 0 & 0 & 0 & 0 & 0 & ---- & Global \\
\hline Quoin & 0 & 0 & --- & --- & --- & ---- & Local \\
\hline Miter end & 0 & 0 & --- & --- & --- & --- & Local \\
\hline
\end{tabular}


Table 17. Quoin block boundary condition variation.

\begin{tabular}{|l|l|}
\hline BC & Analysis Description \\
\hline $\begin{array}{l}\text { Miter } \\
\text { Gate }\end{array}$ & $\begin{array}{l}\text { Q100: } \\
\text { Full quoin boundary condition. }\end{array}$ \\
\hline $\begin{array}{l}\text { Miter } \\
\text { Gate }\end{array}$ & $\begin{array}{l}\text { Q75T: } \\
75 \% \text { of the quoin area measured from top to bottom. }\end{array}$ \\
\hline $\begin{array}{l}\text { Miter } \\
\text { Gate }\end{array}$ & $\begin{array}{l}\text { Q50T: } \\
50 \% \text { of the quoin area measured from top to bottom. }\end{array}$ \\
\hline $\begin{array}{l}\text { Miter } \\
\text { Gate }\end{array}$ & $\begin{array}{l}\text { Q25T: } \\
25 \% \text { of the quoin area measured from top to bottom. }\end{array}$ \\
\hline $\begin{array}{l}\text { Miter } \\
\text { Gate }\end{array}$ & $\begin{array}{l}\text { Q75B: } \\
75 \% \text { of the quoin area measured from bottom to top. }\end{array}$ \\
\hline $\begin{array}{l}\text { Miter } \\
\text { Gate }\end{array}$ & $\begin{array}{l}\text { Q50B: } \\
50 \% \text { of the quoin area measured from bottom to top. }\end{array}$ \\
\hline $\begin{array}{l}\text { Miter } \\
\text { Gate }\end{array}$ & $\begin{array}{l}\text { Q25B: } \\
\text { 25\% of the quoin area measured from bottom to top. }\end{array}$ \\
\hline $\begin{array}{l}\text { Miter } \\
\text { Gate }\end{array}$ & $\begin{array}{l}\text { Q50C: } \\
50 \% \text { of the quoin area measured from the center. }\end{array}$ \\
\hline $\begin{array}{l}\text { Miter } \\
\text { Gate }\end{array}$ & $\begin{array}{l}\text { Q25C: } \\
\text { 25\% of the quoin area measured from the center. }\end{array}$ \\
\hline $\begin{array}{l}\text { Q0: } \\
\text { No quoin boundary condition. Free Nodes. }\end{array}$ \\
\hline
\end{tabular}

When the gate is closed, the water level in the upstream face of the gate is the maximum head and the water level in the downstream face of the gate increases to reach the upstream level. A total of ten steps were used to represent the filling of the lock chamber. Each step represents an increase in the water level of the downstream side of the gate. In the final step the hydrostatic pressure in the upstream surface of the gate is balanced with the downstream water pressure. Figure 47 presents the different water levels used in the analysis. After these ten steps the stresses in the pintle zone and in the critical members were investigated. 


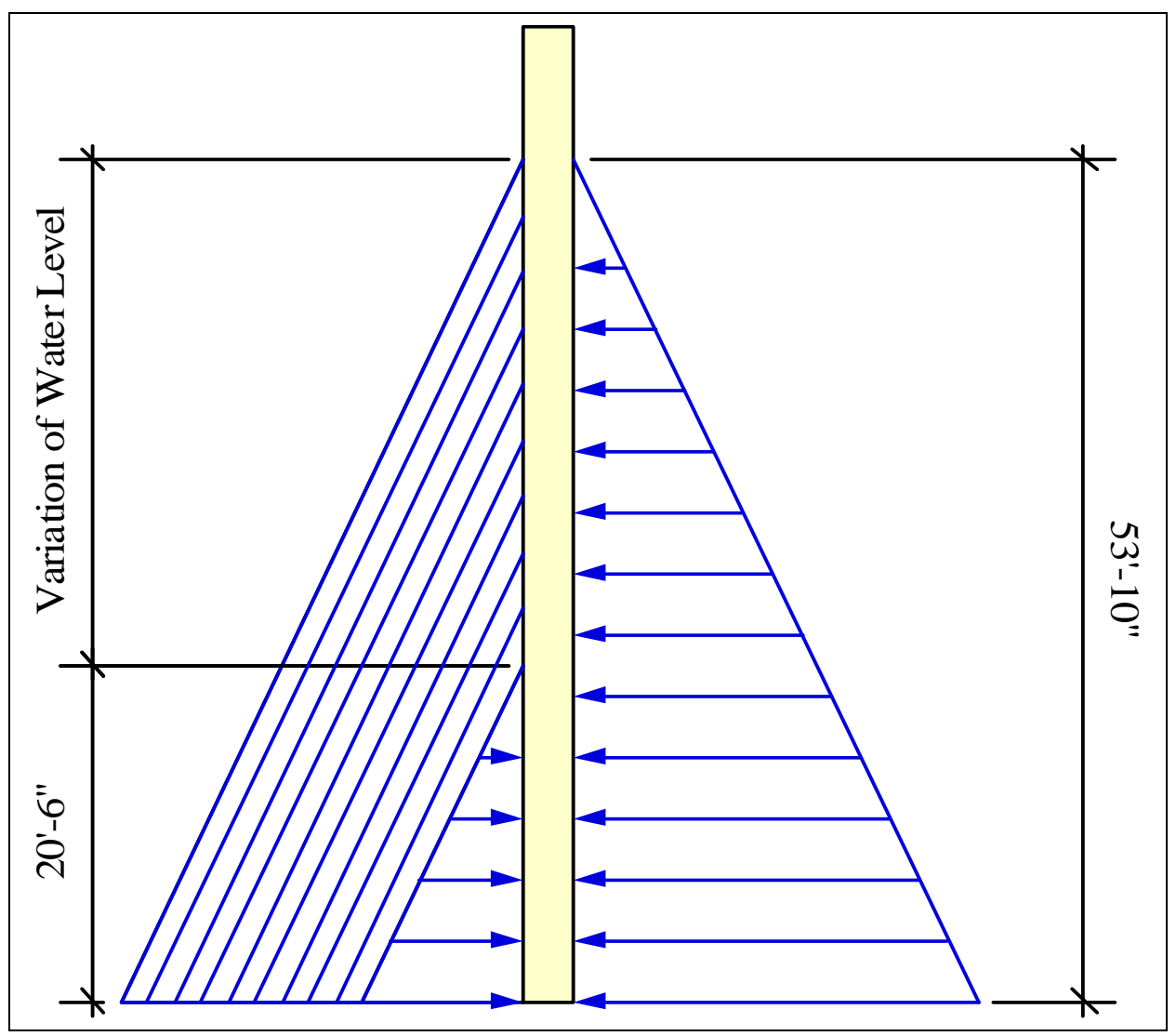

Figure 47. Different downstream water levels.

\subsection{Stress concentration at pintle zone}

Table 18 summarizes the stresses in the pintle zone for each of the cases. The results reveal an increase in the stresses in the pintle zone for the cases where the quoin block is deteriorated from top to bottom $(\mathrm{Q} \# \mathrm{~T})$ and from the center $(\mathrm{Q} \# \mathrm{C})$ compared with $\mathrm{Q100}$, which represents a full action of the quoin block. Figure 48 presents the results obtained for quoin blocks deteriorating from top to bottom. This plot demonstrates clearly an increment in the stresses at the pintle zone when the quoin block area that transfers the axial load is reduced. Figure 49 presents the results for the quoin block cases deteriorating from the center up and down. When the quoin block starts to be ineffective, the stresses in the pintle zone begin to rise as a function of the effective area. The maximum stress value was obtained in the analysis when the quoin block was inactive in the structure (Qo). Some of the stresses obtained in the different analyses were above the yield strength of the members (50 ksi). The cases when the quoin block is deteriorating from the bottom portion to the top $(\mathrm{Q} \# \mathrm{~B})$ do not produce an increment in the stresses at the pintle zone. The values obtained in the results are around $10 \mathrm{ksi}$ (Figure 50). After a careful study of the structure 
behavior in the model, a concentration of stresses in the quoin block effective area was detected. This effect produces increments in the stresses of the structural elements in the gate. Table 19 and Figure 51 present the stresses in the critical zone for these cases. The stress values are closer to the yield strength of the members, and a quoin block effective area less than 25 percent can exceed the member capacity. Figure 52 demonstrates the stress concentration in the quoin load transfer area for Case Q25B.

Table 18. Summary stresses at pintle zone.

\begin{tabular}{|l|l||l|l|}
\hline $\begin{array}{l}\text { Quoin } \\
\text { Case }\end{array}$ & $\begin{array}{l}\text { Stress } \\
\mathrm{ksi}\end{array}$ & $\begin{array}{l}\text { Quoin } \\
\text { Case }\end{array}$ & $\begin{array}{l}\text { Stress } \\
\mathrm{ksi}\end{array}$ \\
\hline Q100 & 10.7 & Q25C & 38.1 \\
\hline Q75T & 29.3 & Q75B & 10.8 \\
\hline Q50T & 47.0 & Q50B & 9.4 \\
\hline Q25T & 63.8 & Q25B & 9.8 \\
\hline Q50C & 29.5 & Q0 & 80.2 \\
\hline
\end{tabular}

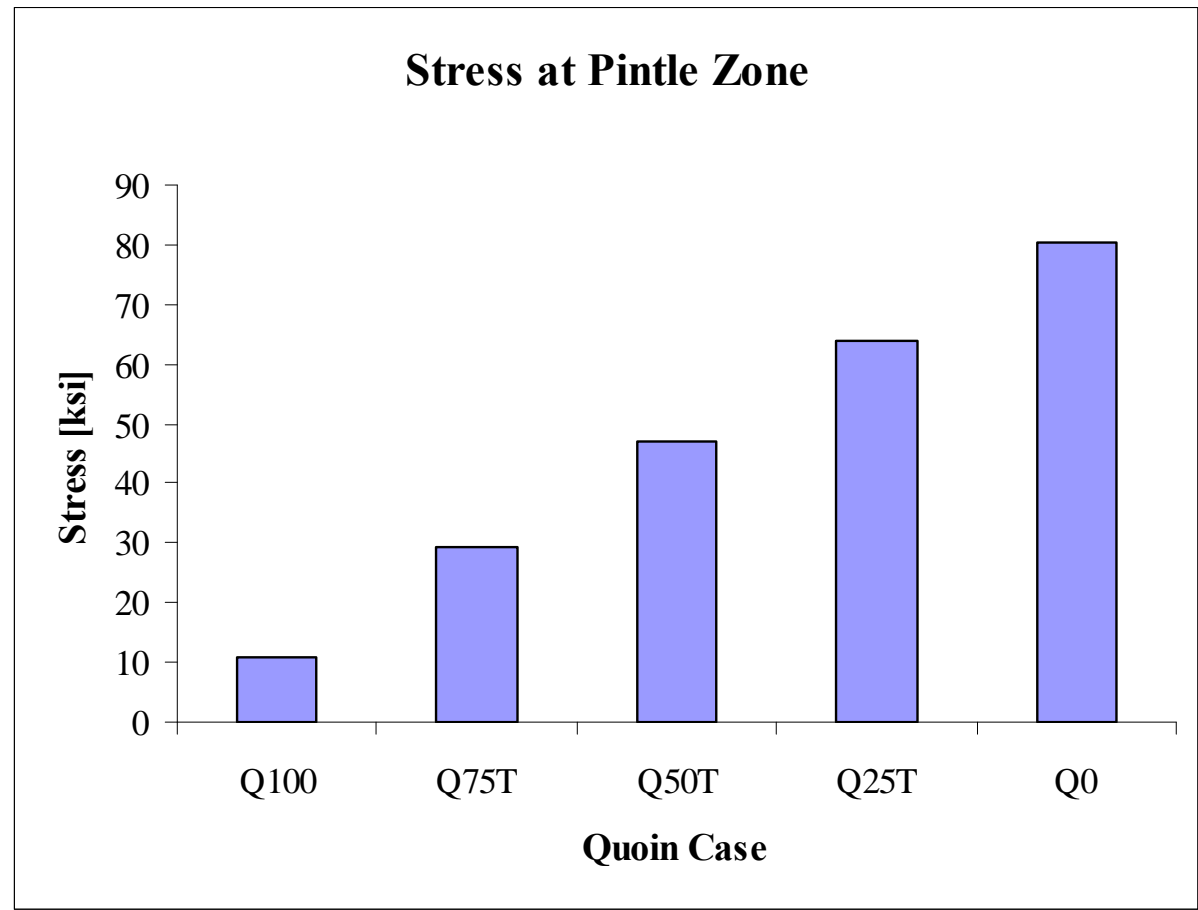

Figure 48. Stress concentration in the pintle zone for cases from top to bottom. 


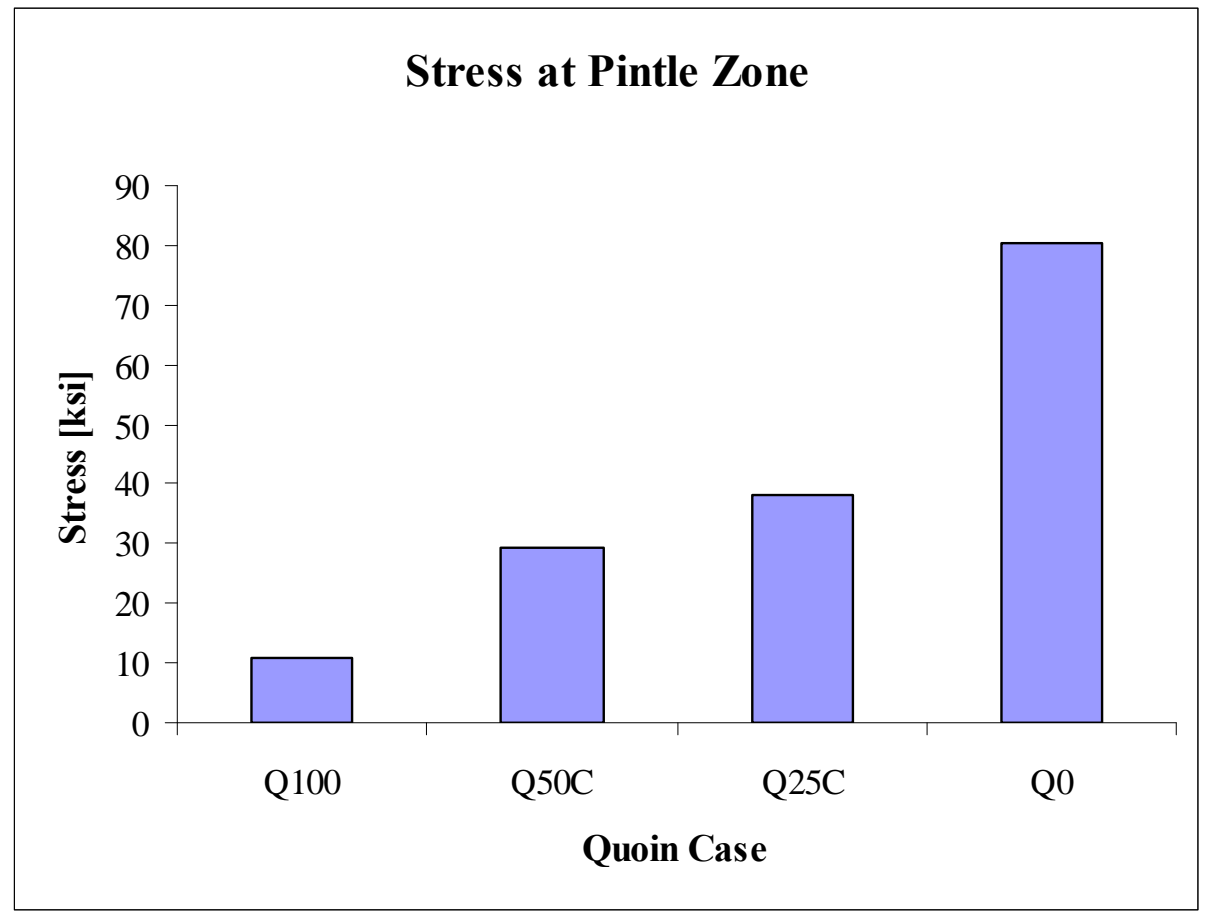

Figure 49. Stress concentration in the pintle zone for cases from center up and down.

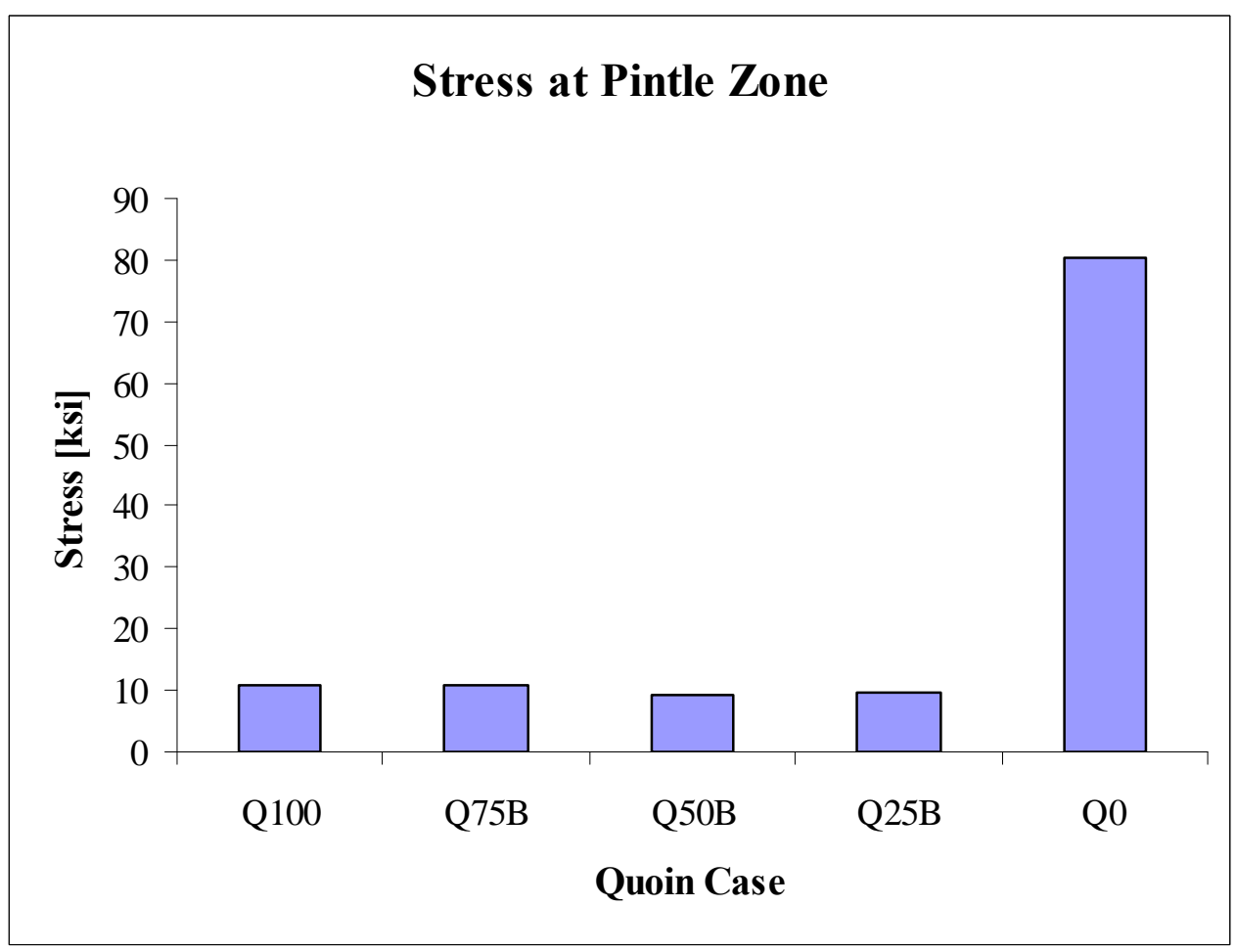

Figure 50. Stress concentration in the pintle zone for cases from bottom to top. 
Table 19. Stresses at the critical zone.

\begin{tabular}{|l|l|}
\hline Quoin Case & Stress ksi \\
\hline Q100 & 10.7 \\
\hline Q75B & 10.8 \\
\hline Q50B & 18.4 \\
\hline Q25B & 45.6 \\
\hline Q0 & 80.2 \\
\hline
\end{tabular}

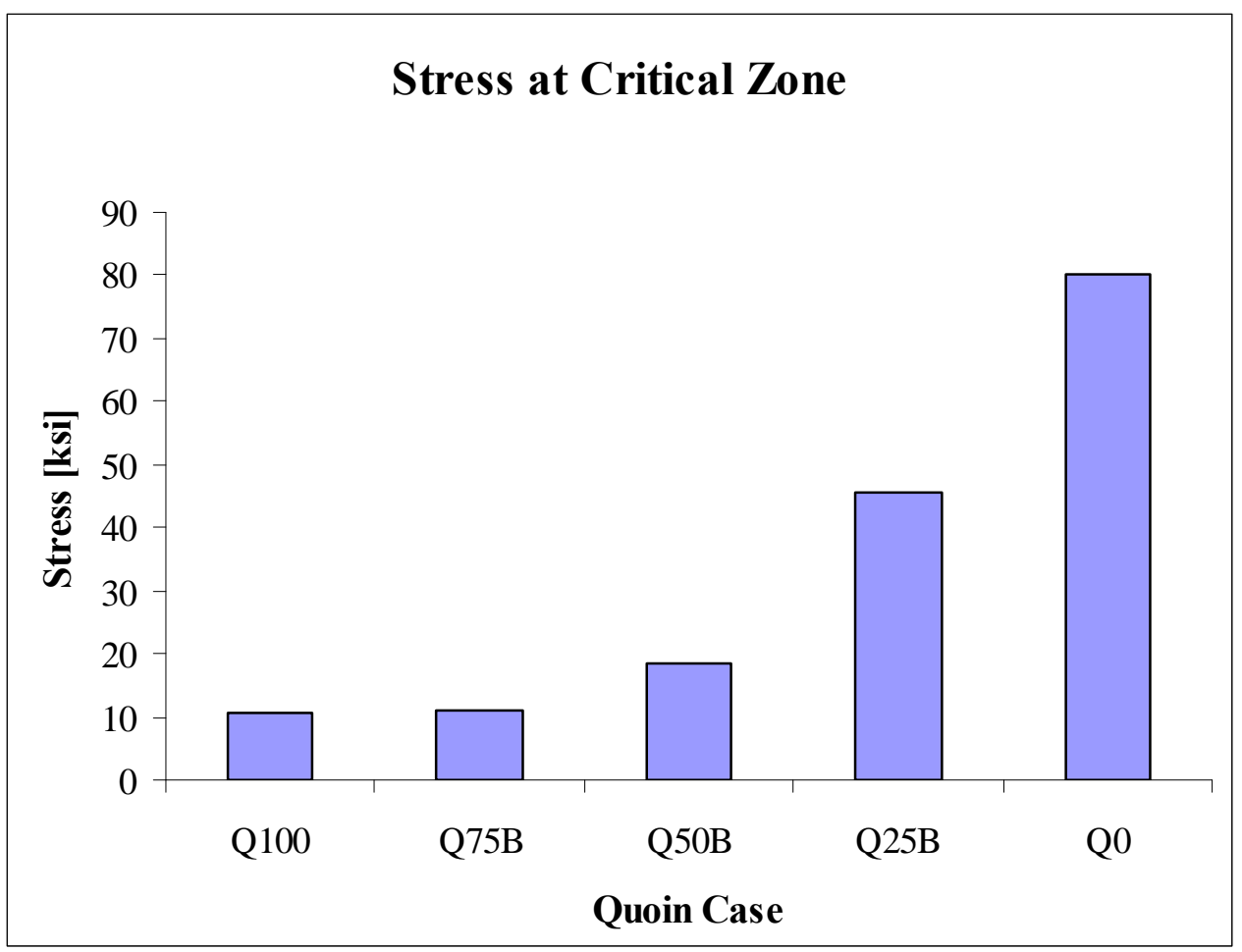

Figure 51. Stress concentration in the critical zone for cases from bottom to top.

The results obtained demonstrate that deterioration in the quoin block impeding the transfers of axial loads to the wall can affect drastically the state of stresses in the pintle region. If the deterioration is severe, the stresses can reach undesirable stress levels. The location of maximum stress concentration depends on the quoin deterioration area: if the deterioration occurs in the pintle area (top - bottom), the maximum stresses will be produced in the pintle zone; and if the deterioration is in the gudgeon pin (bottom - top), the maximum stress will be produced in the elements near the quoin block effective area end. 


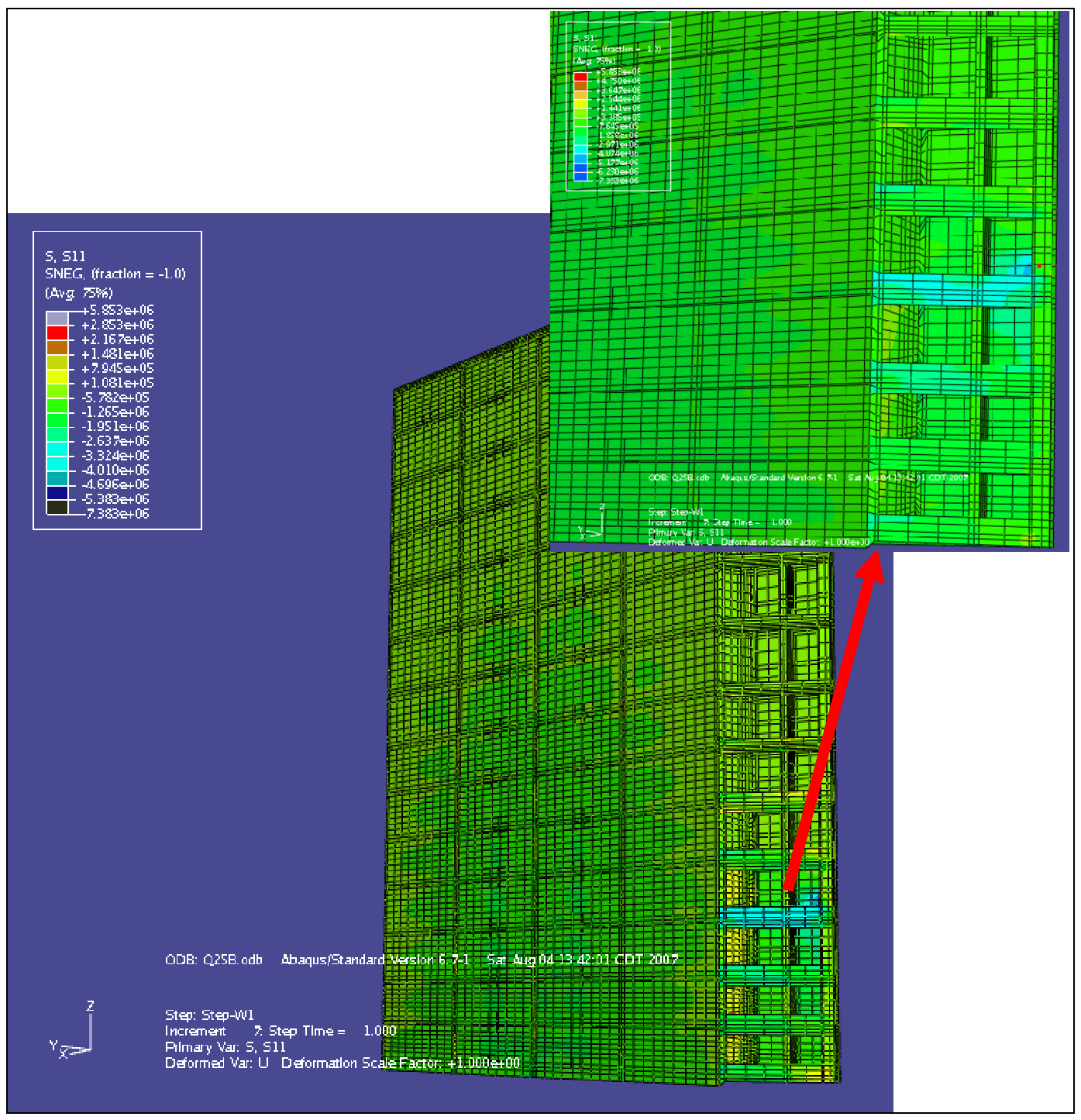

Figure 52. Stress concentration in the critical zone for Case Q25B. 


\section{Conclusions and Recommendations}

\subsection{3-D finite element analysis of miter gate with multiple cracks}

This Technical Report has described the capability of calculating stress intensity factors using state-of-the-art analytical techniques. The calculation of the stress intensity factors can be obtained from a 3-D finite element analysis. 3-D finite element meshes can be automatically generated within commercially available applications using IGESformatted CAD drawings.

The first example showed that the J-integral approach successfully predicted the stress intensity factors for a semi-infinite plate with throughthickness crack, double-edge cracks, single-edge crack, and cracks growing from round holes. The example showed a difference of less than 2 percent between the numerically calculated values and the ones calculated with closed-form solutions.

In the second example, the 3-D meshing technique utilizing CAD drawings imported into the finite element application was demonstrated. The meshing procedure allows the gates with all its components to be modeled completely without needing to make any simplifying assumptions regarding the geometry. Once again, the stress intensity factors of the upstream flanges of a horizontal girder and a vertical diaphragm were calculated. For this example, the stress intensity factors showed that the cracks will not grow. Therefore repairs can be postponed.

The J-integral methodology can certainly be used to evaluate cracked hydraulic steel structures and to determine remaining life based on the operation conditions. The methodology can also be used to decide the criticality of the cracking problem and whether repairs are needed. Suggested repairs can also be evaluated numerically to predict reliability and safety conditions. These techniques when coupled with a library of all of the Corps hydraulic structures will allow quick analysis whenever problems are found.

Further studies regarding crack initiation should be performed. Crack initiation in welded steel structures is influenced by fatigue loading, connection details, thermal residual stresses, and material properties. 
Fracture modes II and III should also be evaluated to establish the contribution of shear and out-of-plane shear to the stress intensity factor.

\subsection{Numerical investigation of diagonals prestress}

The comprehensive miter gate diagonals prestress analysis demonstrated the importance of maintaining the adequate levels of prestress. Opening and closing the gate produces an additional lateral displacement. Relaxation will develop over time and vertical and lateral displacement on the miter end will increase, causing misalignment and additional torsional stresses on the pintle region.

Optimum values of prestressing can easily be calculated using numerical simulations. Once the different diagonal prestressing models are obtained, a series of curves relating prestressing levels with relative displacements can be accomplished, then for a predefined tolerance the optimum prestressing levels can be easily extracted from these graphs. During the gravity analysis the results revealed a twist in the miter gate end. The quoin end of a miter gate is held vertical by the pintle and gudgeon pin, leaving the miter end free to twist out of vertical alignment. This twist was produced because the center of gravity and the shear center are not in the same vertical plane.

The case of gravity with positive diagonal showed that the greater the prestressing in the positive diagonals, the smallest the vertical deflection becomes. Zero or positive vertical deflections can be accomplished for prestress values higher than the yield strength; therefore, a negative diagonal is required to provide additional vertical stiffness. Prestressing of the positive diagonal contributes to reduce the twisting generated by the gravity load.

The gravity and positive and negative diagonal case shows that the greater the prestressing in the negative diagonals, the greater the vertical displacement becomes. With this analysis the optimum prestressing levels can be obtained by using plots generated with different levels of prestressing.

The case involving gravity with positive and negative diagonals during gate operation showed that the gate will experience a relative lateral displacement when opening and closing, but an adequate diagonal prestressing combination can maintain the lateral displacements between tolerable 
limits. These limits can be found from the figures included showing the vertical and lateral displacements fro different diagonal prestressing.

Quoin block deterioration analysis demonstrated that deterioration in the quoin block can affect drastically the state of stresses in the pintle region. If the deterioration is severe, the stresses can reach undesirable stress levels. The location of the stress concentrations depends on the quoin deterioration area: if the deterioration occurs in the pintle area (top bottom), the maximum stresses will be generated in the pintle zone; and if the deterioration is in the gudgeon pin (bottom - top), the maximum stress will be produced in the elements near the quoin block effective area end.

\subsection{Recommendations}

A comprehensive 3-D finite element analysis can be used to determine the stress intensity factor for cracked hydraulic steel structures. This factor is essential for the assessment and determination of the remaining life of a fatigue-induced cracking problem.

The advanced numerical modeling can also be used to asses the optimum values of diagonal prestressing for new and existing miter gates, eliminating the possibility of diagonal connection failures.

It is essential that most of the Corps of Engineers navigation hydraulic steel structures be evaluated numerically. This type of analysis will help in the maintenance and evaluation of repairs when necessary. Furthermore, considering the aging navigation infrastructure in this country, by conducting these advance numerical evaluations, the Corps will be proactive instead of reactive to possible problems. By being proactive, the Corps will obtain substantial savings when performing repairs and maintenance, or when a critical problem arises. 


\section{References}

Anderson, T. L. 1991. Fracture mechanics fundamentals and application. Boca Raton, FL: CRC Press.

Barsom, J. M., and S. T. Rolfe. 1987. Fracture and fatigue control in structures application of fracture mechanics. $2^{\text {nd }}$ ed. Englewood Cliffs, NJ: Prentice Hall.

Bazant, Z. P., and J. Planas. 1998. Fracture and size effect in concrete and other quasibrittle materials. Boca Raton, FL: CRC Press.

Bocca, P., A. Carpinteri, and S. Valente. 1991. Mixed mode fracture of concrete. Materials Structures 27(90): 1139-1153.

Cherepanov, G. P. 1967. The propagation of cracks in a continuous medium. Journal of Applied Mathematics and Mechanics, 31(3): 503-512

Griffith, A. A. 1921. The phenomena of rupture and flow in solids. Philosophical Transition, Series A, 221: 163-197.

Headquarters, U.S. Army Corps of Engineers. 1993. Design of hydraulic steel structures. EM 1110-2-2105. Washington, DC: Headquarters, U.S. Army Corps of Engineers, . 1994. Lock gates and operating equipment. EM 1110-2-2703. Washington, DC: Headquarters, U.S. Army Corps of Engineers.

Ingliss, C. E. 1913. Stress in a plate due to the presence of cracks and sharp corners. T. Inst. Naval Architects 55: 219-241.

Irwin, G. R. 1957. Analysis of stress and strain near the end of a crack traversing a plate. Journal of Applied Mechanics, ASME 24: 361-364.

Rice, J. R. 1968a. A path independent integral and the approximate analysis of strain concentrations by notches and cracks. J. Appl. Mech., ASME 35:379-386. . 1968b. Mathematical analysis in the mechanics of fracture. Fracture - An Advance Treatise, Vol. 2, H. Liebowitz, ed., New York: Academic Press.

Swamy, R. N. 1979. Fracture mechanics applied to concrete: Developments in concrete technology, London, 221-281.

Tada, H., P. C. Paris, and G. R. Irwin. 1985. The stress analysis of cracks handbook. 2nd ed., St. Louis: Paris Productions. 


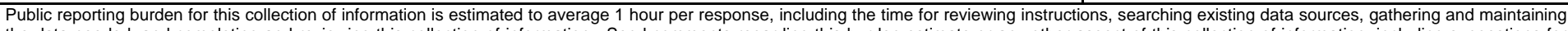

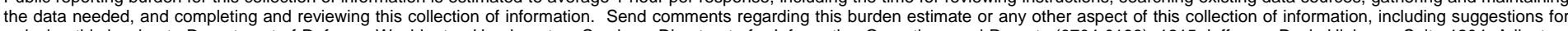

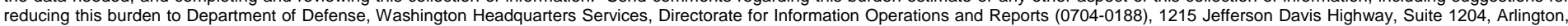

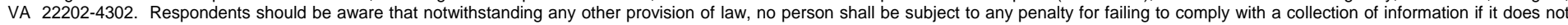
display a currently valid OMB control number. PLEASE DO NOT RETURN YOUR FORM TO THE ABOVE ADDRESS.
1. REPORT DATE (DD-MM-YYYY)
2. REPORT TYPE
3. DATES COVERED (From - To)

June 2009

Final

\section{TITLE AND SUBTITLE}

Numerical Investigation of Miter Gates

5a. CONTRACT NUMBER

5b. GRANT NUMBER

5c. PROGRAM ELEMENT NUMBER

\section{AUTHOR(S)}

Guillermo A. Riveros, Jorge L. Ayala Burgos, and Jaime Perez

5d. PROJECT NUMBER

5e. TASK NUMBER

5f. WORK UNIT NUMBER

\section{PERFORMING ORGANIZATION NAME(S) AND ADDRESS(ES)}

8. PERFORMING ORGANIZATION REPORT NUMBER

U.S. Army Engineer Research and Development Center

Information Technology Laboratory

ERDC/ITL TR-09-1

3909 Halls Ferry Road

Vicksburg, MS 39180-6199

9. SPONSORING / MONITORING AGENCY NAME(S) AND ADDRESS(ES)

10. SPONSOR/MONITOR'S ACRONYM(S)

11. SPONSOR/MONITOR'S REPORT NUMBER(S)

\section{DISTRIBUTION / AVAILABILITY STATEMENT}

Approved for public release; unlimited distribution

\section{SUPPLEMENTARY NOTES}

\section{ABSTRACT}

This report presents results of a three-dimensional (3-D) finite element analysis of a generic miter gate with multiple cracks used to calculate the stress intensity using the J-integral approach. The model was also used to determine the optimum diagonals prestressing. Stress intensity factors and J-integral approach were validated numerically against closed-form solutions of semi-infinite plates with through-thickness cracks, double-edged cracks, single-edged crack, and cracks growing from round holes. Only a 2 percent difference between the closed-form solution and the numerical calculated values was obtained. Additionally, the report shows meshing techniques that facilitated the construction of the complex 3-D model. Finally, results and graphical methods of the parametric analysis to calculate the optimum diagonal prestresses are illustrated.

\begin{tabular}{|c|c|c|c|c|c|}
\hline \multicolumn{2}{|l|}{ 15. SUBJECT TERMS } & \multicolumn{2}{|l|}{ J-integral } & \multicolumn{2}{|c|}{ Diagonal prestressing } \\
\hline \multicolumn{2}{|l|}{ Miter gates } & \multicolumn{2}{|l|}{ Finite Elements } & \multicolumn{2}{|c|}{ Meshing techniques } \\
\hline \multicolumn{2}{|l|}{ Fracture Mechanics } & \multicolumn{2}{|c|}{ Stress intensity factor } & \multicolumn{2}{|c|}{ Hydraulic steel structures (HSS) } \\
\hline \multicolumn{3}{|c|}{ 16. SECURITY CLASSIFICATION OF: } & $\begin{array}{l}\text { 17. LIMITATION } \\
\text { OF ABSTRACT }\end{array}$ & $\begin{array}{l}\text { 18. NUMBER } \\
\text { OF PAGES }\end{array}$ & $\begin{array}{l}\text { 19a. NAME OF RESPONSIBLE } \\
\text { PERSON }\end{array}$ \\
\hline $\begin{array}{l}\text { a. REPORT } \\
\text { UNCLASSIFIED }\end{array}$ & $\begin{array}{l}\text { b. ABSTRACT } \\
\text { UNCLASSIFIED }\end{array}$ & $\begin{array}{l}\text { c. THIS PAGE } \\
\text { UNCLASSIFIED }\end{array}$ & & 79 & $\begin{array}{l}\text { 19b. TELEPHONE NUMBER (include } \\
\text { area code) }\end{array}$ \\
\hline
\end{tabular}

